\title{
Mild hypertension : studies on pathophysiology and treatment
}

Citation for published version (APA):

Böhm, R. O. B. (1986). Mild hypertension : studies on pathophysiology and treatment. [Doctoral Thesis, Maastricht University]. Rijksuniversiteit Limburg. https://doi.org/10.26481/dis.19861010rb

Document status and date:

Published: 01/01/1986

DOI:

10.26481/dis.19861010rb

Document Version:

Publisher's PDF, also known as Version of record

\section{Please check the document version of this publication:}

- A submitted manuscript is the version of the article upon submission and before peer-review. There can be important differences between the submitted version and the official published version of record.

People interested in the research are advised to contact the author for the final version of the publication, or visit the DOI to the publisher's website.

- The final author version and the galley proof are versions of the publication after peer review.

- The final published version features the final layout of the paper including the volume, issue and page numbers.

Link to publication

\footnotetext{
General rights rights.

- You may freely distribute the URL identifying the publication in the public portal. please follow below link for the End User Agreement:

www.umlib.nl/taverne-license

Take down policy

If you believe that this document breaches copyright please contact us at:

repository@maastrichtuniversity.nl

providing details and we will investigate your claim.
}

Copyright and moral rights for the publications made accessible in the public portal are retained by the authors and/or other copyright owners and it is a condition of accessing publications that users recognise and abide by the legal requirements associated with these

- Users may download and print one copy of any publication from the public portal for the purpose of private study or research.

- You may not further distribute the material or use it for any profit-making activity or commercial gain

If the publication is distributed under the terms of Article $25 \mathrm{fa}$ of the Dutch Copyright Act, indicated by the "Taverne" license above, 
MILD HYPERTENSION:

STUDIES ON PATHOPHYSIOLOGY AND TREATMENT 



\section{Mild hypertension: studies on pathophysiology and treatment}

Proefschrift

ter verkrijging van de graad van doctor in de geneeskunde aan de Rijksuniversiteit Limburg te Maastricht, op gezag van de rector magnificus, prof. dr. F.I.M. Bonke,

volgens het besluit van het College van Dekanen, in het openbaar te verdedigen op vrijdag 10 oktober 1986 des namiddags om vier uur

door

Roland Oskar Bruno Böhm

geboren te

Schwäbisch-Hall (West-Duitsland) in 1957. 
Promotor

Referenten
: Prof. dr. K.H. Rahn

: Prof. dr. A.J.M. Donker

Prof. dr. H. -G. Sieberth

Prof. dr. H.A.I. Struyker Boudier

Financial support for the publication of this thesis by the Dutch Kidney Foundation is gratefully acknowledged. 
Puisqu"an ne peut être universel et savoir tout ce qui peut se savoür sur tout, il fout savoir peu de tout. Car il est bien plus beau de savoir quelque chose de tout que de savoir tout d'une chose.

Blaise Pascal (1623-1662)

"Pensées sur l'esprit" 

TABLE OF CONTENTS

Chapter 1: General introduction

1.1 What is normal blood pressure and what is hypertension?

1.2 Epidemiologic aspects of hypertension 12

1.3 Classification of hypertension 14

1.4 The risk factor hypertension 1.7

$\begin{array}{ll}\text { 1.5 Blood pressure regulation } & 20\end{array}$

1.6 The autonomic nerwous system 22

1.7 Theories on the pathogenesis of essential hypertension

1.7.1 Genetic aspects

1.7.2 Environment

1.7.3 Sodtum intake

1.7.4 The role of the renin-anglotensin system

1.7.5 The role of the sympathetic nervous system

1.7.6 The role of the parasympathetic nervous system

1.8 Borderline hypertension

1.9 Treatment of mild hypertension

Chapter 2: A long-tern study of plasma catecholamine levels and plasma renin activity in borderline hypertension

2. 1 Summary

2.2 Introduction

2.3 Patients and methods 54

2.4 Results $\quad 56$

2.5 Discussion 63

Chapter 3: Salivary flow in borderline hypertension 69

3.1 Summary 70

3.2 Introduction $\quad 70$

3.3 Patients and methods 70

3.4 Results 71

3.5 Discussion 73

Chapter 4: Chronic anthypertenslve therapy with three different beta blockers: blood pressure and Indices of sympathetic activity at rest and during exercise, and the influence on submaximal exercise tole rance

4.1 Summary 76

4.2 Introduction 76

4.3 Patients and methods 77

4. 4 Results 81

4.5 Discussion 86 
Chapter 5: Long-tern antihypertenstve therapy with three different beta-blockers: metabollc effects at rest and durting submaximal endurance exerclse

5.1 Sumbary

5.2 Introduction

5.3 Patients and methods 91

5.4 Results

5.5 Discussion

Chapter 6: Studies of the antihypertensive effect of the angiotensin converting enzyme inhibitor ramipril

(HOE 498) in man

6.1 Summary

6.2 Introduction

6.3 Patients and methods 109

6.4 Results

6.5 Discussion

Chapter 7 : Concluding remarks

7. 1 Pathogenests

7.2 Treatment

Chapter 8: List of references

Chapter 9

9.1 Summary

9.2 Sanenvatting

9.3 List of publications

9.4 Dankwoord

9.5 Curriculum vitae 
Chapter 1

GENERAL INTRODUCTION 
1.1 WHAT IS NOKMAL BLOOD PRESSURE AND WHAT IS HYPERTENSTON?

After the introduction of the standard method to measure arterial blood pressure indirectly with a cuff and a mercury manometer by Sclplone Riva-Rocci in 1896 and the observation of Nicolai Sergeivich Korotkoff in 1905, who related the sounds during deflation of the cuff to gystolic and diastolic blood pressure (0'Brien et al., 1985), it became possible to measure blood pressure more accurately than with the methods described earlier by Reverend Stephen Hales in 1733 and Siegfried Karl Ritter von Basch in 1881 (Folkow, 1982). From then on medical doctors and other personnel have been measuring blood pressure for years wh the anaeroid or the mercury sphygmomanometer. Especlally in the last few years, new devices measuring blood pressure indirectly have been developed, being automatic (Arteriosonde, Dinamap) or semi-automatic. The latter are being used for home measurements by patients (Steiner et al., 1985). Until today the blood pressure measurement is still of great importance in the everyday work of medical personnel. Research and development together made 1 t even posslble to measure intra-arterial blood pressure during 24 hours with the oxford method (Mancia et al., 1983) in order to follow blood pressure in normal or untreated subjects or to get an impression af blood pressure of the patient during antihypertensive treatment. The latter could be seen as an advancement in control as compared to the casual blood pressure measurements during the short moments of the patient"s visit to the hospital or at the office of the practitioner.

But what is "normal" blood pressure and what is "hypertension"? The helght of the values of the arterial blood pressure is continuous1y distributed in the general population in a normal Gaussian fashton, at least in young age (20-25 years) (Doyle, 1983). In the years 19601962 the National Health Survey performed a study in the white population of the United States (18-79 years), a randon sample was taken and a representative distribution of blood pressure was found (MHS, 1964). So, arterial blood pressure has 1ts distribution to both sides. It is furthermore stated that arterial blood pressure is a quantity and not a quality (Hansson, 1983). The intra-1ndividual varlability of the blood pressure has become apparent (M11lar-Craig et al., 1978). 
Thus, blood pressure is a continuous variable, even in the same person, due to intra-individual varlability depending on factors like circumstances of measurement, time of the day, etc.

The term hypertension has its roots in the greek prefix "hyper", meaning too strong or high, and the latin "tensio" meaning tension or stress. The term hypertension is arbitrary and was born out of the need to describe a blood pressure which was higher than nomal. practical reasons and the lack of a better alternative (Jullus and Hansson, 1983) have made the term hypertension a more conventent and shorter description than the term "high blood pressure". It should be borne in mind, however, that the terms defined as normotension and hypertension are based on epidemlologic and statistical data. The term hypertension means in descriptive sense (the chronically elevated) arterial blood pressure above the mean of the group or in the upper end of a normal distribution. The demarcation between normal and abnormal (high) blood pressure indicates higher morbidity and mortality within 5-20 years in the group wh high blood pressure (Peart, 1983). . Normotension in the same sense describes the mean blood pressure In the population with a low risk. Thus, the term hypertenstion suggests that we are dealing with a value which carries exceeding risks for morbidity and mortallty. In short, "the relationship between arterfal pressure and mortallty is quantitative, the higher the pressure, the worse the prognosis" (Pickering, 1972).

According to the definition of the World Health organisation (WHO), nomotension is the systolic/diastolic blood pressure < $140 / 90$ $\mathrm{mm} \mathrm{Hg}$ and hypertension $1 \mathrm{~s}$ systollic $>160$ and/or diastolic $>95 \mathrm{~mm} \mathrm{Hg}$, diastolic blood pressure measured in phase $V$ (Korotkoff sound V) (Wtio report, 1978). Blood pressure between these two definitions, $1 . e$. $<160 / 95 \mathrm{~mm} \mathrm{Hg}$ but $>140 / 90 \mathrm{~mm} \mathrm{Hg}$ is destgnated borderline hypertenston. This will be dealt with extenstvely in chapter 1.8 . However, the definitions of the WHO are subject to discussion (Julius et al., 1980), because the age related increase of blood pressure is disregarded. It is generally accepted that there is a tendency for blood pressure to r1se with age (Metropolitan Life Insurance Bullet1n, 1969; Valkenburg et a1., 1980; Hofman and Valkenburg, 1980 ; Lancet Editorial, 1981; Watt, 1986). So with age, in the nomal distribution of blood pres- 
sure, there 11 be an extension of the distribution towards higher values. An adjusted definition by Jullus and Hansson (1983) seems to be more practical regarding the age related blood pressure increase:

$\begin{array}{lll}\text { nomotensive: } & 17-40 \text { years } & <140 / 90 \mathrm{~mm} \\ & 41-60 \text { years } & <150 / 90 \mathrm{~mm} \mathrm{Hg} \\ & >60 \text { years } & <160 / 90 \mathrm{mg} \\ \text { hypertensive: } & 17-60 \text { years } & >160 / 95 \mathrm{~mm} \mathrm{Hg} \\ & >60 \text { years } & >175 / 95 \mathrm{~mm} \mathrm{Hg}\end{array}$

1.2 EPIDEM IOLOGIC ASPECTS OF HYPERTENSION

Hypertension is recognized as a world wide problem, but is no doubt a more serlous problem and belleved to be more common among the population in the industrialized western countries; however, there are exceptions. With the increasing occurrence of studies in which blood pressure data become avaliable, estimates of the prevalence of hypertension appear in the 1iterature. As early as 1925 blood pressure data of 560.000 men have been published (Saciety of Actuaries, 1980). It is now commonly accepted that the prevalence of hypertension is around 15-20\% (Soclety of Actuartes, 1980; Epstein, 1983). But since prevalence rates in these studies depend on multiple factors like age, sex, way and number of blood pressure measurements, the level or defintion of the blood pressure, etc., it is difflcult to look at these percentages alone whthout including these factors. The Nat onal Health Study performed a study from 1960 to 1962 whlch glves a clear impression how the factor age plays a role in the prevalence. In this study three measurements of blood pressure were performed th the standard mercury sphygmomanometer with korotkoff phase $v$ as diastollc pressure. It was reported that malles and females with an age of $18-24$ years had a frequency of $6.9 \%$ and $2.1 \%$ respectively of diastoltc blood pressure $>90$ mmHg, whereas nales and females in the group of $55-64$ years, $23.1 \%$ and $22.2 \%$ respectlvely had diastollc blood pressure $>90 \mathrm{~mm}$ (Gordon, 1964). Another study in the Unites States, the U.S. Public Health and Nutrition Examination Survey (HANES) of the years 1971-1974 reported that $15 \%$ of the white and $28 \%$ of the black population surveyed were 
hypertensive ( $>160 \mathrm{~mm}$ systollc or $>95 \mathrm{~mm} g$ diastolic biood pressure) and a progressively rising prevalence with age was found (Roberts, 1977). Confirmation of the higher prevalence of hypertension in blacks, $38 \%$ vs. $29 \%$ in whites, was found in the report of the National. Health and Nutrition Examination Survey (NHANES) II in 1985, but it is unknown whether genetic or environmental factors account primarily for these differences (Epstein, 1983). A newer report on the NHANES II data, performed in the years 1976-1980, confirms that hypertension is a highly prevalent condition among the population of the Unites states: 29.8\% have hypertension (Joint Mational Commitee, 1985). However, certain limitations of this study must be noted. Only once blood pressure was measured, not all population groups are included and only blood pressure < $140 / 85 \mathrm{mmHg}$ was defined as normal. Studies in Sweden reported among men of 43-46 years old a prevalence of $55 \%$ (Wilhelmsen et al., 1973) and in Australia among women and men between 50-59 years $12.7 \%$ (Prineas et a1., 1973). In the Federal Republ1c of Germany a blood pressure study was performed in Munich from 1980-1981. Two years later another study was performed in Libeck, a clty in the northern part of the Federal Republic. The WHO definition of hypertension was used in both studies and when including the borderline hypertensive subjects, every third citizen in Munich in the age group of $30-69$ years had rafsed blood pressure readings. $22.7 \%$ of the men and $12.2 \%$ of the women are classified in the mild hypertension category (diastollc 90-104 mmig) (Ke11 et al., 1983). In Lubeck in the same age group the prevalence for hypertenston was among males $19.9 \%$ and $13.5 \%$ among females (Keil et al., 1985).

There seems to be a higher Incldence of hypertension among the population in the industrialized countrles. There are low blood pressure population groups described, e.g. Kalahari desert bushen, Chinese aborigines and West Malayslans, in whom also a slight or no tendency at all for the age-related blood pressure rise is found (Page, 1983). The explanation must be sought among environmental factors (Page, 1976). Thus, hypertension in today's modem western society is. one of mankind's most common diseases and is a major health problem affecting about $15-20 \%$ of all adults. 
The different forms of arterial hypertension can be classifled according to their etlology or cause. The following table (Table 1 ) lists the different types of hypertension by their cause (Julius and Hansion, 1983). It 111 ustrates quite clearly the problems general practitioners and cliniclans are faced with when dealing with and diagnosing the cause of hypertension in their patients.

Arterial hypertenston is classified as elther essential (I) or secondary (II). Essentlal hypertenston is also deseribed by other terns like primary or idlopathlc hypertension. The German clinician Frank contributed the prefix "essential" ("essentlelle Hypertonie") to imply that the elevation of blood pressure was of unknown origin (Erank, 1911). As described in chapter 1.2, the disease hypertension is prevalent in about $15-20 \%$ of the population. Within this hypertensive population, the frequency of essential hypertenston ranges between $89-95 \%$ as studies in different countries have shown (Kaplan and Lieberman, 1982). The term secondary hypertension is used when a factor or disease can be associated with the rise of the blood pressure, e.g. chronic nephritis or pheochromocytoma.

For the purpose of clarity and the fact that the studies described later in this thesls deal with essential hypertension, no further details wll be discussed about secondary or malignant hypertension. For further Information and detalls conceming both, see the text books and review articles clted.

In order to dlagnose elther essential hypertension or to exclude secondary hypertension some basic tools are needed. Correctly performed and multiple blood pressure measurements and a thorough history Including a careful physical examination are important. Further tools for the clinical classification are fundoscoptc examination, assessing vascular damage with the scale by Kelth, Wagener and Barker, urinalysis, assessment of renal function (serum creatinine) and if indicated an Intravenous pyelogram. Further factors analyzed are plasma sodium, potassium, calctum, cholesterol, blood uric acld and sugar. Furthermore, an electrocardlogram is made, to look for signs of left ventricular hypertrophy. It should be taken into consideration, however, that 


\section{Tablel}

1. Essential hypertension

l.t. Secondary Mypertersion

A. Renal

1. Parenchymal

a. Acute glomerufonephritis

3. Chronic nephrit is, glomer ulonephritis, pyelonephritis, heredity in fadiation, bupas erythervatosus

c. Polycystic kidney diserase

d. Hydronephrosis

e. Renin-prodtucing tumor

4. Diabetic nephropathy (Kirmetstiel" Wilson)

2. Renowarcular

a. Fibromuscular anterial sitenosis

b. Atheroscherolic arter hat stenosis

c. Renal infarctions

d. Polyarteritys

3. Trauma

a. Perirenal hematoma

b. Renal anterial thrombosis

c. Renal arterial dissection

B. Endoerine

1. Thyroid

a. Hyperthyroidism

b. Hypothyroidism

2. Adrenal

a. Pheochromacytoma

b. Primary aldosteronism

c. Adenorma

d. Hyperplasia

e. Clucocorticoid seppressible hyperaldosteronism

f. Congenital adrenal hyperplasia.

(1) H18-Hydroxylation deficiency

(2) $17 a-4$ - ydroxylation deficiency

g. Cushing"s discease

3. Pafathyroid

a. Hyperparathyroidism

4. Phitutaty

a. Acromegaly

C. Neurogenic

1. Respinatory acidosis (carbon dioxide retention)

2. Brain turnor

3. Encephathitis

4. Bublibar poliomyelings

5. Fannilial dyrautomomia

6. Acute porphyria

"Quadriplegia ("micturitional crisis")

8. Extragdremal chromafin thmors

a. Paragangliomas

b. Von Recklinghausen's disease

D. Mechanical interterence with How

1. AV fistulas (Pagel's disease, patent ducius arteriosus)

2. Aortic insuffociency

3. Coarctation of the aorta

4. Atheroscterotic systollic hypertension

E. Exogenous

1. Poisoning
a. Lead
b. Thalilium

2. Medication

a. Sympathelic amines

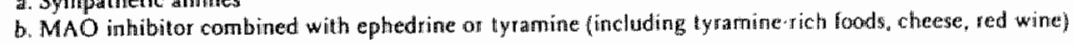

c. Birth control pills

d. Prednisone-migh doses:

3. Forod

a. Licorice ingestion 


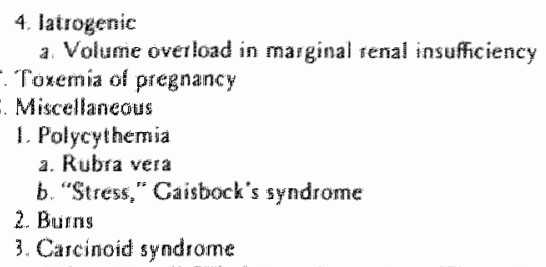

Table 1 (continued)

the simplest, cheapest and least invasive tests should be always performed first, before those more complex, expensive and unconfortable are perfomed (Menard et al., 1983).

The severity of hypertension in the individual hypertensive patient can be further classteled. A clinical classification, based also on the investigations and parameters as described above, can be used. The clintical classification can be of much help for further decistons regarding urgency and cholce of treatment. "Table 2 shows this classiflcation (Julius and Hansson, 1983). Fundoscoplc examination is of utmost importance for the classification. Some basic princlples about this classification should be described:

- very high blood pressure need not be accompanied by laboratory abnormallties. In this case the severtty of hypertension is in direct proportion to the blood pressure measured;

- the category of severity Increases with the presence of laboratory abnormalities;

- If retinopathy grades III or IV are present, this finding detemines the category of severdty in this patient irrespective of the height of the blood pressure measured at the same tine.

At each level of the basic class of the classiflcation in severity the hypertension can be uncomplicated or complicated. Hypertension is complicated if there is evidence of congestive heart fallure, anglna pectoris, cardiac arrhythmias; furthermore, if there 1 s evidence of present or past vascular events (stroke, arterial aneurysms, myocardial infarction). 
Table 2 Classification of severity of hypertension (Eron Julius arad Hansson, 1983)

\begin{tabular}{|c|c|c|c|c|c|}
\hline Class & BP level & Funduscopic texanai nation & $\mathrm{ECG}$ & Urine & $\begin{array}{l}\text { Aherual } \\
\text { Annetions }\end{array}$ \\
\hline $\begin{array}{l}\text { Borderlime } \\
\text { hypentension }\end{array}$ & See text. & Normat & Normal & Normal & Normal \\
\hline Mild hypettension & $161 / 10+4-180 / 120$ & $\begin{array}{l}\text { Crade l. Il } \\
\text { Normal or grade ll Il }\end{array}$ & $\begin{array}{l}\text { WHH } \\
\text { Normal }\end{array}$ & $\begin{array}{l}\text { Nor fuxial } \\
\text { Nornmal }\end{array}$ & $\begin{array}{l}\text { Normal } \\
\text { Nommal }\end{array}$ \\
\hline \multirow{2}{*}{$\begin{array}{l}\text { Moderate } \\
\text { hypertension }\end{array}$} & $161 / 101-180 / 120$ & Normal or grade lll & $1 \mathrm{KHH}^{\prime}$ & Albuinant & Depersed \\
\hline & $181 / 21-190: 30$ & Nonnal or grade $1-1 /$ & $:$ & $:$ & 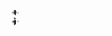 \\
\hline Severe hyperternsion. & $\begin{array}{l}\text { Hypertension } \\
>|9| / 13 \mid\end{array}$ & $\begin{array}{l}\text { Hemgrthages and exididues } \\
\text { lgrade III } \\
\text { Grade ll }\end{array}$ & $\vdots$ & $:$ & : \\
\hline $\begin{array}{l}\text { Malignant } \\
\text { Hypertension }\end{array}$ & Hypertension & Papilledema (gade $\mid V$ ) & $\vdots$ & $\vdots$ & : \\
\hline
\end{tabular}

Ainy lone of these pieserat.

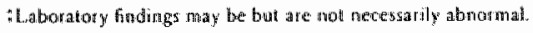

\subsection{THE RISK FACTOR HYPERTENSION}

Since years, it has become more obvious that (untreated) hypertension plays an important contributing role in cardiovascular morbidity and mortality (Thom and Kannel, 1981). The ten leading causes of death in the United States from 1900 to 1980 (Levy and Moskowitz; 1982) indicate that diseases affecting the cardiovascular systern are the leading cause of death (Hollander, 1976).

At the time when effective antihypertensive drugs were not yet avallable, the mean survival time in years in several patients with malignant hypertension was on 1 y 8.4 months, as described by schottstedt and Sokolow (1953). Some years later, the Metropolitan Life Insurance Company (1961) reported a reduced expectation of 11 fe in years in benlgn hypertension. The higher the blood pressure and the age, the lower the expectation of 11 fe in years, e.g. 45 year old males with a blood pressure of $150 / 100 \mathrm{mmll} g$ have an expectancy of 20.5 years vs. 32 years in the same group with only $120 / 80 \mathrm{mmH}$. A prospective study performed by Sokolow and Perloff (1961) in 439 consecutive essentlal hypertensive patients $(>160 / 90 \mathrm{mmg}$ ) confirmed a progressive rise in 
mortality In the group of patients with a blood pressure of $250 / 130$ ming wen compared to the group with 200/110 mmilg. In another study patients with fundoscoplc grade I and II lesions were followed for 5 years and it was found that the more flxed the high blood pressure, the worse the prognosis (Sulrk, 1964). It is now accepted that the cardlovascular consequences or complications of hypertension are proportional to the helght of the blood pressure (Dawber and Kanne 1 , 1972; Kanne1, 1974; Doyle, 1976; the Pooling project, 1978; Lancet Editorial, 1978; Svardsudd and Thbblin, 1979) and that hypertension is one of the major risk factors for coronary heart disease (Stamler, 1979). Furthermore, clinical, experimental and studies in pathology strongly indicate that hypertension plays a major role in coronary heart disease, sudden death, stroke, congestive heart fallure and renal insuffictency (Holiander, 1976; Johnson and Mul rhead, 1980). Hollander (1976) and Levy and Moskowitz (1982) reported considerable evidence that wh the increase in awareness and the control of blood pressure in the population, a decline in mortality from diseases associated with hypertension w11 occur. Furthermore, a prevention of many cardlovascular complications like congestive heart failure, hemorrhaglic stroke, progressive renal damage, dissecting aneurysm, etc. would result. But despite the awareness and the major efforts to educate the public and to screen and treat persons with hypertension in the United States (Harlan et al., 1984), the comparison of the blood pressure level from the years 1960 to 1980 suggests only a modest decline in blood pressure during this period (Rowland and Roberts, 1982). One of the Important problems of hypertension among the population 18 the awareness of having hypertension. In the National Health Survey performed from 1960 to 1962 about $58 \%$ of the hypertensives were unaware of the high blood pressure (Roberts, 1977). An Improvement, 1.e. a decline of unawareness was seen during the following years as Levy and Moskowttz (1982) reported. The Hypertension Detection and Follow-up Program (HDFP) from 1973 to 1974 reported that only $25 \%$ of the hypertenslve subfects were unaware (HDFP, 1977). W1th the help of several programs, the decline of unawareness of high blood pressure and a more effective control of blood pressure including an adequate treatment, was a remarkable achlevement as stated by Moser (1983). 
However, as already Ames and Hill (1982) have reported in their study, hypertension intervention studies like the Veterans Adninistration Study I and II $(1967,1970)$, the Australlan Therapeutic Trial in mild hypertension (1980) and the Oslo Study (Helgeland, 1980) Indicate no benefit on the incidence of coronary heart disease. But in these studies, a clear-cut benefit on the incidence of stroke was reported. This was later confirmed in the Medical Research Council Working Party Trial of treatment of mild hypertension (MRC Trial, 1985) and the European Working Party on High Blood Pressure in the Elder1y (1985). Moser (1983), too, reports a decrease of stroke death rate of $45 \%$ in the United States over the past 15 years. He sees the reason for this in the implementation of the National High Blood Pressure Education Program and other modalities of care, like reduction of the tobacco and saturated fat consumption. Other factors which could induce high blood pressure like excessive salt intake, overweight and intake of oestrogens should be thought of as wel1. Furthermore, the incidence of congestive heart failure is reduced by anthhyertenslue therapy, as the Veterans Administration Cooperative Study Group on antihypertensive agents I and II $(1967,1970)$ showed.

In a recent article, staessen et a1. (1983) analyzed the different intervention studies which compared treated with untreated hypertensive patients. Total mortality incidence appears to be reduced in the active treatment group compared to the control group, when looking at a11 trials. However, only in 3 individual trials, there was a statistically significant difference in favor of active treatment or stepped care, 1.e. the Goteborg Trial, the ADFP and the Australian Trial in mild hypertension. In other trials, no difference was found (Hypertension Stroke Cooperative Study; US Public Health Service Mild Hypertension Trial (McFate-Smith, 1977); the 0s10 Study (Berglund, 1978)) or no difference indicated (Veterans Administration Cooperative Study on antihypertensive agents I and II, 1967, 1970). The authors Staessen et al. (1983) conclude that antihypertensive drug treatment can improve prognosis in we11-defined segments of the hypertensive population, such as middle-aged men with diastalic blood pressure on repeated examination $>95 \mathrm{~mm} \mathrm{Hg}$. But unfortunately, hypertension, as stated before, is (only) one of the major risk factors, associated 
prognostically th other major risk indlcators for cardlovascular disease, e.g. clgarette smoking, hypercholesterolemia, to a lesser extent obesity, impaired glucose tolerance (diabetes mellitus) and phystcal unactivity. Thus, when treating hypertension with active drug therapy, these risk factors could outweigh the hypertensive risk factor and therefore possibly prevent a decrease in morbidity and mottallty. Does this mean that possible treatment in hypertensive patients with several additional risk factors should be started earlier in time and at a lower height of increased blood pressure? The answer to this needs confirmation in further studies.

High blood pressure is thus associated th excess mortality and morbldty when compared with normal blood pressure, especially when other rlsk factors are present. With the ald and the efforts of the public programs dealing with active treatment, awareness and epidemiologic aspects of hypertension, performed in the United states and elsewhere especially in the last years, the benefits may not be statistically significantly provable with hard data at the moment. However, at least the trends in awareness, treatment and control states (Joint National Comittee, 1985) could bring some benefits in the long rum. Awareness of the population and thus possibly earlier intervention to prevent complications are two of the important factors which could play a role in the long run.

\subsection{BLOOD PRESSURE REGULATION}

Physiologic control of blood pressure and the circulation is very complex. This chapter is not meant to glve a complete description but rather a short overview. The control of arterial blood pressure is reallzed by several systems interacting and influencing each other. Arterial blood pressure, cardiac output and total peripheral resistance are related together as follows:

arterial pressure = cardiac output $\times$ total peripheral resistance. 
Any condition influencing the factors cardlac output or total peripheral resistance will cause an effect on arterlal pressure, supposing the other of the two factors does not change. But neither of the two factors is the fundamental controller because each of the two is influenced and controlled by other subfactors. The short-tem and long-term regulation of blood pressure are important for the regulation of blood pressure in different situations. Short-term regulation processes include: (1) the influences from the autonomic nervous system through the baroreceptors, chemoreceptors and somatic afferents, and the ischemic mechanism in the central nervous system; (2) the hormonal system, e.g. renin-anglotensin vasoconstriction, the vasopressin mechanism and the noradrenaline and adrenaline vasoconstrictor mechanisms; (3) the capillary fluid shifts to and from the circulation, and (4) the stress relaxation of the vasculature (Guyton et al., 1981; Guyton, 1981a). It must be emphasized that the sympathetic nervous system is one of the important factors regulating renin release. Furthermore, there seems to be an important relationship or mediating effect between the augmented release of the neurotransmitter amines in the sympathetic nerve terminals and the vasoconstrictive action of anglotensin II (Kuche1, 1983).

The long-term mechanism for arterial blood pressure regulation includes renal-body fluld-pressure control involving several subsystems: the rentn-anglotensin-aldosterone axis, the renal fluid control through pressure diuresis and pressure natriurests. The renal output of water and salt and the net rate of fluid intake are the important determinants on the long-term (Guyton, 1981a). A change on the level. of one or both determinants, such as stimulation of the kidneys by excess renin-anglotensin-aldosterone or sympathetic slgna1s, w11 change the renal output. Decrease of glomerular illtration rate and primary aldosteronism are pathological states which influence the blood pressure on the long-term.

Furthermore, whin every organ and tissue an adequate flow is maintained by a system of autoregulation, so when blood pressure falls, vasodilatation occurs and when blood pressure rises a vasoconstriction takes place. The theory about autoregulation was at first suggested by Borst and Borst-de Geus (1963). This term refers to the 
capaclty of vascular beds to control regional blood flow in accordance wth changing needs (Kornex, 1980). It can be seen as a rapldiy reacting process as well. More detalls are described in the articles by Korner (1980) and Cowley (1980).

The cardiac output can be influenced by the autonomic nervous systen through the sympathetic and parasympathetic branch, both can chenge heart rate and strength of contraction. Parasympathetic activation causes a decrease of the heart rate and a decrease of the strength of contraction, whereas sympathetic actlwation leads to the opposite. An increase of sympathetic activity and/or a decrease of parasympathetic activity will lead to a change of cardiac output. Thus, an activation of the sympatho-adrenal system will cause an increase of cardiac output and systemic arterlal resistance. This could have an important consequence for the development of hypertension. Although other factors such as prostaglandins, the kallikrein-kinin system, oplold peptides, atrial natriuretic peptides and others may be of importance, however, their preclse function in the regulation of arterial blood pressure have not been fully deflned. For a more detalled description of all mechanisms and factors which regulate arterial blood pressure, there are a number of papers and reviews which I refer to (Struyker Boudier and Rahn, 1979; Brody, 1981; Guyton et al., 1981; Guyton, 1981b; Dustan, 1982; Folkow, 1982). A11 in all, with the knowledge we have today about the influence of the autonomic nervous system and 1 ts sympathetic and parasympathetic branch, together with thel $\mathrm{r}$ effects on various levels and through the activation of humoral factors, $1 t$ becomes obvlous that the sympatho-adrenal system is one of the major factors regulating blood pressure.

\subsection{THE AUTONOMLC NERVOUS SYSTEM}

The cardiovascular system and the refore also blood pressure 1 is to a large extent under the influence of the autonomic nervous system* In humans, a complexity of blood pressure regulating mechanisms maintain an adequate blood pressure in supine and upright position and in other situations, e.g. mental and physical stress (Kuche1, 1983). 
Through a complex reflex arc, by means of a negative feedback mechanism, blood pressure is controlled autonomically (Edis and shepherd, 1970). The reflex arc depends on three systems and they can be described shortly as follows: an afferent limb sending information from the periphery to the central part, the centril mediating and modulating part, and the efferent limb transmitting limpulses from the central part to the peripheral cardiovascular organs or effectors.

The afferent $\mathbb{I i m b}$ can be shortly described as follows. The baroreceptors, being sensory sites in the carotid sinuses, aortic arch and some larger vessels, are activated by local vascular distension resulting from an increase in intra-arterial pressure. The arterial barareceptors (hỉgh pressure receptors) are very important in buffering excessive falls or increases of blood pressure, within the systollic blood pressure range of $60-160 \mathrm{~mm} H \mathrm{Hg}$ particularly. The afferent impulses from the aortic arch are transmitted via the vagal nerve ( $x$ th cranial nerve) and from the carotid sinuses via the glossopharyngeal nerve (IXth cranial nerve) to the medulla oblongata. Other receptor systems include low pressure receptors in the atria and ventricles of the heart and in the pulmonary circulation, and chemoreceptors in the arcus aortae activated by hypoxemia. It is now generally belleved that the afferents arising from all these receptors synapse exclusively within the nucleus tractus solitarius (Dampney, 1981). From all these receptors, also via other somatic afferents, stimuli are transmitted to the medullary cardlovascular or vasomotor center. Belonging to the central part, this is a well-defined area of the brain stem from mid pons to medulla oblongata. Here, also other influences are recelved by and modulated through higher integrative centers which are located in the hypothalamus, the limblc system and the cortex cerebrl. These areas are belleved to represent a possible link between blood pressure and emotional stimuli (Kuche1, 1983). The nacure of the central control and pathways presents a difficult problen and has been a matter of controversy (Seller et al., 1980; Kollat and Koizumi, 1981; Chalmers et al., 1981; Korner, 1981). There are at least 5 basic processes accurring in the central nervous system in mediating autonomic function (Brooks, 1981): (1) feedback to or on the afferent pathways; (2) interactions between centers; (3) central interaction between central 
representations of the parasympathetic and sympathetic divisions of the autonomic system; (4) reactions organizing and inftiating pattems of efferent discharge; (5) continuing actions that modify the activitles started, on the basis of feedback triggered by the effector activity Initiated. Dampney (1981) states that the 1 s evidence for the opinion that there is no all-important "vasomotor center" within a speclific part of the lower brain stem, but there are indications for several parallel central pathways along which both tonic and reflex control of activity in sympathetic preganglionic neurones is mediated (Dampriey, 1981).

So, in the central nervous system, a constant flow occurs of afferent impulses from the periphery, the somatic afferents and the higher centers. Through an integration of this input, the result is a continuously readjustment of the tone of the peripheral cardovascular system through the efferent network of autonomic fibers (De Champlain, 1977). The autonomic system is constantly in action; not all its efferent neurones show a high level of tonic activity, but certainly those which innervate the heart and the blood vessels (Brooks, 1981).

The two important efferent pathways of the autonomic nervous system are the sympathetic and the parasympathetic nervous system. For the regulation of the circulation the sympathetic nervous system is the most important of the two. Sympathetic nerve fibers leave the spinal cord through all the thoracic and the first one to two lumbar spinal nerves. The preganglionic neurones symapse with postganglionic neurones in the peripheral ganglia (Dampney, 1981). In the periphery the most densely Innervated sympathetic segments of the whole vascular tree are the small arterioles which have a cructal influence on blood pressure homeostasis (Me1lander and Johansson, 1968). Furthemore, the Innervation of the larger arteries and veins makes it possible to change the volume of the peripheral circulatory system. Sympathetic stimulation markedly increases heart rate and the pumping strength of the heart. In addition, the sympathetic nervous system is responsible for the catecholamine secretion by the adrenal medulla Malmejac, 1964).

The parasymathetic nervous system has its fibers leaving through several of the crantal nerves and the second and third sacral 
spinal nerve. The vagal nerves possess about $75 \%$ of all parasympathetic nerve fibres. The entire thoracic and abdominal regions are recelving vagal fibers. Also, flbers of the seventh nerve pass to the lacrimal, nasal and submaxillary glands. The ninth nerve is sending fibers to the parotid gland. Parasympathetic stimulation causes a marked decrease of heart rate and a slight decrease of contractility. The salivary secretion, which will be dealt with in the later described study in chapter 3 , is controlled by parasympathetic nervous signals. The preganglionic fibers pass directly to the organ to be innervated. In the wall of the organ they synapse with their postganglionic neurones. All preganglionic neurones, in both the sympathetic and parasympathetic nervous system have acetylcholine as neurotransmitting substance. Most of the postganglionic sympathetic neurones are noradrenergic, with the exception of sweat glands (Guyton, 1981) and some blood vessels like umbilical and placental blood vessels (Vanhoutte, 1981). The pastganglionic neurones of the parasympathetic fibers are again chollinergic.

Two major receptor types are the sites of action for the catecholamines noradrenaline and adrenaline. Almost 40 years ago, Ahlquist (1948) classified the adrenergic receptors in alpha- and beta-adrenoceptors. In short, alpha-adrenergic receptors mediate responses as the constriction of vascular and uterine smooth muscle; noradrenaline is the major agonist. More recently, these alpha-adrenoceptors have been subdivided into alpha -receptors and alpha $_{2}$-receptors (Langer, 1974 ; Berthelsen and Pettinger, 1977). Lands et al. (1967) subdivided the beta-receptors 1 toto beta ${ }_{1}$ - found predominantly in heart, brain and ad1pose tissue, and the beta $a_{2}$-receptors found in blood vessels, bronchl, liver and skeletal muscle. Beta-adrenoceptors are mainly stimulated by adrenaline resulting in a relaxation of smooth muscle, dilatation of arteries, uterus relaxation, bronchodilatation and inducling glycogenolysis. Beta ${ }_{1}$ mediated effects are cardiac dronotroplc and chronotropic responses and 11polysis. So, for the cardiovascular system the noradrenaline-mediated beta-adrenoceptor effects are increased heart rate, cardiac output and a further effect is the increase of plasma renin activity (Bihler et al, 1985). A further detailed description about the regulation, the effects and the struc- 
ture of adrenoceptors will be omitted. A numer of articles and reviews w11 be referred to (Lefkowitz, 1979; Van Zwieten and Timermans, 1980; Lees, 1981; Malinoff et a1., 1981; Wanhoutte, 1981; Nahorskl, 1981; Motulsky and Inbel, 1982; Timermans and Van Zwieten, 1982; Hedberg, 1983; McGrath, 1983; Venter and Fraser, 1983; Inse1, 1984; Stlles et al., 1984 ).

The locatlons for catecholanine syathesis are in the brain, the sympathetic nerve endings and at sites where chromafin tissue is found, including the adrenal medulla. The maln pathway for the synthesis of the major neurohumoral transmitter noradrenaline starts with the essential amino actd L-tyrosine. The postganglionic adrenergic nerve endings take up tyrosine from the extracellular fluld (Shepherd and Vanhoutte, 1981). It is hydroxylated by the action of the enzyme tyrosine hydroxylase, which is present in the mitochondria, to form dihydroxyphenylalanine (L-DOPA). Tyrosine hydroxylase is the main rate-limiting enzyme in the synthesis of the adrenerglc transmitters (Vanhoutte, 1981). L-dopa is converted by the cytoplasmic dopa decarboxylase to dihydroxyphenylethylamine (dopamine). Dopamine is transported into the granulated storage vesicles where the final hydroxylation takes place. Intravestcular dopamine beta-hydroxylase transforms dopamine to noradrenaline. The newly synthesized noradrenaline is then stored and bound to ATP within the storage vesicles in an inactive form. Additionally, an intracellular pool of noradrenaline exists, which is netther bound nor stored; presumably in equilibrium with the noradrenaline in the vesicles. An increase in the neuroplasmic concentration of noradrenallne exerts a negative feedback on tyrosine hydroxylase (end product inhibition), whereas increased activity of the adrenergic neuron or depletion of the catecholamine stores has the opposite effect (Vanhoutte, 1981). The neural impulse, generated in the ganglionfe cell body and passing to the periphery via the sympathetic fibers, reaches the nerve endings in the effector organ. Upon this action potential and the consequent penetration of $\mathrm{Ca}^{2+}$ ions into the neuroplasm, the vesicles migrate to and fuse with the neuronal cell membrane (Shepherd and Vanhoutte, 1981). Their entire soluble content, Including noradrenaline and dopamine beta-hydroxylase, is emptied into the functional cleft (exocytotic release (Smith and 
Winkler, 1972)). The noradrenaline released on stimulation diffuses through the symaptic cleft to act locally on specific receptors of the effector cells. Exceptions to this constitute the adrenal medulla and certain brain neurones (Hökfelt et al., 1974), where noradrenaline can be converted via methylation to adrenaline, by the phenylethanolamine-N-methyl-transferase (PMMT) (Axelrod and Weinshilboum, 1972). The Induction of this enzyme and, consequently synthesis of adrenaline, is dependent on cortisol, which is delivered to the adrenal medulla via an intra-adnenal portal vascular system (Pohoreky and Wurtmann, 1971).

Most of the synthesis of the neurotransitter acetylcholine occurs probably in the axoplasm of the terminal endings of the cholinergic nerve fibers. From the extracellular fluid, choline is taken up into the cholinergic nerve endings. In the mitochondria another precursor, acetyl co-enzyme-A is formed (Shepherd and Vanhoutte, 1979). The enzyme choline acetyltransferase catalyzes in the neuroplasma the reaction from acetyl-Co $A$ and choline to acetylcholine. Acetylcholine $(\mathrm{ACh})$ is then transported to the interior of the vesicles. After an action potential has reached the nerve ending, $\mathrm{Ca}^{2+}$ ions diffuse from extraneuronal to intraneural space. Upon this, the vesicles lying with their stored ACh against the cell membrane release their content into the junctional cleft. This again is probably by a process of exocytosis (Burnstock, 1977). The released ACh diffuses to the effector cells where it binds to the receptors on the cell membrane. Most of the ACh Is split into acetate lons and chollne by the enzyme acetylcholinesterase. This enzyme is present in both terminal nerve endings and the surface of the receptor organ. All tissues innervated by cholinergic nerves have a high activity of acetylcholinesterase (Shepherd and Vanhoutte, 1979). The choline formed is actively resorbed into the termnal nerve ending where it is used again for the synthesis of new ACh and may be important in maintaining a continued transmitter synthesis (Burnstock, 1977). Normally, most of the ACh 1 s destroyed within a fraction of a second after its secretion, only a small amount diffuses to surrounding fluids. The latter contaln serum chollnesterase which destroys the remaining ACh within seconds. Therefore, the action of ACh released by cholinergic nerve fibers usually lasts for a few seconds at most (Guyton, 1981a). 
Three different ways of removal of moradrenaline can be described: (1) Most of the noradrenaline is taken up by the sympathetic nexve endings (re-uptake mechanlsm). This is an active transport process and accounts for re-uptake of 50-80\% of the secreted noradrenaline (S1lwerberg et al., 1978). Part of the noradrenaline which is taken up by the neuronal membrane is broken down enzymatically by mono-amine oxydase (MAO) to 3,4 dthydroxyphenylglycol (DOPEG) before it reaches again the storage sites. DOPEG then diffuses to the extracellular space. The rest of the noradrenallne is stored in the storage vesicles again; (2) Part overflows into the extracellular fluid and into the blood and is efther excreted in the urine or metabolized by the liver. (3) Subsequent metabolism by the enzymes catechol-o-methyltransferase (COMT) and mono-amine oxidase (MAO). The major pathways of degradation for noradrenallne are: (1) 0-methylation via catechol-omethyl-transferase (COMT). This extraneuronal pathway removes the circulating catecholamines released from the adrenal medulla and the diffused part from the nerve endings. COMT is present diffusely in a11 tissues (Graefe and Henseling, 1983) and in the liver. The major metabolite is normetanephrine and to a lesser extent vanillylmandelic acid (VMA) and 3-methoxy-4-hydroxyphenylglycol (MHPG); (2) Oxidative deamination via the enzyme mono-amino oxldase (MAO). The product is 3,4-dihydroxy-mandelic acid which in turn is degraded by ComT extraneuronally into 3-methoxy-4-hydroxymandelic acid; (3) Sulfoconjugation, which accurs both in the central nervous system and in the pertphery (Roth and Rivett, 1982), is suggested because of the high proportions of circulating individual catecholamine sulfates $(70 \%, 85 \%$ and $99 \%$ for noradrenaline, adrenaline and dopamine, respectively) (Kuchel, 1983). Platelet phenolsulfotransferase (PST) is the main enzyme. But as only a small proportion of noradrenaline circulates as free noradrenaline, so only this part is exposed to PST of the platelets. The product of sulfoconjugation are catecholamine-3-0-sulfate and catecholamine-4-0-sulfate of dopamine, noradrenallne and adrena1ine. The preclse regulation and the role of a possible autoregulation of sulfoconjugation are still not clear (Cryer, 1980). The ratio of the rate of excretion of the metanephrines, $1 . e$. the products of $0-$ methylation, to the excretion rate of vanillylmandelic acid (VMA) In 
nomal humans is 1:10. The metabolites are further conjugated in the 11 ver and excreted by the kidneys. These three processes very rapidly remove the transmitter. These mechanisms of removal protect the system against excessive extraneuronal noradrenaline concentrations and conserve the neurotransmitter so that it does not fall to release noradrenaline upon stimulation. A similar pattern of metabolic linactivation is true for adrenaline resulting in MA and metanephrine excretion. A higher proportion of adrenaline (85\%) goes into conjugates than noradrenaline $(70 \%)$. Dopamine is also similarly metabolized except that the end products of oxidative deamination are 3-methoxy4-hydroxyphenylethylamine and 3-methoxy-4-hydroxyphenylacetic acid (homovanilitc acid, HVA). Dopamine has a high component of sulfoconjugation.

Recently, an important role has been attributed to presynaptic receptors which modulate the release of neutransmitters in response to nerve impulse (Vanhoutte et al., 1980, 1981; Westfal1, 1984). The effects of inhibitory modulators (products of cellular metabolism and histamine) on pre-junctional alpha-receptors and facilitating modulators (angiotensin II) on beta-adrenergic receptors have been reported, which alter the amount of transmitter released from the sympathetic nerve terminals in the face of a constant frequency of activation of the postganglionic sympathetic fibers (Shepherd and Vanhoutte, 1981). For more details, the aforementioned authors are referred to.

As Indicated before, in the adrenal medulla, catecholamines are released directly into the circulation to reach thell effector organ. Noradrenaline may subserve a hormonal function under conditions of stress, including vigorous physical exerclse (S11verberg et al., 1978).

\subsection{THEORIES ON THE PATHOGENESIS OF ESSENTLAL HYPERTENSION}

Since the recognition of hypertension as a symptom, a multitude of factors have been mentioned to explain the possible pathophysiology and/or etlology. Up to now, many researchers have devoted their attention to this field, elther experimental or clinical, and have contri- 
buted remarkable results while trying to solve this complicated and often controversial puzzle. The never ending amount of articles which Ls produced on this topic gives an impression of the role which this symptom hypertension plays. The many different theorles about pathophyslology and etlology have been extensively reviewed (see reference 1ist). So only certain aspects of the major theories will be sumarily 111ustrated in this chapter.

\subsubsection{Genetic aspects}

A multifactorial and not a single causal factor is postulated by several authors (Beyer and Peuler, 1983). It is now accepted that both genetic and environmental factors are, whether in a combination or not, involved in the rise of blood pressure to essential hypertension (Page, 1976; Beyer and Peuler, 1983; Houston, 1986). Some authors favour a polygentc model of inheritance or predisposition (Ostfeld and Paul, 1963; Plckering, 1965; Mil11 and Love11, 1967; Kannel et al., 1969; Folkow, 1982; Rapp, 1983), both in man and 1n various hypertensive rat strains (Folkow, 1982). In other words, many minor and different genes could influence blood pressure, perhaps by cumulative action (Yamor1, 1983). The effects of genes at the loci are not readily discernible one from the other in the frequency distributions for blood pressure (Rapp, 1983). Several authors believe in a single autosonal model (Weltz, 1923), whlch could be a stingle incompletely dominant autosomal gene (Platt, 1963). The controversles between these two models, the polygentc and the single autosonal model, have not been solved yet. Another possibllity was outlined, the model of genetic heterogenelty. Due to the lack of conformity with a single pattern of Influence, $1 \mathrm{t}$ was concluded that all types of genes (e.g. polygenes, polymorphic genes) contribute to the genetic variation underlying, the blood pressure distribution in human populations. So, the continuous distribution of blood pressure is related to different types of genes (Cruz-Coke, 1983). Unt11 now, however, desplte thorough research no individual genes which control blood pressure or induce essential hypertension have been 1dentified. 


\subsubsection{Environment}

Among the environmental influences are two important factors, habits of salt intake and certain excitatory psycho-emotional influences (Folkow, 1982). Page (1976) describes these environmental factors as acculturation, dietary changes, welght galn, psychosocial and stress factors. Among the latter prevail soclal and environmental stress factors, as these have been linked with elevated arterial pressure in human and anfmal studies (DeQuattro and Hamad, 1985). It cannot be excluded that environmental factors as overeating or high salt intake could exaggerate a genetic or familial predisposition to obesity or hypertension (Beyer and Peuler, 1983). Furthermore, 1 remains probable that a spectrum of different hereditary, environmental and acquired factors may complement each other in a multifactorial pathogenesis of essential hypertension (Weidmann, 1981).

\subsubsection{Sodium Intake}

Already some 80 years ago, Ambard and Beaujard (1904) suggested that salt intake might influence high blood pressure. But they were not the first to recognize the importance of the sodium ion. A cltation from the "yellow emperor" 2600 B.C.: "If too much salt is used in food the pulse hardens. When the heart pulse beats vigorously and the strokes are markedly prolonged, the corresponding 11 iness makes the tongue curl up and the patient unable to speak" (from Lever et $a 1$., 1981 ; Berglund, 1983 ).

Since then, the etiological factor of excessive salt intake or sodium excess has been discussed extensively in the literature. Population surveys demonstrated a strong positive correlation between sodium intake and hypertension in nonindustrialized and industrialized societies (Page et al., 1974; Frels, 1976). Simpson (1979) concluded in his analysis of avallable data that the combined evidence does not suggest any correlation between salt intake and blood pressure, in contrast to Morgan et al. (1979). Sodium-sensitive and sodium-resistant patients with established hypertension have been described (Fuj1ta et al., 1980). Houston (1986) describes in his review that the part of the population which develops essential hypertension, particularly 
blacks, Low-renin hypertensives and elderly, are at risk due to salt senstelvity.

An abnornal sodium metabolism has been postulated as a cause for the sodium sensitivity of certain patients. The 3 important posible pathophysiological factors conceming cellular sodium transport in essential hypertenston are revlewed by filton (1986). There is convincIng evidence that an abnormality of the sodium pump is the cause for elevated intracellular sodium in leucocytes among persons with hypertenston and probably in erythrocytes $1 \mathrm{n}$ at least some hypertensives. In this context, there appear to be genetic factors which are important. It seems also reasonable that genetic defects in electrolyte transport might be present not only in blood cells but in many tissues (B1austein, 1984). Furthermore, the serum of persons with hypertension contains one or more substances which inhibit the sodium pump (inhibiting factor). Dysfunction of the renal sodium excretion and accumulation of sodium in vascular smooth muscle cells are other possible hypothetic factors (Houston, 1986). On the other hand, the mechanism why $\pm 80 \%$ of a gtven population can handle high habitual intakes of salt without danger of developing essential hypertension is not quite understood (Freis, 1976). However, the dietary sodium restriction as part of the nonpharmacological therapy in essential hypertension is beyond any doubt.

\subsubsection{The role of the renin-angtotensin system}

The renin-anglotensin system has important influences on clrculatory homeostas1s. In short, the enzyme renin induces the formation of angiotensin II, one of the most potent pressor hormones known and stimulates the secretion of aldosterone. The resulting effects, vasoconstriction, volume expansion, interaction with the sodium excretion and further stimulating effects on the perlpheral and central sympathetic nervous activity, lead to an increase of blood pressure. For more detalled descriptions of the different actions of the reninangiotensin-aldosterome axis, see Davis and Freeman (1976), Zanchetti (1977), Corvol et al. (1983), Deboden et al. (1983), Freeman and Davis (1983), Haber and Carlson (1983), Sambhi (1983), Ribeiro et al. 
(1985). The role of the prostaglandins and the kallikrein-kinin system w111 not be discussed efther.

Laragh (1973) and Drayer et al. (1982) reported different levels of plasma renin in patients with essential hypertension and classified them into groups of high, normal and low renin. Hypertension in the high-level plasma renin group, which had an incidence of $11-16 \%$ of the population studied, is believed to be caused by vasioconstriction due to an increase of the activity of the renin-angiotensin system. But doubts about this theory have been pointed out by Weidmann (1981). He argues that hypovolemla and low peripheral vascular resistance found in high-renin states are arguments against it. Furthermore, it is not clear how low-level renin leads to high blood pressure. Also, Inverse rellationships between arterial blood pressure and plasma renin have been reported in normotensive subjects (Weidmann, 1977) and in essential hypertensives (Vetter et al., 1980) or no relationship (AgabitiRoseil et al., 1983). Factors as advanced age and/or blunted betaadrenergic responsiveness and increased adrenal sensitivity to anglotensin II-induced aldosterone secretion are held responsible for a reduced renin secretion (Bühler et al., 1973; Drayer et al., 1982). Plasma renin activity is thought to decrease with age, but the influence of age upon plasma renin has been discussed as well (Pedersen, 1979; Vetter et al., 1980; Weldmann, 1981). It is however not clear whether the varlous renin-angiotensin systems in the kidney, plasma and in other tissues like brain, arteries, adrenal gland or other organs are Involved in the induction of essential hypertension (Ganten et al., 1983). Chronic oral treatment with anglotensin converting enzyme inhibltors also lowers blood pressure in spontaneous hypertensive rats, which are known to have low plasma renin (Unger et al., 1981). The blood pressure lowering action could therefore act through inhibition of the local tissue renin-anglotensin system. This could also possibly mean that tissue renin is elevated even when low plasma renin levels are measured.

Furthermore, an elevated plasma renin activity could be an indcator for other pathophysiological processes, perhaps reflecting enhanced sympathetic nervous activity, which produces both hypertension and a concomitant release of renin (Esler et al., 1977a). Support for 
this wew that the sympathetic nerwous system is in part responsible for Increased levels of plasma renin activity can be drawn from the study by Agabit-Rosel and co-workers (1983). They found a rellationship between levels of plasma noradrenaline and plasma renin activity in 76 patients wh essential hypertension when compared with normotensive controls. In his review, Toretti (1982) concludes that sympathetic outflow influences the renin release through modification of the renal merves and plasma catecholamine concentration. However, these influences may inftiate either changes of the renin secretion rate or modulate the response initiated by another mechanism that controls renin release.

\subsubsection{The role of the sympathetic nervous system}

As described before, the sympathetic nerwous system is an important factor complementing the body sodium-volume state, the reninangiotensin-aldosterone system and some other components in the regulation of blood pressure. Owing to the complexity of the function of the sympathetic nervous system, it is not simple to identify its role in the pathogenesis of essential hypertension.

For long it has been thought that an increased sympathetic tone is involved in the etiology of essential hypertension. There are indications that make it likely that an Increased sympathetic tone plays a role.

Several observations are important to consider first: it is known that sleep lowers blood pressure in both normotensive subjects and hypertensive subjects. Drugs which interfere with the sympathetic nervous system like guanethidine lower blood pressure. Pheochromocytoma is the only human "natural" model in which blood pressure increases with the release of plasma catecholamines. Furthermore, stress in subjects, 1ike undesirable life events and features of suppressed anger and/or hostlity, has been linked to the development of essential hypertenston (Esler et al., 1977a; Osti et al., 1980; Sullivan et al., 1981; Jultus and Johnson 1985). Furthermore, the Increase of plasma catecholamines during physical exercise 1 s correlated with the magnitude of the effort in healthy subjects (Dimsdale et al., 1984).

The methods of measurement of the activity of the sympathetic 
nervous system have been discussed for some time. It is obvious that direct invasive analysis of the neurotransmitter discharge is not likely to be performed in man. It has been accepted that measurements of noradrenaline in plasma are reliable indirect means or at least an index of the overall activity of the sympathetic nervous system (DeChamplain, 1977; Weidmann, 1981; Folkow et a1., 1983; Goldstein et al., 1983a; Conway, 1984; Esler et al., 1985). The interpretation of the plasma noradrenaline values should be done with caution. Concentrations of plasma catecholamines are difficult to measure and are usually very small. Plasma catecholamine levels represent, as I have described before, not only the product of the sympathetic and sympatho-adrenomedullary secretion, but depend also on diffusion to the circulation, re-uptake and degradation. Recent studies have shown that plasma concentrations of noradrenaline at rest tend to reflect outflow or release of the transmitter from synaptic terminals in skeletal muscles in nomotenstve and hypertensive patients (Wallin et al." 1981; Folkow et al., 1983; Mörlin et al., 1983; Wallîn, 1984). Animal studies in dogs have provided evidence that the noradrenaline concentration is closely related to the sympathetlc nerve discharge rate (Yanaguch1 et al., 1975). Furthermore, Esler et al. (1981a) demonstrated that supine plasma noradrenaline is highly correlated to the noradrenaline spillover rate in normotensive and hypertensive subjects evaluated after infusions to steady-state tritiated L-noradrenaline.

Higher basal circulating catecholamines (Dequattro and Hamad, 1985) and a higher sympathetic reactivity in response to postural changes has been found in $25-40 \%$ of the patients with essential hypertensilon (DeChamplain, 1977; DeQuattro and Hamad, 1985). In a review by Goldstein and Lake (1984), 78 published studies comparing plasma catecholamine levels at rest in patients with essential hypertension and in normotensive controls have been analyzed. They report that plasma noradrenaline levels are abnormally high in some patients with essential hypertension, and especlally $1 \mathrm{n}$ those patients who are young and consistently hypertensive. The authors suggest that abnormalities in sympathetic neural or sympatho-adrenomedullary activity occur in those patients. In a study by Esler et al. (1977b), 21 patients with mild essential hypertension were investigated. A subgroup with ele- 
vated plasma noradrenaline concentration was characterized by a high cardiac Index and heart rate at rest, thus supporting partly a hyperactivity of the sympathetic nervous system in these patients. Increased heart rate at rest has been found consistently in borderline hypertensive subjects (Julius et al., 1980), and in other studies with essentlal hypertensive patients (Berglund et a1., 1974; Berglund and Whelmsen, 1975; Ohlsson et al., 1981). Peripheral resistance is elevated in established hypertension (Conway, 1984) and in borderline hypertension (Jullus et al., 1971b). As Abboud (1982) describes, it could be plausible that an increased sympathetic activity can enhance blood pressure through a number of mechanisms: noradrenaline released in several vascular beds leads to arteriolar constriction and the sympathetic drive to the heart increases stroke volume, heart rate and cardiac output.

Some authors propose to make detalled analyses of different reglons where noradrenaline overflow accurs, like in myocardial and renal vascular beds (Folkow et al., 1983; Esler et a1., 1984a; Young et al., 1984; Esler et al., 1985). The reason for this suggestion could be the fact that, though in man peripheral plasma noradrenaline correlates with overall sympathetic nervous activity, it does not allow the detection of regional disturbances in noradrenaline outflow which could be of pathogenic significance. In a study performed by Esler and co-workers $(1984 \mathrm{~b})$, using the radiotracer method, an increased noradrenaline release by the kidneys and increased cardiac noradrenaline release was found in 31 patients with essential hypertenstion with a mean age of 51 years. An increased renal sympathetic nervous tone was associated in especially the young patients with a high noradrenaline release and a mild high-renin level.

Another controversial issue is the factor age. It has been found that plasma noradrenaline levels increase with age (Lake et al., 1977; Weldmann et al., 1980; Rubin et al., 1982), but others found no correlation between plasma noradrenaline and age (DeChamplain et al., 1980; Agabit1-Rosei et a1., 1983; Goldsteln and Lake, 1984). Esler et al. (1981a) found no difference in release of noradrenaline into the circulation between young and old subjects, but suggested a reduced clearance in old subjects as the reason of possibly elevated levels of 
plasma noradrenaline. Another reason could be the responsiveness of the adrenergic receptor system. There 1 is evidence for a decreased responsiveness in beta-adrenoceptor-mediated function with aging in man (Kelly and O'Malley, 1984). Evidence for changes of alpha-adrenoceptor mechanisms is not fully conclusive. It is not clear which mechanism is responstble for a decreased responsiveness. Receptor changes and post-receptor alterations, the role of adenylate cyclase and cyclic AMP among other factors are being discussed (for review, see Levitzki, 1981; Wesslau, 1983).

The hypothesis about the relationship of stress, adrenaline and hypertension has been outlined by Rand and Majewski (1984). Adrenaline released from the adrenal medulla in stress may be incorporated in noradrenergic transmitter stores and reach a sufficient concentration. As a cotransmitter it can then activate the autofacliltatory feedback loop of noradrenaline release involving presynaptic beta ${ }_{2}$-adrenoceptors. An increase in vasomotor tone and cardiac activity results. Repeated stress may progress to a hypertensive state, as was reported in this chapter and shown in several studies (see Rand and Majewski, 1984). Furthermore, plasma adrenaline levels are elevated in a number of hypertensive patients (DeChamplain et al., 1977; Bolli et al., 1981; Dominiak and Grobecker, 1982). However, recently doubts about this theory have been published by Brown et al. (1985), who investigated patients with mild hypertension and normotensive controls from the MRC Trial.

The theory was attractive enough to suggest that raised catecholamine levels are the manifestation of the early phase in the development of hypertension, as was suggested by sever et al. (1977) and was consistent with others (Esler et al., 1977a; Goldateln et al., 1983b). Possibly in the early phase of hypertension, an elevation of catecholamines occurs in some patients and at least contributes to the manfestation of hypertension. Furthermore, functional trigger elements in essentlal hypertension including neurogentc ones, need only to be marginal and may well be intemittent (Folkow, 1982). In most studies, measurements of plasma noradrenaline have been performed in patients with established essential hypertension. That could be the reason that partly elevated levels and no signiflcant change of levelsi 
when compared wth nomotensives was found (Dechamplain, 1977; Goldstein and Lake, 1984). One of the reasons for this outcome could be seen in the fact that many patlents present themselves for the first time when hypertension is well established. At this stage a relatively large part of the elevated arterial blood pressure is maintained by hypertrophied vessels and heart (Korner, 1984). So on the other hand, normal peripheral plasma concentrations and clearance values of noradrenaline in humans wth essential hypertension do not exclude the existence of an early pathogenetic stage or in the chronic phase of hypertension an increased sympathetic drive in some local regions. It may not be necessary for the increased activity of the sympathetic nervous system to be continuously present to be an important etiological agent.

For further comprehensive and detalled analysis of the role of an enhanced sympathetic nervous system dealing with the great amount of studies on the hemodynanilc, pharmacological and biochemical aspects, I refer to review articles by Frohlich (1977), Dechamplain et al. (1981a), Abboud, (1982), Taraz1 (1983), Chalmers and West (1983), Abboud (1984), Izzo (1984).

\subsubsection{The role of the parasympathetic nervous system}

As the counterweight to the sympathetic nervous system, the parasympathetic nervous system, is too often ignored and publications In this fleld are scarce. One of the reasons could be that acetylcholithe mediated processes are diffcult to measure.

Recently it was found that the parasymathetlc system can inhibit the liberation of noradrenaline, presumably through an action of acetylcholine on the muscarinic receptors lacated presynaptically (Levy and Blattberg, 1976; Lavallé et al., 1978). In view of this finding, $1 \mathrm{t}$ was logical to postulate that a loss of parasymathetic tone might lead to an increased sympatho-adrenal tone.

Several studies supported the view of a decreased or altered cardiac parasympathetic inhibition in borderline hypertensive subjects (Jullus et a1., 1971a, 1975; Johnston, 1980) and 1 n essential hypertensive patients (Korner et al., 1973; Simon et al., 1977). Sallva flow results malnly from stimulation of the parasymathetic. Inner- 
vation (Schneyer et al., 1972). Recently, studies of sallwary flow In borderline hypertensive subjects suggested a reduced parasympathetic drilve to salivary glands at rest (Henquet et al., 1982; Rahn et al., 1983; Van Hooff et al., 1984a). It could therefore be possible that the decrease of the parasympathetic inhibitory mechanism could reinforce sympathetic activity.

\subsection{BORDERLINE HYPERTENSION}

According to the definition of the WHO, described in chapter 1.1, borderline hypertension is defined as the blood pressure (systolic/diastolic) between $>140 / 90$ and $<160 / 95 \mathrm{mmHg}$. Many published studies deal with this borderline hypertensive range differenty. Descriptions as "labile", "occasional", "early" "latent" or "pre-hypertension" can be found. Some terms, such as labile or occastonal, indicate actually that blood pressure fluctuations are common in these patients. The term labile implies an increased wariability. It has been found that blood pressure varlability is not abnormal and not a characteristic feature of borderline hypertensive subjects (Julius et al., 1980; Watson et al., 1980a; Horan et a1., 1981; Kubo, 1983; Weder and Julius, 1985). The terms pre- and early hypertension in the context of borderline hypertension should be used with caution as well, because they indicate a condition which leads to hypertension, but, as will be noted later, not all borderline hypertensive subject become hypertensive. Latent hypertension describes a condition which may develop into hypertension or which may remain fin this gray zone. Julius (1977) defines the tert borderline hypertension in the group from 17-40 years further: the blood pressure levels (as defined above) are always between the hypertensive and normatensive range or some values in the borderline or hypertensive range wh occasional normal. values. Furthermore, no evidence of target organ damage is present.

Borderline hypertension is a wide spread condition. Prevalence rates depend on age and on other factors mentioned earlier. The prevalence above 20 years of age ranges between $8 \%$ and up to $29 \%$, the average prevalence belng 20\% (Jullus and Schork, 1971; Jullus et al., 
1980; JuLlus and Hansson, 1983). Borderline hypertension is not a innocuous condition. Overall mortality exceeding the age-adjusted mortaLity from cardlovascular disease has been described as twice as high when compared with the normotensive population (Julius and Schork, 1971; Jullus, 1977). Furthermore, Increased morbidity from coronary heart disease has been reported as well by Jullus and Hansson (1983), who analysed several studles. Borderline hypertensive subjects frequently have overwelght and a family history of hypertension has been assoclated with borderline hypertension (Julius et al., 1980). The association between hypertension and obesity has been made. It is furthe rmote known that obesity is an important additional risk factor in hypertensive patients. Among the posstble mechanisms discussed for the assoclation of hypertension and obesity are hyperinsulinemia and/or Increased sympathetic activity (S1ms, 1982; Dustan, 1983; Lucas et al., 1985; Modan et al., 1985). However, studies of plasma catecholamines in obese hypertensives are scarce and give inconclusive results. There have been reports about elevated supine plasma noradrenaline levels in abese borderline hypertensive subjects when compared with non-obese borderline subjects (Sowers et al., 1982), as well as no differences between abese normotensive and hypertensive subjects (Boehringer et al., 1982; Tuck et al., 1983). Messerli et al. (1982) reported higher plasma noradrenaline levels in lean borderline hypertensive subjects when compared to obese borderline and lean nomotensive subjects.

However, the medleal significance of the condtion borderline hypertension 1s uncertain. Evidence for the indictment of being a precursor of hypertenslon has been described by stamler et al. (1958). But recent studies performed have confirmed that the subsequent development of hypertension occurs only in the minorlty of the subjects with borderline hypertenston (Jullus and Schork, 1971; Hedstrand and Rberg, 1975; Jullus, 1977; Jullus et al., 1980; Kubo, 1983; Sasakawa et a1., 1983; Ueda et a1., 1983). However, at least the development of later established hypertension has been associated with borderline hypertensive subjects twice as high as in normotensive subjects (Julius and Hansson, 1983).

A wide range of physlological abnormalities underlines the im- 
pression that borderline hypertension is not only a minimal blood pressure elevation. A large proportion of borderline hypertensive subjects exhibit increased heart rate at rest as many studies have shown (Frohlich et al., 1970; Julfus and Hansson, 1983). Furthemore, it is well dacumented that cardiac output at rest is increased in a part $(30 \%)$ of the whole group of borderline subjects; but the differences between normotensives and borderline subjects seem to decrease with age (Julius and Conway, 1968). One study reported that the high cardiac output and a high renal blood flow was found predominanty among borderline pattents younger than 30 years Messerli et al., 1981). The cause for the higher cardiac output in the borderline hypertensive subjects was thought to be the elevated heart rate or an increased stroke volume or both (Jullus et al., 1980). An earlier study showed that the elevated cardiac output nomalized to the level of normotensive controls only after blockade of the heart with propranolol and atropine (Julius et al., 1971a). Changes in arterial baroreflex control of the circulation occur in essential hypertension. The possible mechanisms for the resetting in hypertension are described in detail by Zanchetti and Mancla (1984). Studies performed in borderline hypertensive subjects indicated a reduced baroreceptor sensitfvity (Takeshita et al., 1975; Hansson et al., 1981; Volpe et al., 1982 ; Saito, 1983), in contrast to findings by Julius and Hansson (1974) and Jullus (1976). The decreased baroreceptor function is belleved to be secondary to the increase of blood pressure in borderline hypertenston (Eckberg, 1979; Julius et al., 1983). Plasma renin activity is thought to be distributed in the same fashion as in established hypertension in high, normal and low renin (Esler et al., 1975). The peripheral resistance in borderline hypertension is efther elevated or inappropriately adjusted to the increased cardiac output (Jullus et al., 1971b). Julius and Johnson (1985) state that the increased cardlac output is neurogenic, and that $\mathbb{1}$, some pattents the elevated plasma renin activity and noradrenaline levels and the increase in vascular resistance are maintalmed by a neurogenic tone. Levels of plasma noradrenaline at rest are usually nomal in borderline hypertensive subjects when compared with normotensives (Julius et al., 1980; Eliasson et al., 1983). Studies performed by Henquet (1980) in some of the borderline 
and nomotentive subjects, belongling to the same group as described in chapter 2, indicated an increased vasoconstrictive responsiveness on noradrenaline infusion in the borderine subjects. This result was conflmed in another study by Iimura et al. (1984). However, Julius et al. (1983) report that results of studles performed on cardiac receptor responsiveness and vascular responslveness in borderline hypertensive subjects are on the whole Inconclusive.

A decreased plasma volume has been described in subjects with borderline hypertenston (Julius et all, 1971c), which could presumably be Blmilar to disturbances in extracellular fluld volume in estabilshed essential hypertension where a reduction of blood volume is seen in most types of hypertension (Tarazi, 1983). Furthermore, a hyperresponse to mental stress was found consistently in subjects with borderline hypertenston (Eliasson et a1., 1983; Jullus and Hansson, 1983; Jullus and Johnson, 1985). The value of exerclse blood pressure as a risk Indicator of hypertension was discussed by Franz (1982). Borderline hypertensive subjects who reacted with a blood pressure increase $>200 / 100 \mathrm{mmHg}$ during $100 \mathrm{~W}$ exercise, developed established hypertension within 3.8 years of observation.

A large number of factors and pathophysiological abnormalities have been reported in subjects with borderline hypertension. The analysis and detailed description of all these factors is beyond the intention of this introduction and would go beyond the studies performed with the borderline hypertensive subjects. Therefore, 1 t is referred to some review articles (Julius and Schork, 1971; Julius and Esler, 1975; Jullus, 1977; Julius et al., 1980; Julius et al., 1983; Julius and Hansson, 1983; Christensen, 1984; E1lasson, 1984; Lund-Johansen, $1984)$.

Established essential hypertension leads to secondary changes; 1t w11 therefore be very difficult to assess the role and the fmportance of the hypothetical trigger which induced hypertension, because it is as such no longer recognizable. Apparently mechanisms for blood pressure elevation change during the history of hypertension as well. As was described, borderline hypertension is a condition which occurs quite frequently. Furthermore, in a number of borderline subjects progression to hypertenstion has been shown. In order to evaluate the 
role of the activity of the sympathetic nervous system in borderline hypertension, a longitudinal study was performed. A group of young men with borderline hypertension and an age-matched nomotensive control. group were followed to study plasma noradrenalline and adrenaline levels as well as plasma renin activity at rest and during exercise. The natural course of blood pressure was followed in both groups through regular controls of blood pressure to evaluate the progression to later hypertension. The aim was to follow both groups as long as possible. The subjects participated on a voluntary basis. Preliminary results about the study have been published already by Henquet (1980), Henquet et al. (1981), Henquet et al. (1982), and Van Hooff et al. (1984a).

\subsection{TREATMENT OF MILD HYPERTENSION}

In the study dealing with borderline hypertensive subjects, as w11 be described in chapter 2 and 3 , the definition for borderline hypertension was a blood pressure $\geqslant 140 / 90 \mathrm{~mm} H \mathrm{Hg}$, but $<160 / 100 \mathrm{mmHg}$. According to some authors, mild hypertension has been defined as the diastolic blood pressure $>90-<110 \mathrm{~mm}$ Hg (Korotkoff phase V) (Hansson, 1983; Miall et al., 1983), >95-99 mm Hg (Strasser and Dowd, 1983). So, mild hypertension varies with the design of the trials. Very recently, mild hypertension has been defined by the who in adults as a diastolic pressure (phase V) persistently between 90-104 um $\mathrm{Hg}$ without obvious signs of left ventricular hypertrophy for damage to the heart or other organs (WHO/ISH Memorandum, 1986). Concerning this blood pressure range, it is obvious that some of the borderline hypertensive subjects could then fall under the description of mild hypertension.

The trial II of the Veterans Administration (VA) Cooperative Group (1970) showed that treatment in inlld hypertensive patients (diastolic blood pressure: 90-104 mm $\mathrm{Hg}$ ) reduced the risk for morbld events $(21 \%)$. However, the risk reduction was greater in the group of patients with diastolic blood pressure of $104-114 \mathrm{~mm} \mathrm{Hg}(52 \%)$. It must be emphasized that patients, without treatment, whose diastollic blood 
pressure averaged 90 through $129 \mathrm{~mm} \mathrm{Hg}$ from the 4 th through the 6 th hospital day were accepted for further follow-up. The VA trial suggested further that the mild hypertensive group with pre-existing cardiovascular or renal abnormalities, benefits from treatment. It was proven not only in the VA trial I (1967) that patients with moderate to severe hypertension benefit from treatment, and no discussion arises about treating this group. The second VA trial (mild hypertension) indicated no firm conclusion; perhaps this was also due to the small sample slze.

In the last few years, several other different intemational studies have been performed in groups of patients with mild essential hypertension. The American Hypertension Detection and Follow-up Program (HDFP, 1979) and the Australian Therapeutic Trial in mild hypertension (1980) have both shown that lowering bload pressure can be of beneftt in these patients. Stroke and myocardial infarction declined signtflcantly in the American study and mortality from cardiovascular disease in the Australian trial. Three groups of patients we re studied in the HDFP study: diastolic blood pressure 90-104, 105-114, and $>115$ mm Hg. Total mortality was reduced by $20 \%$ in the group with diastolic bload pressure 90-104 mro Hg. It must be noted that in this study the intention was to compare mortality of rígorous stepped-care and communtey referred-care. In the Australian study, mild hypertension was defined as diastollc blood pressure (Korotkoff V) $>95-<110 \mathrm{~mm}$ Hig; in the active treatment group the average diastolic blood pressure fell $13 \mathrm{~mm} \mathrm{Hg}$ compared to $7 \mathrm{~mm} \mathrm{Hg}$ in the placebo group. Recently, results from the Medical Research Council Working Party Trial of mild hypertenstion (MRC, 1985) were published. Agalin the stroke rate was reduced, but the overall rate of coronary events was not influenced by the treatment. This made the impression of beneficlal aspects of treating mild hypertension stand on a less secure ground.

For several years now, the active drug treatment in mild hypertension has been discussed by several authors (Peart, 1981; Freis, 1982; Levinson et al., 1982; Kaplan, 1983; McAlister, 1983; Memorandun WHO/ISH Meeting 1983; Pickering, 1983; Toth and Horwitz, 1983; Venkata and Ram, 1984; Berglund, 1984; Hyman and Kaplan, 1985). The attention was focused on this subject also by the number of trials performed. 
Speaking against treatment of mild hypertension, and this has to be taken into consideration, is the fact that some patients with mild hypertension 11 clearly show a fall of blood pressure without active interference. Other factors are the potential side-effects of the drugs prescribed and the bearing of the hallmark of hypertension. However, patients with even a mild elevation of blood pressure are at increased risk of cardiovascular disease. If symptoms have appeared, morbidity and mortality are higher than before. In young patients in the mild hypertensive range, the progression to moderate or severe hypertension could be at least postponed with active treatment before target organ involvement or damage in the long run appear. If the latter or additional risk factors are present, treatment should be started. Recently, the WHO (1986) proposed to treat patients with antihypertensive drugs who have a diastolic blood pressure $>100 \mathrm{~mm} / \mathrm{g}$ during three months of follow-up. In subjects with additional risk factors like smoking, increased plasma cholesterol and diabetes mellitus and in subjects with target organ damage active treatment is proposed to start at a lower level of blood pressure. The refore, prescribing therapy in mild hypertensive patients should be done with caution and be judged carefully in the lindividual case. Clearly the risk of active treatment should not exceed the risk of mild hypertensiion.

Non-pharmacological methods (reduction of weight, smolung, and hedvy alcohol consumption, dietary sodium and saturated fat restriction) have been recommended as an adjunct to drug therapy. other adjuncts or measures to lower blood pressure include physical exercise, relaxation techniques, stress reduction and supplementary intake of calcium. Different drugs can be prescribed for patients with mild hypertension. The goal is to lower blood pressure to normotenslve levels or at least to below diastolic $90 \mathrm{~mm} \mathrm{Hg}$ (WHO/ISH memorandum 1986). As the initial therapy, beta blockers and diuretics can be used. These two agents will control blood pressure in the majority of patients with mild hypertension. In the last few years, calclum channel blockers have been 1 trtroduced and found their place in monotherapy. A newer class of drugs, the angiotensin converting enzyme imhibitors have been developed and are also used in essential hypertension. 
The intention to use the latter in monotherapy in mild hypertension thas been proposed already (Freis, 1983; Schalekamp, 1985; Zanchett1, 1985a, b; Bühler, 1986).

Diuretics, like the thiazlde diuretics (bydrochlorothlazide) hawe been used in the initial step in the treatment of hypertension. The primary action of diuretics is the increase in renal excretion of sodium and water. The consequence is a fall in extracellular and blood volume; this leads to the fall in cardiac output and blood pressure. The long-term effect of diuretics is a relative reduction of the vascular resistance together with the return of cardiac output near control values. Among other factors a decrease of extracellular volume and a change of electrolytes in the tissue have been suggested as explanation for the decrease of vascular resistance (Struyker Boudier et a1., 1983). Plasma renin activity will increase and renal blood flow remalns unchanged. The blood pressure decrease will range about 10-20 $\mathrm{mm} \mathrm{Hg}$ during diuretic therapy. Among the side-effects of thiazide diuretics are metabolic effects (hyperuricemia, glucose intolerance, hypercholesterolemia) and hypokalenta, which could have serious consequences in elderly patients. Other side-effects are Impotence, fatigue and dizziness. Additional potassium suppletion or using a thiazide diuretic in combination with a potassium sparing diuretic (trlamterene) could prevent events triggered by hypokalemia. However, potassitum sparing diuretics may lead to hyperkalemia in impaired renal function. Older patients are most likely to be treated first with a diuretic. The lowest dose of diuretic drugs should be used to achieve the target blood pressure because of manifestation of side-effects with increasing doses. Estimations of plasma potassium, uric acid, creatintine and urinary glucose should be made after beginning of the therapy and are recommended subsequently once every year.

Beta-adrenergic blocking agents have been used for different indications, they are avallable for treatment of essential hypertenston for a longer time now. Their antihypertensive mechantsm has, however, not been fully explalned. They all share their specific action to block the beta-adrenoceptor (Man in ' $t$ Veld and Schalekamp, 1983). Numerous agents are avallable; the different beta-blockers on the Dutch market have been recently reviewed (Man In 't Veld, 1985). But 
they may differ further in pharmacodynamics (cardioselectivity, intrinsic sympathomimetic activity (ISA), membrane stabilizing activity) and pharmacokinetics (metabollsm, lipid solubll1ty). The hemodynamic effects of the majority of the beta blockers are comparable. Acute administration of beta blockers results in a blockade of cardlac beta-adrenoceptors leading to a rapid decrease of heart rate and cardiac output. An immediate rise in peripheral resistance will follow. An acutely administered beta blocker with strong ISA, at least at rest, leads to less or no cardiac output reduction and hardly affects total peripheral resistance (Van Baak et al., 1985). The blood pressure fall at rest can be explained by beta $2^{- \text {adrenoceptor stimulation }}$ leading to vasodilatation. Chronic treatment with beta blockers results in reduction of cardiac output, although stroke volume is normal, and so are plasma volume, blood volume and central blood volume. Total peripheral resistance remains unchanged or is silightly increased. Plasma renin activity is decreased. Beta blockers with strong ISA hardly affect cardiac output at rest, while total peripheral resistance is reduced. However, in situations with increased sympathetic activity, e.g. standing and physical exercise, beta blockers with ISA behave like normal beta blockers. The antihypertensive mechanisms of beta blockade have been reviewed recently in detail by Van Baak et al. (1985). Side-effects of beta blockers 1nclude bradycardla, hypertriglyceridemia and decreased high density lipoprotein cholesterol. Sedation and bad dreams are believed to be effects on the central nervous system. Cardloselective beta blockers still could cause bronchoconstriction in patients with chronic obstructive pulmonary disease; non-selective beta blockers should be generally avolded in these patients. Provocation of claudication in patients with peripheral vascular disease or Raynaud's phenomenon is particularly described during treatment with propranolol. Hypoglycemia in patients with diabetes mel11tus was reported by non-selective beta blockers. Due to other side-effects, such as muscular fatigue and less physical exerclse performance, a study was performed and 1 s presented in chapters 4 and 5, which deals with endurance performance in mild hypertensive patients during long-term beta blocker therapy. Contra-indications for beta blockers are congestive heart fallure, bradycardia, AV-block 
grade II, and sick sinus syadrome. In general, beta blockers may be favored in younger patients because the excessive bradycardia or congestlve heart fallure are more frequent in the aging heart. Furthermore, plasma renin values and cardiac output differ in young and old patients. The combination with diuretics is recommended if the blood pressure goal is not reached with beta blockers alone. Beta blockers could then decrease the plasma renin stimulation induced by diuretics. The anthypertensive action of beta blockers 1 s comparable to that of the diuretics.

In the last 5-10 years, calclum channel blockers have been introduced in antihypertensive therapy and they have been used lately in monotherapy for mild hypertension. Their effect is believed to be a lowering of peripheral resistance, which is increased in patients with essential hypertension, through blocking the slow channels of the calcium influx and thus resulting in vasodilatation and reduction of the total peripheral resistance. Nifedipine acts more on vascular smooth muscle cells in coronary and systemic arterles. In contrast, both verapanil and diltlazem produce less vasodilatation than nifedipine and affect AV-conduction. No sodium or fluid retention and no postural hypotenston occurs during chronic therapy in contrast to other vasodilators. The frequency of side-effects during therapy with calctum channel blockers is minor. The major side-effects of calcium channel blackers can be predicted from their pharmcological actions. Verapand has a negative inotropic effect and prolongation of AVconduction time occurs, but no reflex tachycardia accurs during verapamil in contrast to nifedipine. Further side-effects of verapamil are constipation, flushing and headache. Side-effects of nifedipine are headache, flushes and local edema in the extremities. The low incidence of sertous side-effects in oral therapy and their valuable antihypertensive effect could therefore result in the use of calcium channel blockers in monotherapy as an altemative for the other drugs like diuretics or beta blockers used in healthy hypertensives or in case of Increasing complatnts of cold extremities, muscle fatigue or obstructive lung disease. Calcilum channel blockers can be used in combination with diuretics and converting enzyme inhibitors. Verapamil is not likely to be combined with a beta blocker due to the suppres- 
sion of AV-conduction by both. The role of calcium channel blockers in the treatment of hypertension has been recently reviewed in detail by Halperin and Cubeddu (1986).

The angiotensin converting enzyme (ACE) inhibitors inhibit the converting enzyme which catalyzes the conversion from angiotensin I to angiotensin II. The antihypertensive action arises primarily from the Inhibition of the formation of the vasoconstricting angiotensin II. Other actions such as reduced degradation of bradykinin and increased release of prostaglandins cannot be entirely discounted (Van Zwieten et al., 1983; Ondetti and Cushman, 1984). The fall of blood pressure is due to peripheral vasodilatation (Johnston et al., 1984), depending on initial levels of plasma renin activity and the decline of circulating anglotensin II concentrations (Kubo and Cody, 1985). The fall of the perfpheral resistance should normally induce stimulation of the sympathetic nerwous system and result in a reflex increase of heart rate and cardiac output, but the counterregulatory system is not activated. Long-term effects are an increase of plasma renin activity. Only little or no salt or water retention occurs. Sodium depletion accentuates the effects of $\mathrm{ACE}$ inhibitors. At the moment, captopril and enalapril are avallable for treatment of hypertension. The second generation of ACE inhibitors with not only a longer duration of action, but dual routes of excretion via kidney and liver are being studied. As mentioned before, some experts considered the use of $\mathrm{ACE}$ inhibitors for the treatment of patients with mild to moderate essential hypertension. It is known that some harmful metabolic side-effects, like alterations of serum uric acld, blood glucose, plasma renin levels, and lipid concentrations, limit the use of diuretics and beta-adrenergic blocking agents. Until now, ACE $\mathbb{1 n h i b i t o r s}$ exert little relevant metabolic side-effects $\mathbb{i n}$ these mild to moderate hypertensive patients. Ramlpril is one of the newer ACE Inhibitors and was studied in patients with essential hypertenston, as will be described in chapter 6. The intention was to find the dose which lowers blood pressure and to investigate the time course of the blood pressure lowering effect in essential hypertensive patients. Side-effects of captopril are hypotension and, especfally in high doses, skin rash, loss of taste, leukopenta or agranulacytosis and it Increases protein- 
uria in patients. Side-effect of enalapril are similar and include headache, rash and hypotension (Todd and Heel, 1986). ACE inhibitors can be used to treat hypertension in patients wh asthma and chronic obstructive lung disease, conditions in which non-selective beta blockers are to be avolded. ACE 1 nhlbitors can be combined with diuretics or beta blockers. 
Chapter 2

\section{A LONG-TERM STUDY}

OF PLASMA CATECHOLAMINE LEVELS AND PLASMA RENIN ACTIVITY IN BORDERLINE HYPERTENSION

Böhm, R.O.B.. ${ }^{1}$, Baak, M.A. van ${ }^{1,3}$, Hooff, M.E.J. van ${ }^{1}$, Mooy, J.2, and Rahn, K.H. ${ }^{2}$

Dept. of Pharmacology 1 , Dept. of Medicine, Division of Nephrology, Hypertension and Clinical Pharmacology ${ }^{2}$, Unlversity of Limburg, and Institute for Sports Medicine Limburg ${ }^{3}$, Maastricht, The Netherlands. 
2.1 SUMMARY

There are conflicting reports on plasma catecholamine levels in subjects wh borderline hypertension. This could be due to the fact that only a subgroup of borderline hypertenstve subjects develops definitive hypertension, whereas others remain in the borderline range or even become normotensive. We therefore studled the development of blood pressure, plasma catecholamine levels and plasma renin activity (PRA) in a group of 26 young borderline hypertensive subjects and a control group with 24 normotensives at rest and during physical exercise. The study started in 1977 and was finished in 1984. Three subjects were lost to follow up. At the end of of the study, 15 normotensive subjects remalned normotensive (mean arterlal blood pressure (MAP) $\leqslant 98 \mathrm{mmHg}$ (subgroup 1)). In 10 borderline hypertensive subjects, blood pressure remalned borderline hypertensive (MAP $\geqslant 107-<120 \mathrm{mmHg}$ (subgroup 3)). During the 7 years of follow up, 5 borderline hypertensive subjects became deflnitively hypertensive (MAP $\geqslant 120 \mathrm{mmHg}$ (subgroup 4) and were exclluded from the study in order to recelve antihypertensive treatment.

At repeated measurements in 1977,1978 and 1984 , the re was no difference in plasma noradrenaline levels at rest and during physical exerclse between the total groups of normotenslves and borderline hypertensives. However, the situation changed when the subgroups were considered separately. Subjects who developed definitive hypertension within the observation period (subgroup 4) had consistently high plasma noradrenaline concentrations at rest. In contrast, subjects who remained nornotensive (subgroup 1) as well as subjects remaining borderline hypertensive (subgroup 3) had relatively high resting noradrenallne levels only at entrance into the study, the concentrations of the amine belng considerably lower than in subgroup 4 at successive measurements.

There were no differences between the groups and the subgroups in plasma adrenaline and PRA at rest as well as in plasma noradrenaline, plasma adrenaline and PRA during exercise.

The study shows that only $20 \%$ of borderline hypertensive subjects become definitively hypertensive during an observation period of 
7 years. These subjects have consistently high plasma noradrenallne levels at rest suggesting enhanced sympathetic activity.

\subsection{INTRODUCTION}

The role of the sympathetic nervous system in the pathogenesis of essential hypertension is still controversial. It could be that enhanced activity of this system causes chronic elevation of blood pressure in man. Plasma concentrations of noradrenaline and adrenaline may be used as an index of sympathetic nervous system activity in man (Wallin et al., 1981; Goldsteln et al., 1983a; Wallin, 1984; Esler et a1., 1985), although plasma catecholamine levels depend upon numerous processes such as release from and re-uptake by nerve endings, metabolic degradation, uptake into non-neural tissue, binding to postsynaptic receptors and diffusion from the synaptic cleft to the clrculation (Goldstein, 1983). Thus, it is understandable that studies performed to get insight into the sympathetfc nervous system activity in patients with essential hypertension have yielded results which are difficult to interpret (Goldstein and Lake, 1984).

In patients with long lasting blood pressure elevation, alterations of plasma catecholamine levels could be the consequence rather than the cause of hypertension. Therefore, the interest of investigators has been focused on subjects with an early phase of high blood pressure, particularly on subjects with borderline hypertension. Studies on plasma catecholamine levels in borderline bypertension have also ylelded conflicting results (Goldsteln and Lake, 1984). This could be due to the fact that only a subgroup of borderline hypertensive subjects develops definftive hypertension in the course of several years, the others remaining in a borderline range or even becoming normotensive (Julius et al., 1980; Ibsen, 1984).

Therefore, a study was designed to follow up blood pressure and plasma catecholamine levels in a group of young subjects with borderline hypertension. The data of these borderline hypertensives were compared with a normotensive control group. Both noradrenaline and adrenaline levels in plasma we determined. Noradrenaline as ex- 
pected to reflect the activity of the sympathetic nervous system. Adrenaline was thought to give an idea of the activity of the adrenal medulla. Plasma catecholamine concentrations were not only determined at rest, but also during physical exercise. Physical activity causes plasma catecholamine levels to increase (Planz et al., 1976; Watson et al., 1980c; Davidson et al., 1984). It seemed passible that thereby differences between subjects wth borderline hypertension and normotensives become more pronounced. Renin release from the kidneys is Hnfluenced by the sympathetic nervous system (Davis and Freeman, 1976). Therefore, plasma renin activity was followed up, too.

There are observations suggesting that blood pressure during exercise reaches extraordinarily high levels in those subjects with borderline hypertension who later become definitively hypertensive (W11son and Meyer, 1981; Jackson et a1., 1983; Franz, 1985). Thus, in borderline hypertensives, the rise of blood pressure during exercise might have a predictive value. Therefore, at entrance into the present study, blood pressure was determined. both at rest and during physical exerclse.

\subsection{SUBJECTS AND METHODS}

Fifty males agreed to participate. Their age ranged from 18 to 30 years at entrance lnto the study. The subjects were recruited as has been described (Henquet et al., 1981). Twenty-four subjects were normotengive. For the purpose of the present study, normotension was defined as blood pressure values of $\leqslant 125 / 85 \mathrm{~mm} \mathrm{Hg}$ with a mean arterial blood pressure (MAP) $\leqslant 98 \mathrm{~mm} \mathrm{Hg}$ after $2 \mathrm{~min}$ standing determined at 8 measurements performed on 4 different days in a period of 3 months. The other 26 subjects were borderline hypertensive. Borderline hypertension was defined as standing blood pressure values $\geqslant 140 / 90$ to $<160 / 100 \mathrm{Hg}$ (MAP $\$ 107-<120 \mathrm{~mm} \mathrm{Hg}$ ) when measured 8 times on 4 different days in a perlod of 3 months. In the subjects with borderline hypertension, secondary hypertension was excluded by history, physical examination, appropriate laboratory tests and intravenous pyelography. None of the subjects with borderline hypertension had 
retinal changes and none of them ever had recelved antihypertensive drugs. All subjects participating in the study had nomal values for creatinine, alkaline phosphatase, gamma-glutamyl transferase and transaminases in serum. Informed consent was obtalned from all subjects. The study had been approved by the Research Committee of the University of Limburg.

The study started with a recruttment phase lasting from the sumer to the end of 1977 . The study was completed by the end of 1984. Thus, all subjects were observed for a total of 7 years. During the observation period, blood pressure and heart rate were measured after 30 min rest in supine position and after 2 min standing in all subjects at 4 months' intervals. If mean arterial blood pressure after 2 min standing was $\geqslant 120 \mathrm{~mm}$ at 2 successive measurements, the subject was considered to be definitively hypertensive and excluded from the study in order to start antihypertensive therapy.

In al1 subjects, plasma catecholamine levels and plasma rentn activity (PRA) were determined at rest and during bicycle ergonetry at entrance into the study in 1977, in 1979 and in 1984. Each time, maximum work load during bicycle ergometry was determined first. The subjects started with a work load of 124 . The work load was increased stepwise until the maximum work load was reached (Henquet et al., 1981). Blood pressure was measured at each work load. Furthermore, heart rate was determined from the continuously monitored electrocardiogram. All ergometric studies were performed $\mathbb{1}$ a temperature-controlled laboratory.

Not earlier than 5 days after the determination of maximum work capacity, the subjects collected a $24 \mathrm{~h}$ urlne sample for the measurement of sodium excretion. The day thereafter, the subjects came back to the laboratory. After a forearm veln had been cannulated, they rested for $30 \mathrm{~min}$ in supine position. Thereafter, heart rate and blood pressure were measured and a blood sample was drawn for the measurement of plasma catecholamine levels and PRA. Then, the subjects exercised in sitting position on a blcycle ergometer, subsequently at $50 \%$ and at $75 \%$ of thelr predetermined maximum work capacity. Each work load lasted for $5 \mathrm{~min}$. In the last $2 \mathrm{~min}$ of each ergometry period, heart rate and blood pressure were measured. Furthermore, at the end 
of the work period with $75 \%$ of maximum capacity a blood sample was drawn to determine the same parameters as during supine rest.

A11 blood pressure measurements were perfomed using a mercury manometer. The point of muffling of the Korotkoff sounds was read as the diastollc value. Heart rate was determined by palpation of the radlal artery at rest and by eletrocardiography during exercise. Mean artertal pressure (MAP) was calculated by adding one third of the pulse pressure to the diastolic blood pressure. Plasma catecholamine levels we measured radionetrically, PRA by radiolmmunoassay (Henquet et al., 1981). Sodium in urine was deternined by flame photometry.

Results are expressied as mean values \pm SEM. Statistical significance was tested with student"s t-test for unpaired data or, if approprlate, with the palred t-test. The level of signiflcance was set at $\mathrm{p}<0.05$.

2.4 RESULTS

2.4.1 Age, height, weight and maximum work capacity at entrance into the study

At entrance into the study, the age of the normotensive subjects was $23+0.7$ years as compared with $25+0.8$ years in the borderilne hypertensives. Length averaged to $180+0.1 \mathrm{~cm}$ in the mormotensives and to $177 \pm 2 \mathrm{~cm}$ in the borderline hypertensive subjects. The differences In both parameters are not statstcally slgnificant. Body welght was higher $(p<0.05)$ in the borderlune hypertensive group $(78+2 \mathrm{~kg})$ than $1 \mathrm{n}$ the normotensive group $(70+1 \mathrm{~kg})$.

Maximu work capactly averaged to $21 \pm 7$ in the nomotensive group as compared with $185+5$ w in the botderline myertenstves. The diference is statistically significant $(\mathrm{p}<0.005)$.

\section{4 .2 Blood pressure and heart rate at rest}

In 1977, at entrance into the study, systollc and diatolic blood pressure as we 1 as $M A P$ and heart rate at rest in suphne as well as in standing posttion were higher in the borderline hypertensive subject than in the nomotensives (wable 1 ). 
Table 1: Resting blood pressure (min Hg) and heart rate (beats/min) at entrance into the study.

Supine

Standing after 2 in in

$\begin{array}{lllll}\text { Sys- Dlas- MAP } & \text { Heart } & \text { Sys- } & \text { Dlas- MAP } & \text { Heart } \\ \text { tolic tolic } & & \text { rate } & \text { tolic tolic } & \text { rate }\end{array}$

\begin{tabular}{|c|c|c|c|c|c|c|c|c|}
\hline $\begin{array}{l}\text { Normo- } \\
\text { Lensive } \\
(n=22)\end{array}$ & $119+1$ & $74 \pm 1$ & $89 \pm 1$ & $63+2$ & $120 \pm 1$ & $81 \pm 1$ & $94 \pm 1$ & $77 \pm 2$ \\
\hline $\begin{array}{l}\text { Border- } \\
\text { line } \\
\text { hyper- } \\
\text { tensive } \\
(n=25)\end{array}$ & $143+1$ & $91 \pm 1$ & $108+1$ & $73 \pm 2$ & $148 \pm 1$ & $95+1$ & $113 \pm 1$ & $88+3$ \\
\hline & $<0.001$ & $<0.001$ & $<0.001$ & $<0.001$ & $<0.01$ & $<0.01$ & $<0.01$ & $<0.01$ \\
\hline
\end{tabular}

MAP is the mean arterial blood pressure; $n$ is the number of subjects in a group. The table does not contain data of the 3 subjects who were lost to follow up. Data represent mean values \pm SEM.

At the end of the 7 years' observation pertad, the 2 groups of subjects who had entered the study were divided into subgroups depen-

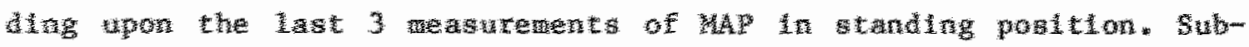

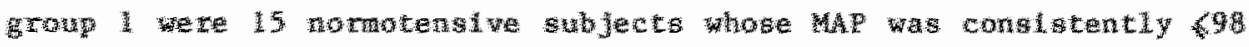

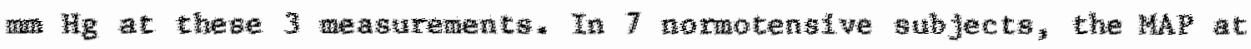

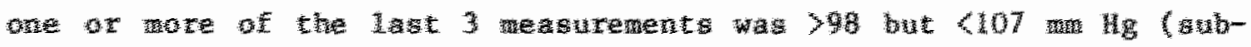

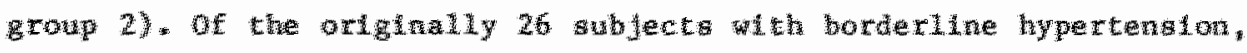

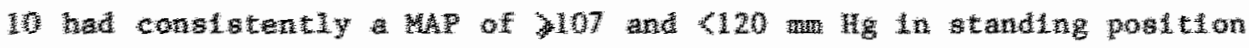

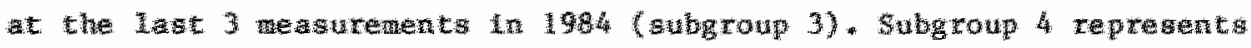

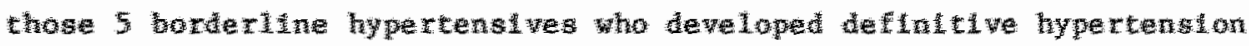

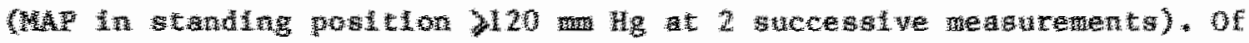

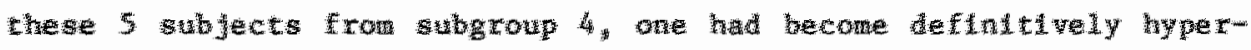

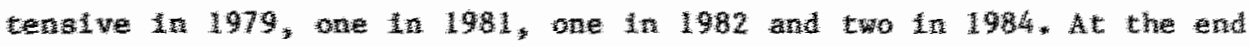

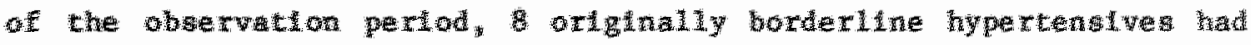
G 
(subgroup 6).

During the observation period of 7 years, 2 subjects of the normotenslwe group were lost to follow up, the first in 1981 and the second in 1983. Both were momotensive (MAP $398 \mathrm{~mm} \mathrm{Hg}$ in standing position) at their last blood pressure control. Of the borderline hypertensive group, one subject was lost to follow-up in 1981. At this time, his standing MAP was $<107 \mathrm{~mm} \mathrm{Hg.} \mathrm{No} \mathrm{data} \mathrm{of} \mathrm{the} 3$ subjects who dropped out of the study are presented.

It seemed particularly interesting to compare the data of the subjects who became defitinfvely hypertensive (subgroup 4) with those of the subjects who were normotensive (subgroup 1) or borderline hypertensive (subgroup 3) at the end of the observation period (Table 2). As could be expected, supine and standing MAP was higher in sub-

Table 2: Resting mean arterial blood pressure (MAP; m $\mathrm{Hg}$ ) and heart rate (beats/min) in the 3 subgroups at the entrance into (a) and at the end (b) of the study.

Supine:

Standing

MAP

Heart
rate

MAP

Heart

rate

Sub-

grou

a

b

a

b

a $\quad b$

a

b

1

$(n=15)$

$89 \pm 1 \quad 87 \pm 1$

$65 \pm 3 \quad 68+3$

$94+1 \quad 94+1$

$78+3 \quad 86+3$

3 $(n+10)$

$109+1 \quad 100+1$

$70 \pm 3 \quad 71 \pm 4$

$114+1 \quad 111+2$

$82+4 \quad 80+3$

4 $(n=5)$

$111+2 \quad 121 \pm 2 *$

$78+5 \quad 95+10$ *

$114 \pm 1 \quad 127 \pm 2 *$

$93+8 \quad 98+9 *$

* Data determined at the time when the subjects became definitively hypertensive. For definition of the subgroups, see text. $n$ is the number of subjects in a subgroup. Data represent mean values \pm SEM. 
groups 3 and 4 than in subgroup 1 , both at the entrance into and at the end of the study $(p<0.001)$. Subgroup 3 and subgroup 4 did not differ in supine and standing MAP at entrance into the study. Not surprilsingly, MAP values in subgroup 3 measured at the end of the observation period were lower than those detemined in subgroup 4 at the time when these subjects became definitively hypertensive $(p<0.01)$.

Neither at entrance $\mathbb{1 n t o}$ nor at the end of the study, the subjects of subgroups 1 and 3 did differ in heart rate (Table 2 ). In contrast, supine heart rate was higher in subgroup 4 than in subgroups 1 and 3 , both at entrance into the study and at the time when the subjects of subgroup 4 became definitively hypertensive $(p<0.05)$. Standing heart rate was also somewhat higher in subgroup 4 than in subgroups 1 and 3 . The difference was, however, not statistically stgnificant.

\subsubsection{Blood pressure and heart rate during exercise}

At entrance into the study, systalic and diastolic blood pressure was higher in the borderline hypertensives than in the notmotensive group at all levels of physical exercise ( $<<0.001$, Table 3$)$. The 2 groups of subjects did, however, not differ in heart rate during bicycle ergometry.

Table 3: Blood pressure ( $m$ m $\mathrm{Hg}$ ) during exercise as determined at entrance into the study.

$50 \% \quad 75 \% \quad 100 \%$

Maximum work capacity

Normotensives

$(n=22)$

$156 \pm 3 / 71+2 \quad 180+4 / 68+3 \quad 197 \pm 3 / 69 \pm 2$

Borderline

hypertensive

subjects

$175+4 / 86 \pm 2 \quad 194 \pm 3 / 86 \pm 3 \quad 208 \pm 3 / 86+3$

$(n=25)$

The table does not contain data of the 3 subjects who were 1 ost to follow-up. Data represent mean values $\pm S E M$. 
Slmlar results were obtalned when the data of subgroups 1,3 and 4 were compared. At entrance into the study, subgroup 1 had lower blood pressure data during exercise corresponding to 50,75 and $100 \%$ of maximum capactey than had subgroups 3 and 4 (p<0.05). In contrast, there were no differences between subgroups 3 and 4 . Heart rate was similar in subgroups 1,3 and 4 at all levels of physical activity.

At entrance into the study, all subjects performed bicycle ergonetry at a work load of $124 \mathrm{~W}$ for a total of $4 \mathrm{~min}$. At the end of this exercise perfod, the subjects of subgroups 3 and 4 had higher systolic and diastollc blood pressure values than subgroup $1(\mathrm{p}<0.01$, Table 4). There was no difference between subgroup 3 and subgroup 4 in systolic blood pressure. In contrast, diastolic blood pressure was hlgher in subgroup 4 than in subgroup $3(p<0.05)$. However, there was conslderable overlap of the data (Table 4).

Table 4: Systolic and diastolic blood pressure (ming) at a work load of 124 W at entrance 1 into the study.

$\begin{array}{ll}\text { Systolic } & \text { Diastollc } \\ \text { blood } & \text { blood } \\ \text { pressure } & \text { pressure }\end{array}$

Subgroup

$1(n=15) \quad 164 \pm 4+40+3$

$3(\mathrm{n}=10) \quad 191 \pm 6 \quad 85+4$

$4(n=5) \quad 204 \pm 9 \quad 96+4$

$n$ is the number of subjects in a subgroup. For definition of the subgroups, see text. Data represent mean values $\pm S E M$.

\subsubsection{Plasma catecholamines and PRA}

Plasma catecholamine levels and PRA as determined in 1977 at entrance into the study, In 1979 and in 1984 in normotensives and in subjects with borderline hypertension are presented in Table 5. There 
I

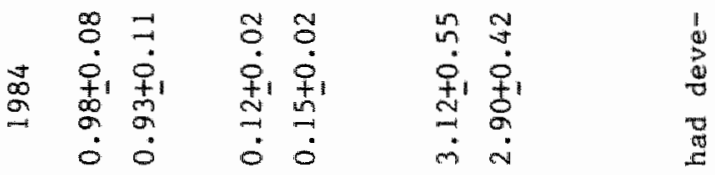

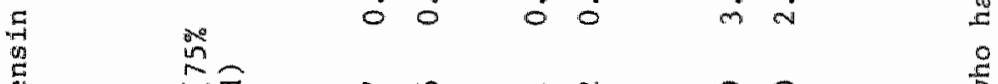

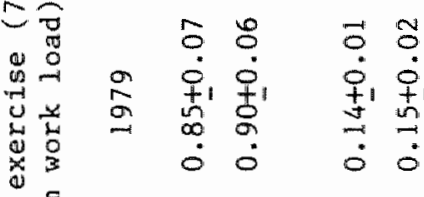

a

它

今.

in 30

的

驾焉

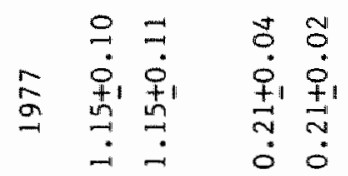

m in

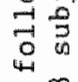

造

$\sum_{\substack{n \\ \text { ind }}}^{3}$

$m$ m

o

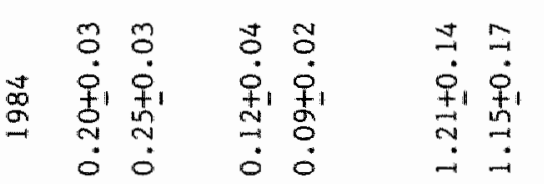

남

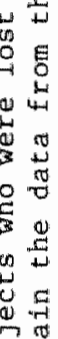

窝

崫

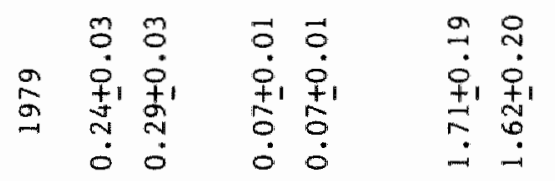

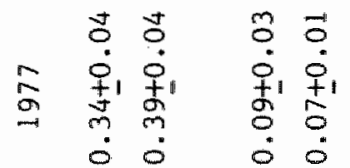

미음

$\dot{0}_{\infty} \dot{0}$

E $\sim$

몸ํำ

들

$\infty$

\pm m

$\stackrel{0}{0}$

$\stackrel{2}{3}$

0 o 0

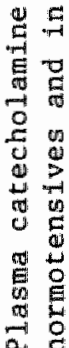
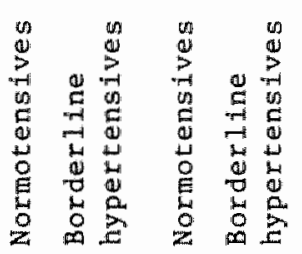

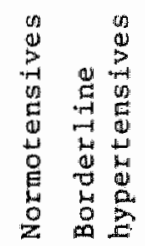

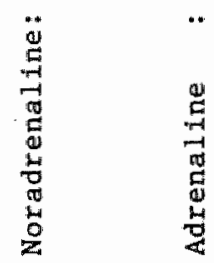

罂

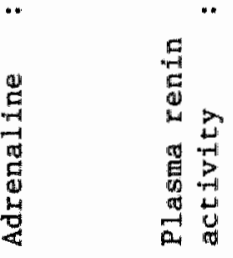


were no statistically significant differences in these data between the 2 groups of subjects studied. In both groups, plasma noradrenaline levels were lower in 1979 than in 1977 ( $p<0.05$ ), whereas plasma noradrenaline levels determined in 1979 and in 1984 did not differ.

As has been described for the total groups of nomotensive subjects and of subjects with borderline hypertension, the plasma noradrenaline levels at rest in supine position were also lower in 1979 than in 1977 in subgroups 1 and $3(p<0.05$, Table 6). In contrast, in subgroup 4 resting plasma noradrenaline concentrations in 1977 and 1979 were simflar. In a11 subgroups, the values measured in 1979 did not differ Erom those in 1984.

Table 6: Plasma noradrenaline levels (ng/ml) at supine rest in subjects remaining nomotensive (subgroup 1), in subjects remaining borderline hypertensive (subgroup 3 ) and in subjects who became definitively hypertensive (subgroup 4) during the observation perlad.

$\begin{array}{llll}\text { Subgroup 1 }(n=15) & 0.38 \pm 0.06 & 0.25 \pm 0.04 & 0.18 \pm 0.04 \\ \text { Subgroup 3 }(n=10) & 0.37 \pm 0.05 & 0.26 \pm 0.05 & 0.19 \pm 0.03 \\ \text { Subgroup 4 }(n=5) & 0.45 \pm 0.15 & 0.40 \pm 0.06 * & 0.42 \pm 0.23^{\mathrm{a}}\end{array}$

a Values of 2 subjects only. The other 3 had been excluded because they had become definitively hypertensive.

*p $<0.05$ when compared with subgroup 1 .

Data represent mean values \pm SEM.

Nett the 1 in 1977 nor in 1979 and in 1984 , subgroups 1 and 3 differed in plasma noradrenaline levels at supine rest (Table 6). In 1977, resting plasma noradrenaline concentrations were slightly higher In subgroup 4 than in subgroups 1 and 3 . The difference was, however, not statistically significant. In 1979, plasma noradrenaline levels at supline rest were significantly thigher in subgroup 4 than in subgroup 1. In 1979, noradrenaline levels were also somewhat higher in subgroup 4 than in subgroup 3. The difference, however, was not statistically 
significant. There are noradrenaline data only from 2 subjects of subgroup 4 in 1984 (Table 6). The other 3 subjects had been excluded frotil the study because they had become definitively hypertensive.

As has been mentioned earlier, 3 subjects with borderline hypertenstion became definftively hypertensive and, therefore, were excluded from the study in 1979-1982, 2 in 1984. Resting plasma noradrenaline levels of these subjects (subgroup 4) as determined closest to the moment of excluston averaged to $0.45+0.08 \mathrm{ng} / \mathrm{ml}(\mathrm{n}=5)$. This value is higher than the resting plasma noradrenaline concentrations measured in subgroup 1 in $1979(\mathrm{p}=0.03)$ as well as the resting plasma noradrenaline levels in subgroups 1 and 3 in $1984(p<0.01)$. The difference with the data of subgroup 3 in 1979 just failed to reach statistical significance $(\mathrm{p}=0.06)$. In subgroup 1 , plasma noradrenaline levels during exercise corresponded to $75 \%$ of maximum work load, plasma adrenaline levels at rest and during exercise as well as PRA at rest and during exercise measured in 1977, 1979, and 1984 were almost identical with the respective values found in the total group of normotensive subjects (Table 5). The data determined in subgroup 3 and 4 did not differ from the values of subgroup 1. Urinary sodiun excretion was $183 \pm 11 \mathrm{mmol} / 24 \mathrm{~h}$. In 1977 , in normotensives, a similar value $(179+11 \mathrm{mmol} / 24 \mathrm{~h})$ was found in subjects with borderline hypertenston. In both groups, urinary sodium excretion had not changed in 1979 and 1984. At no time did urinary sodium excretion of subgroups 1,3 and 4 differ from the values of the total groups of normotemsives and bor derline hypertensives, respectively.

\subsection{DISCUSSION}

In the present study, 5 of orlginally 26 subjects with borderIIne hypertension became definitively hypertensive within an observation period of 7 years. This figure is comparable with data reported by Jullus and Schork (1971), Hedstrand and Rberg (1975), Ju11us (1977), Kubo et al. (1983) and Sasakawa et al. (1983). Falkner et al. (1981) reported that $56 \%$ of borderline hypertensive adolescents developed defintive hypertension in a follow-up period af up to $4 \mathbb{1}$ 
months. This rather high percentage of hypertensives may be due to the definttion of borderline hypertension used by Falkner et al. (1981) which differs from the deflnition of the other authors mentioned.

In 10 of the originally borderline hypertensive subjects of our study, mean arterial blood pressure (MAP) fell to levels below 107 mm $\mathrm{Hg}$ during the observation period. Similar findings were reported by Hedstrand and Aberg (1975), Kubo et al. (1983) and Sasakawa et al. (1983). In 7 subjects from our normotensive group, there was a slight increase of blood pressure during the follow-up period. However, in none of them did the blood pressure reach the borderline hypertensive range. These data show that the group of borderline hypertensives is rather heterogeneous as far as the development of blood pressure is concerned. Nevertheless, the chance to develop definitive hypertension is considerably higher in borderline hypertensives than in normotensive subjects as has also been reported by previous authors (Julius and Sichork, 1971; Jultus et al., 1980; Ibsen, 1984).

In the total group of borderline hypertensive subjects, heart rate at rest in suplne and standing position was higher than in the group of normotensive subjects. Similar findings have been published prevlously (Julius et al., 1971a; Van Hooff et al., 1984a). These authors also have shown that the higher heart rate in borderline hypertensives is at least partly due to reduced activity of the parasympathetic nerwous system. This is compatible with the observation in the present studies and in a previous one (Henquet et al., 1981) that differences in heart rate between normotensives and borderline hypertensive subjects become less or even disappear during higher levels of physical activity. As Robinson et al. (1966) have shown, the influence of the parasympathetic nervous system on heart rate decreases or even is absent during strenuous exercise.

In the present study, subjects of subgroup 1 (consistently normotensive) and subgroup 3 (consistently borderline hypertensive) did not differ significantly in heart rate at rest, although this parameter was slightly higher in the latter group. In contrast, subjects of subgroup 4, that is subjects who became definitively hypertensive during the observation period, had higher resting supine heart rates, both at entrance into the study and at the time of definitive 
hypertension, than subgroups 1 and 3 . These findings suggest that the abnormalities which cause elevated heart rate in borderline hypertension are more pronounced in those subjects who develop definitive hypertension within a few years.

As compared with normotensives, borderline hypertensive subjects had higher blood pressure values not only at rest but also during physical exercise at entrance into our study. Similar findings have been reported by Henquet et al. (1981), Chalx et a1. (1982), and Franz $(1979,1983)$. In the present study, subjects of subgroup 1 had lower blood pressure values than subjects of subgroup 3 and 4 during all levels of exercise on a bicycle ergometer. This was true tif the exercise level was expressed as percentage of the maximum tolerated work load or 1 a constant absolute work load of 124 W was used.

of particular interest is the question whether blood pressure at rest or during exencise has a predictive value for the further development of blood pressure in subjects with borderline hypertension. In our study, both subgroup 3 (consistently borderline hypertensive) and subgroup 4 (subjects who became definitively hypertensive) did not differ in supine and standing blood pressure at the time of recruitment. At this time, there was also no difference between the two subgroups in blood pressure values measured during physical exercise corresponding to 50,75 and $100 \%$ of maximum work capacity. However, at the same absolute work load of $124 \mathrm{~W}$, diastollc blood pressure was signiflcantly higher in subgroup 4 than in subgroup 3, whereas the difference in systolic blood pressure was not statistically signtficant. On the basis of our data, one nay assume that the predictive value of diastolic blood pressure during physical exercise is $11 \mathrm{mited}$ since there was considerable overlapping of the data from those subJects who remalned borderline hypertenstve and those who developed definitive hypertension during the observation period. Using bicycle ergometry with a final work load of $100 \mathrm{~W}$, Franz (1983) divided a group of borderline hypertenstves into two subgroups. Those who had blood pressure values exceeding $200 / 100 \mathrm{~mm}$ Hg durling exercise were classifled as ergometry positive, those who had blood pressures up to $200 / 100 \mathrm{~mm} \mathrm{Hg}$ as ergometry negative. $97 \%$ of the subjects from the ergonetry positive group developed definitive hypertension within an 
observation period of 3.8 years. However, $32 \%$ of the ergometry negative subjects with borderine hypertenston became definitively hypertenstve, too. Taken together, one may concllude from the study by Franz (1983) and from our data that in subjects with borderline hypertension the predictive value of blood pressure during physlcal exercise is Linited.

The plasma catecholamine concentrations measured in normotensive subjects at suplne rest in the present investigation are comparable with levels reported by other authors using radiometric techniques (Engelman and Portnoy, 1970; Dequattro and Chan, 1972; Louis et a1., 1974: Pedersen and Christensen, 1975; Esler et al., 1977a; Lake et a1., 1977; Sever et al., 1977). Plasma catecholamine levels measured during physical exercise in the presient study are comparable with data obtained under similar conditions (Rahn et a1., 1978; Christensen et a1., 1979). In the present investigation, plasma noradrenaline concentrations measured during suplne rest in the total groups of nomotensive and borderline hypertensives as well. as in subgroups $\mathbb{l}$ and 3 were higher in 1977 when the subjects were studied first than in 1979 and in 1984. There was, however, no difference between the values determined in 1979 and in 1984 . The decline of resting plasma noradrenaline levels after the first determination may be due to the fact that the subjects became familiar with the study procedures. Jones et al. (1979) have pointed out that this may significantly influence the plasma catecholamine levels.

In the present study, there were no differences in plasma noradrenaline levels at rest and during physical activity between the total groups of normotensive and borderline hypertensive subjects at repeated determinations. These results are comparable with data by Weldmann et al. (1979) and in contrast to reports by Mlura et al. (1978) and Cousineau et al. (1978). The discrepancies could be due to the fact that the groups of borderline hypertensives contain different percentages of subjects who develop definltive hypertenston. In our investigation, the situation changed when subgroups were considered separately. Subjects who developed definltive hypertension within the observation perlod (subgroup 4) had consistently high plasina noradrenaline levels. In contrast, subjects who remained normotensive (sub- 
group 1) as well as subjects remaining borderline hypertensive (subgroup 3) throughout the observation period had relatively high resting plasma noradrenaline concentrations only at the first determination, the levels of the catecholamine being considerably lower than in subgroup 4 at successive measurements. Our findings could be explained by assuming that borderline hypertensives who develop definitive hypertension within a few years have continuously somewhat elevated plasma noradrenaline concentrations as compared with momotensive subjects. The differences can best be demonstrated under reseing conditions, whereas they are obscured in situations with psychic or physical stress. Most probably, the higher plasma noradrenaline concentrations measured in subgroup 4 are due to increased sympathetic activity and thereby enhanced release of the amine into the circulation. An altered noradrenaline clearance is a less likely explanation since the subjects of subgroup 4 did not differ from subgroups 1 and 3 in age and since all subjects studied had normal liver and kidney function.

In the present investigation, no differences in plasma adrenaline concentrations at rest and during physical exercise were found between the total groups of nomotensives and borderline hypertensives as we 11 as between subgroups 1,3 and 4 . These findings are compatible with data by Robertson et al. (1979), Messerli et a1. (1981), E11asson (1984) and Saito et a1. (1984). The PRA measured in our study at rest and during physical activity in normotensives is similar to data reported for subjects with a comparable salt 1 ntake (Kotchen et al., 1971 ; Brunner et a1., 1972; Costi11 et a1., 1976; Kosunen and Pekar1nen, 1976). Like Werning et al. (1972), Robertson et al. (1979), Aoi et a1. (1983), Salto et al. (1984) and Sullivan et al. (1984), we did not find differences between normotensives and borderline hypertensive subjects at supine rest. The same is true $\mathbb{1}$ s subgroups 1,3 and 4 were compared. Furthermore, the total groups of nomotensives and borderline hypertensives as well as subgroups 1,3 and 4 did not differ in PRA during physical exercise. 
Chapter 3

SALIVARY FLOW IN BORDERLINE HYPERTENSION

Böhm R.O.B.' ${ }^{1}$, Baak M.A. van ${ }^{1}$, Hooff M.E.J. van ${ }^{l}$, Mooy J. ${ }^{2}$, and Rahn K. H. 2

Dept. of Medicine, Division of Nephrology, Hypertension and Clinical Pharmacology $y^{2}$, and Dept. of Phamacology $y^{1}$, University of Limburg, Mastricht, The Netherlands

Published in Klin Wschr 63 (supp1 III): 154-156, 1985. 


\subsection{SUMMRY}

Salivary flow was studed in nomotensives and in subjects with hypertenston. Salivary flow rate was lower in borderline hypertensives than in nomotensives. Propranolol, phentolamine and noradrenaline had no influence on sallvary flow. Atropine decreased this parameter. The stimulating effect of neostigmine on sallva production was more pronounced in normotensives than in borderline bypertensives. The data support the assumption that in subjects with borderline hypertension the parasympathetic influence on the salivary glands is reduced.

\subsection{INTRODUCL LON}

Studies by Julius et al. (1971a) have shown that the influence of the parasympathetic nervous system on the heart 1 s decreased in subjects with borderline hypertension. It appeared interesting to know whether this 1 s a more general phenomenon which is also true for other organs. In man, saliva production at rest is predominantly under the influence of the parasympathetic nervous system. Therefore, a study was designed to compare the salivary flow in normotensive volunteers and in subjects with borderline hypertension (Van Hooff et al., $1984 \mathrm{a})$.

\subsection{SUBJECTS AND METHODS}

Forty-two men particlpated in the study. Thelr age ranged from 22-34 years. Twenty-three of them were nomotensives, that is their blood pressure after $2 \mathrm{~min}$ standing was equal to or lower than $125 / 85$ min $\mathrm{Hg}$ when measured twice with an interval of 2 weeks. The 19 other subjects had borderline hypertiension. For the purpose of this study, borderline hypertension was defined as blood pressure values measured after $2 \mathrm{~min}$ standing of $140 / 90 \mathrm{~mm} \mathrm{Hg}$ or above but lower than $160 / 100$ mimig •

Salivary flow was measured in all subjects after $15 \mathrm{~min}$ of 
supine rest using a method described by Dollery et al. (1976). The method is based on the welght gain of dental cotton wool cylinders placed in the mouth. All measurements were performed between 4 and 6 p.m. when the subjects had refrained from food, beverages and swoking for at least $2 \mathrm{~h}$. Control experiments had shown that under these conditions, salivary flow is constant when measured repeatedly every $10 \mathrm{~min}$ for a total of $1 \mathrm{~h}$. Sodium and potassium in sallva were measured by flame photometry after the dental cotton wool cyllinders had been soaked in distilled water. Furthermore, in all volunteers participating in the study, blood pressure and heart rate were determined after $30 \mathrm{~min}$ rest in supine position. After these measurements, blood was drawn for radionetric determination of plasma noradrenaline and adrenaline levels. Subsequently, blood pressure and heart rate were determined again after 2 min standing. Data are presented as mean \pm standard error of the mean. The $t$-test and the paired $t$-test were used for statistical analysis.

\subsection{RESULTS}

As could be expected, subjects with borderline hypertension had higher supine and standing blood pressure values than the normotensive controls $(p<0.001)$. After 30 min supine rest, heart rate was $63 \pm 2$ beats/min in normotensive controls. Suplne heart rate was $73+2$ beats/ min in borderline hypertensive subjects. The difference is statistically significant $(p<0.01)$. After 2 mith standing, subjects with bor derline hypertension also exhibited a somewhat higher heart rate than nomotensives. However, the difference was not statistically signifLeant $(p>0.05)$.

Plasma noradrenaline levels were $0.25+0.03 \mathrm{ng} / \mathrm{ml}$ in normotensives and $0.28+0.03 \mathrm{ng} / \mathrm{ml}$ in borderline hypertensives. The difference is not statistically slgniflcant $(p>0.1)$. The same holds for plama adrenaline levels.

Salivary flow averaged $0.85+0.08 \mathrm{~g} / \mathrm{min}$ in the normotensive subjects. This parameter was significantly lower $(p<0.001)$, that $1 \mathrm{~s} 0.51 \pm$ $0.04 \mathrm{~g} / \mathrm{min}$, in borderline hypertensives. Sodlum and potassium concen- 
trations in saliva were studied in 8 nomotensive subjects and in 8 borderline hypertenstves. In the normotenstve volunteers, sallvary sodiun concentation was $9.2 \pm 1.96 \mathrm{\mu mol} / \mathrm{g}$ and salivary potassium concentration was $21.2 \pm 1.93 \mu$ mol/g. These values did not differ $(p>0.2)$ from the concentrations medsured iti sallva from borderline hypertensives. Since galivary flow was considerably higher in nomotensives than in borderline hypertensive subjects the potassium secretion rate in saliva has higher in nomotensive subjects than in borderline hypertensives (Flg. 1). Also sodium secretion rate was somewhat higher in nomotensives than in borderline hypertensives. However, the difference was not statistically significant.

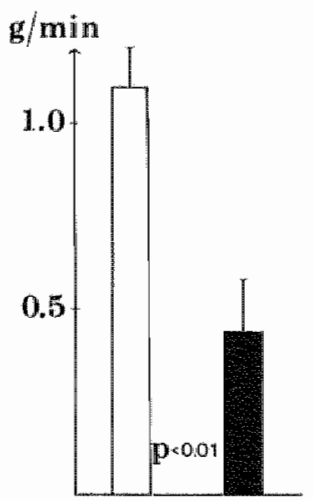

flow rate

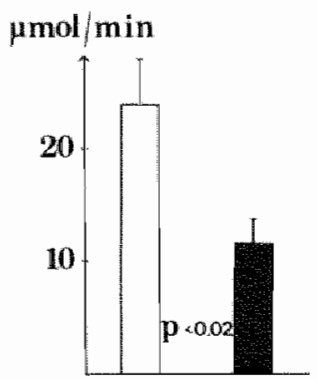

potassium secretion rate

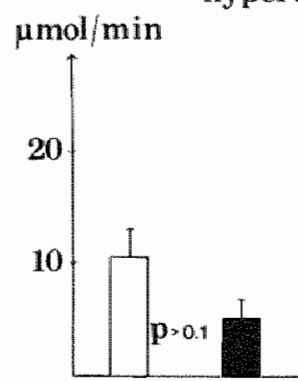

sodium secretion rate

Eigure 1: Salivary flow and electrolyte secretion. Data represent mean + SEM of 8 normotensive subjects and 8 subjects with borderIine hypertension.

In 8 subjects from elther group, the effect of adrenergic blocking agents on salivary flow was studied. Intravenous injection of $5 \mathrm{mg}$ phentolamine and of $5 \mathrm{mg}$ propranolol on another day had no influence on sallvary flow. Furthemore, in 4 subjects from elther group noradrenaline infused intravenously at a rate of $3 \mu \mathrm{g} / \mathrm{min}$ during $30 \mathrm{~min}$ did not alter sallvary flow $(p>0.1)$. A dose of $0.5 \mathrm{mg}$ atropine given intravenously, reduced salivary flow in both groups of subjects studied $(p<0.001)$. The decrease of salivary flow was more pronounced in normotenstues than in borderline hypertensive subjects $(p<0.01)$. An intravenous dose of $1.5 \mathrm{mg}$ atropine almost completely abolished sallva secretion in normotensive controls as well as in subjects with border- 
line hypertension.

In 6 subjects of either group, the effects of cumulative intravenous doses of neastigmine were studied. The parasympathomimetic drug caused a dose-dependent increase of saliva production in normotenslve volunteers, a maximum increase of about $1.9 \mathrm{~g} / \mathrm{min}$ belng obtained with doses of $50 \mu \mathrm{g}$ neastigmine/min. In borderline hypertensives, neostigmine also led to a dose-dependent increase of sallvary flow. As compared with the nomotensives, the dose-response curve for the stimulating effect of neostigmine on sallva production was shifted to the right in borderline hypertensive subjects. From the individual doseresponse curves, the dose of neostigmine which increased salivary flow by $1 \mathrm{~g} / \mathrm{min}$ was determined. This was $28+0.9 \mathrm{\mu g} / \mathrm{m} i \mathrm{n}$ in nomotensives and $4 \pm+3.8 \mu \mathrm{g} / \mathrm{min}$ in borderline hypertensives. The difference is statistcally significant $(p<0.001)$.

\subsection{DISCUSSION}

This study demonstrates that salivary fllow at rest is lower in subjects with borderline hypertension than in age-matched nomotensive controls. The experiments with adrenergic blocking agents and with noradrenaline infusions show that under the conditions used in this study the sympathetic nervous system has no influence on saliva production. Plasma noradrenaline and adrenaline levels did not differ 1 in the two groups of subjects studied. These data, thus, gave no ind cation of differences between the two groups in sympathetlc activity.

Apparently, the salivary glands of borderline hypertensive subjects were able to respond to parasymathetic stimulation since Intravenous neostlgmine was able to increase salivary flow. Atropine had a more pronounced inhibitory effect of sallwary flow rate in nomotensives than in borderline hypertensives. In contrast, the stimulating action of neostigmine on saliva production was more pronounced $\mathbb{i n}$ normotensives than in borderline hypertensives. These observations are compatible with the view that the amount of acetylcholine present at the level of the salivary glands is lower in borderline hypertensives than in normotensive controls. The data support the assumption that in 
subjects th borderline hypertension, the parasympathetic influence on the salivary glands is reduced. 


\title{
Chapter 4
}

\author{
CHRONIC ANTIHYPERTENSIVE THERAPY \\ WTTH THREE DIFFERENT BETA BLOCKERS: \\ BLOOD PRESSURE AND INDICES OF SYMPATHETIC ACTIVITY \\ AT REST AND DURTNG EXERCISE \\ AND THE INFLUENCE ON SUBMAXIMAL EXERCISE TOLERANCE
}

Roland 0 . Böhm ${ }^{1}$, Beate G. Arends ${ }^{1}$, Marlies E. van Hooff ${ }^{1}$, Karl-Helnz Rahn $^{2}$, Marleen A. van Baak ${ }^{1,3}$

Department of Pharmacology 1 , Dept. of Mediclne, Division of Nephrom logy, Hypertension and Clintcal Phamacology ${ }^{2}$, Untvergity of Limburg, and Institute for Sports Medicine Limburg ${ }^{3}$. Mastricht, The NetherLands 
4.1 SUMARY

The effects of long-ted anthypertensive treatment of 6 months with 3 different beta blockers (propranolol, metoprolol and pindolol) were studied at rest and during submaxtimal exercise in 7 patents wh essential hypertenston. All 3 beta blockers reduced supine and exercise systollc blood pressure. Díatollc blood pressure fell only slgnificantly at rest $(p<0.05)$. The effect of the 3 beta blockers on resting and exercise blood pressure was similar. Suplne heart rate was decreased during propranolol and metoprolol ( $<0.01$ ), but stayed unchanged during pindolol. Heart rate during exercise was decreased ( $p<0.01)$ by all 3 beta blockers. No differences between the 3 drugs were found. Plasma noradrenaline levels at rest and during exercise tended to be reduced during pindolol. No consistent changes we re found during propranolol and metoprolol.

The endurance time of submaximal bicycle ergometer exercise was reduced signiftcantly by all 3 beta blockers. No significant difference between the $3 \mathrm{drugs}$ was found. The impalrment of exercise performance was more pronounced after 6 months of treatment than after 1 week.

\subsection{INTRODUCTION}

Beta-adrenoceptor blocking agents have been recommended and are widely used as first-step therapy in the treatment of essential hypertension. Despite of their wide-spread use, the mechanism of their antihypertensive action is not fully understood. One of the hypotheses is that beta blockers act by interfering with sympathetic nervous activity. Conflcting data on the effect of beta blockers on plasma noradrenaline levels have been reported (Brecht et al., 1976; NIsson et al., 1978; Rahn et a1., 1978; Rahn, 1980; MacDonald et al., 1984; Van Baak et al., 1985; Dequattro and Hamad, 1985), although during chronfc adnitatistration the finding of unchanged levels is predominant. Plama concentrations of noradrenaline depend on the rate af release into plasma and on the rate of clearance and re-uptake from plasma. A 
decreased clearance, due to a reduction of liver blood flow during beta blockade, may compensate for a decreased release from sympathetic nerve endings (Esler et al., 1981c; Van Baak et al., 1985). Beta blockers, with and without ISA (intrinsic sympathomimetic activity) may affect resting hemodymamics differently (Van Baak et al., 1985), but the effects during physical exercise are similar (Kostis and DeFelice, 1983 ; Lund-Johansen, 1983). One of the alms of this study was, therefore, to compare plasma noradrenaline levels, both at rest and during physical exercise, during treatment with different types of beta blockers with and whout ISA.

In the same study, the effect on submaximal exercise tolerance was studied. One of the side-effects of beta blocker therapy $1 \mathrm{~s}$ muscular fatigue, especially in relation to physical exercise. Impalment of exercise capacity after acute administration and during short-term treatment has been found (Galbo et al., 1976; Lundborg et al., 1981). However, it is not known whether these effects diminish or disappear during long-term therapy and if there are any differences between different types of beta blockers. Thus, a study was designed to evaluate the effects of the following 3 beta blockers during chronic treatment: propranolol (a non-selective beta blocker), metoprolol (a beta ${ }_{1}$-selective blocker) and pindolol (a non-selective blocker with ISA) in patients with mild to moderate essential hypertension. Blood pressure, heart rate and indices of the sympathetic nervous system (plasma noradrenaline and plasma renin activity) at rest and durfing submaximal bicycle ergometer exercise, as well as the effect on exercise tolerance were inwestigated.

\subsection{METHODS}

\subsubsection{Patients}

Seven patients ( 6 males, 1 female), age at entrance into the study ranging from 29 to 48 years (mean age 37 years), weight ranging from 62 to $91 \mathrm{~kg}$ (mean weight $75 \mathrm{~kg}$ ) with mild to moderate essential hypertension particlpated in the study. Secondary hypertension had been excluded by history, physical examination, appropriate laboratory 
tests and 1.v. pyelography. All patients were recrulted from the hypertenston clinic at $\mathrm{St}$. Annadal Hospital. The study was approved by the Ethical Commltee of the University of Llmburg.

\subsubsection{Study deslgn}

At entrance into the study, all anthypertensilve medication was withdrawn. At 2-weekly intervals blood pressure (BP) and heart rate (HR) were measured, after $15 \mathrm{~min}$ of supine rest and after 2 min standing, during 4 weeks. At the end of this period standing $B P$ had to be $>140 / 90$ but $<170 / 110 \mathrm{mmHg}$. Then placebo treatment was started for 6 weeks. In the $3 \mathrm{rd}$ week maximal oxygen uptake ( $\mathrm{V}_{2} \mathrm{max}$ ) was estimated by a submaximal bicycle ergometer test (Lundborg et al., 1981). Submaximal endurance exercise tests at $70 \%$ of the estimated $\dot{V O}_{2}$ max were performed in the 4 th and $6 \mathrm{th}$ week of the placebo period. The parlents were then treated oraliy in a single blind randomized manner with the beta-blocking drugs propranolol (Pr), metoprolol (Me) and pindolol (P1) for 6 months each. A placebo period of 4 weeks followed each 6 months of active treatment. In the beginning of each active treatment perlod $B P$ and HR were measured at weekly intervals to assure an adequate $B P$ reduction. The dose of the drug was adjusted until a standing diastolic BP $<90 \mathrm{mmHg}$ was reached. Starting dose in the Pr period was $40 \mathrm{mg} /$ day. It was increased weekly with $40 \mathrm{mg} / \mathrm{day}$ up to $240 \mathrm{mg} / \mathrm{day}$ maxlmally if necessary. A similar procedure was used to determine the doses of Me and PI. Average dally doses of Pr were $108+17 \mathrm{mg}$, Me $150 \pm 31 \mathrm{mg}$ and $P_{\mathbb{I}} 14+2 \mathrm{mg}$. When the alm, standing diastolic $B P<90$ mmHg, was reached, $B P$ and $H R$ were measured at monthly intervals. After 6 weeks of active treatment, a blood sample was drawn after 30 min of suplne rest for determination of plasma noradrenaline (PNA). In each 5 th and 6 th month of the active treatment perlod and at the end of each placebo perlod ( 4 th week), the patients performed a submaximal endurance exercise test (protocol see below). In 11 out of the total of 20 treatment periods an additional exercise test was performed after 1 week of beta blocker treatment; 4 patients in the $\mathrm{Pr}$ and $\mathrm{PI}$ treatment perlod and 3 patients in the Me period. 


\subsubsection{Submaximal exercilse test}

A protocol for the submaximal exercise test simflar to that described by Lundborg et al. (1981) was used In our study. The patients were exercising in a temperature controlled laboratory $\left(18-21^{\circ} \mathrm{C}\right)$ an a bicycle ergometer at $70 \%$ of their predicted $\mathrm{V}_{2}$ max until exhaustion. Maximal duration of the test was $3 \times 30 \mathrm{~min}$ with 10 min rest in between. The tests were perfomed $2-4$ hours after the intake of the last tablets, at least 2 hours after a meal. Furthermore, the patients were advised not to consume alcohol, coffee or nicotine on the day of the test and to avoid exhaustive physical exercise. After placing a cannula into a vena cubitalls, $B P$ and $H R$ were measured for 30 min in supine position. Blood was then drawn for determination of PNA, plasma renin activity (PRA) and the plasma drug level. The samples were centrifuged and the plasma immediately frozen at $-20^{\circ} \mathrm{C}$. Then, $\mathrm{BP}$ and HR were measured after 2 min standing. Subsequently the exercise test was started. HR was determined during exexclise at 10 min intervals. Durfing the last $2 \mathrm{~min}$ of each 30 min exerclse phase and at the point of exhaustion, $B F$ and $H R$ were measured and blood was drawn for determilnation of PNA and PRA. After exhaustion the patient rested supine for 15 min. During this time BP and HR were measured and again at the end blood was drawn for determination of PNA and PRA.

\subsubsection{Methods}

Blood pressure ( $B P$ ) and heart rate (HR) at rest were measured with an automatic recorder (DINAMAP, Applied Medical Research Corporation, Tampa, USA). HR during exercise was obtained electrocardiographtca11y. Exercise BP was measured with a standard mercury sphygmomanometer; the muffling of the sounds (Korotkoff IV) was regarded as exercise diastolic BP. All ergometry studies were performed on the same Lode bicycle ergometer in upright stiting position. PNA was determined radioenzymatically (Henquet et al., 1981) and PRA was measured by radioimmunoassay (Henquet et al., 1981). Plasma drug levels of $\mathrm{Pr}$, Me and $\mathrm{P} 1$ were measured by HPLC with fluorometric detection (Schoeffel, FS 970). For the analysis of $\operatorname{Pr} 1 \mathrm{ml}$ of heparinized plasma with metoprolol as internal standard was extracted twice with hexane/ pentanol $(98.5 / 1.5)$. The organtc layer was reextracted with $250 \mu 1$ 
$0.01 \mathrm{~N} \mathrm{H}_{2} \mathrm{SO}_{4}$. The $\mathrm{H}_{2} \mathrm{SO}_{4}$ phase was injected 1nto the HPLC using a mi.crosphere $C_{18}$ colum (Chrompack no. 28410). Actonitrile * methanol: $0.01 \mathrm{~N} \mathrm{HClO}_{4}(71: 25: 4)$ was used as eluent. The $\mathrm{pH}$ of the eluent was brought to 6.0 using $\mathrm{H}_{3} \mathrm{PO}_{4}$. The excitation wavelength of the detector was $208 \mathrm{~nm}$ and the emission filter was set at $320 \mathrm{~nm}$. The Me plasma samples wete determined as follows: $50 \mu 1.10 \mathrm{~N} \mathrm{NaOH}$ and $5 \mathrm{ml}$ ether/ hexane (3:1) were added to $1 \mathrm{mi}$ plasma. The organic phase was reextracted by adding $200 \mu \mathrm{M} 0.1 \mathrm{~N} \mathrm{NaH}{ }_{2} \mathrm{PO}_{4} \cdot \mathrm{H}_{2} \mathrm{O}(\mathrm{pH} 3)$. The organic phase was discarded and allquots of the aequows phase (100 $\mathrm{pl}$ ) were injected directly onto the HPLC colum ( $C_{18}$ microsphere, Chrompack no. 28410 ). The excitation wavelength of the detector was $224 \mathrm{~nm}$ and the emission filter was set at $320 \mathrm{~nm}$. Plasma $\mathrm{P} 1$ levels were determined by a modiflcation of the HPLC method described by Bengah et al. (1980). To $2 \mathrm{ml}$ heparinized plasma, $500 \mu I \perp \mathrm{N} \mathrm{NaOH}$ and $6 \mathrm{ml}$ diethylether were added. The organtc phase was reextracted with $200 \mu 10.1 \mathrm{~N} \mathrm{NaH}{ }_{2} \mathrm{PO}_{4} \cdot \mathrm{H}_{2} \mathrm{O}$ (pH 3). Then, $1 \mathrm{ml}$ n-heptane was added to the aequous phase. After extraction, allquots of the aequous phase $(100-150 \mu l)$ were injected directly onto the HPLC column ( $C_{18}$ microsphere, chrompack, no. 28410). The luent was $0.02 \mathrm{~N} \mathrm{NH}_{4} \mathrm{Ac} / \mathrm{AcCN}(13: 7)(\mathrm{pH} 5.5)$. The excitation wavelength was $220 \mathrm{~nm}$ and the emission filter was set at $320 \mathrm{~nm}$. The detection limit of all three procedures was $1 \mathrm{ng} / \mathrm{ml}$ plasma. The interassay coefficlent of variation was $<5 \%$.

Results are expressed as mean \pm SEM. Values of the exercise tests during the placebo period before and after each active treatment and values of exerctse tests in the 5 th and 6 th month of the active treatment period were averaged unless indicated otherwise. This was consldered acceptable since no statistlcally significant differences In exerclse heart rate whthin those palrs of tests were found. This suggests that no consistent change in cardiaresplutary fitness had occurred between the two tests.

Statistical analysis was performed by paired student's t-tests; the level of signiflcance was set at $p<0.05$. 
4.4. RESULTS

One patient was withdrawn from $\mathrm{Pi}_{1}$ treatment after 2 weeks because of severe headache. In another patient the PI treatment period was shortened because of complaints about fatigue. Plasma drug levels were $63+15 \mathrm{ng} / \mathrm{ml}$ ( $5 \mathrm{th}$ month) and $69+30 \mathrm{ng} / \mathrm{ml}$ ( $6 \mathrm{th}$ month) durling $\mathrm{Fr}$ $(\mathrm{n}=7), 73+25 \mathrm{ng} / \mathrm{ml}(5 \mathrm{th})$ and $94+22 \mathrm{ng} / \mathrm{m} 1$ (6th) during Me $(\mathrm{n}=7), 29+5$ $\mathrm{ng} / \mathrm{ml}$ (5th; $\mathrm{n}=6)$ and $17 \pm 3 \mathrm{ng} / \mathrm{mL}$ ( 6 th month; $\mathrm{n}=5)$ during $\mathrm{Pi}$.

\subsubsection{SBP and DBP at rest}

During the placebo periods, the BP of several patients was lower than at the end of the wash-out period. The effect of the 3 beta blockers on supine systolic (SBP) and diastolic blood pressure (DBP) is shown in Fig. 1. After one week of treatment, supine SBP and DBP was already decreased from $144+4 / 90+4$ to $132+4 / 82 \pm 3 \mathrm{~mm} \mathrm{Hg}$ during $\mathrm{Pr}$ $(p<0.01)$, from $145+5 / 90+4$ to $136 \pm 5 / 80 \pm 2 \mathrm{~mm} \mathrm{Hg}$ during Me $(p<0.05)$, and from $144+4 / 90 \pm 2$ to $134 \pm 6 / 84 \pm 5 \mathrm{~mm} H g$ during P1 (SBP: $p<0.01$; DBP: NS). An adequate reduction of supine SBP and DBP was attalined at nearly all control intervals during the 6 months of treatment with all 3 beta blockers (Fig, 1 ).

Standing SBP and DBP measurements at the same control intervals showed similar results. After one week of treatment, standing SBP and DBP were decreased from $146+5 / 98+4$ to $133+4 / 90+3 \mathrm{~mm} H \mathrm{Hg}$ during $\mathrm{Pr}$ $(p<0.01)$, from $145+5 / 98+3$ to $137 \pm 6 / 89+4 \mathrm{~mm} \mathrm{Hg}$ during Me (SBP: NS; DBP: $\mathrm{p}(0.01)$, and from $143+3 / 95+3$ to $132+4 / 89 \pm 4 \mathrm{~mm}$ Hg durting $\mathrm{Pi}$ (SBP: p $(0.01$; DBP: NS). When comparing the 3 beta blockers, suplne and standing SBP and DBP revealed no consistent statistically significant differences during the treatments.

\subsection{2 $\mathbb{H R}$ at rest}

Resting HR (Fig. 1) was reduced during Pr and Me. After 6 weeks of treatment, HR at rest was lowered significantly $(p<0.01)$, from 69+2 to $61 \pm 1$ beats/min during $\operatorname{Pr}$ and from $75+4$ to $56 \pm 2$ beats/min durlng Me, and stayed in that range for the rest of the observation pertod. Supine HR during $P 1$ showed no significant decrease throughout the 
treatment period. When comparing the beta blockers, HR at rest differed lgnificantly between Pr and Pi, and Me and Pi ( $<<0.001$ ) (Fig* 1). Wo consistent differences between $\operatorname{Pr}$ and Me were found.

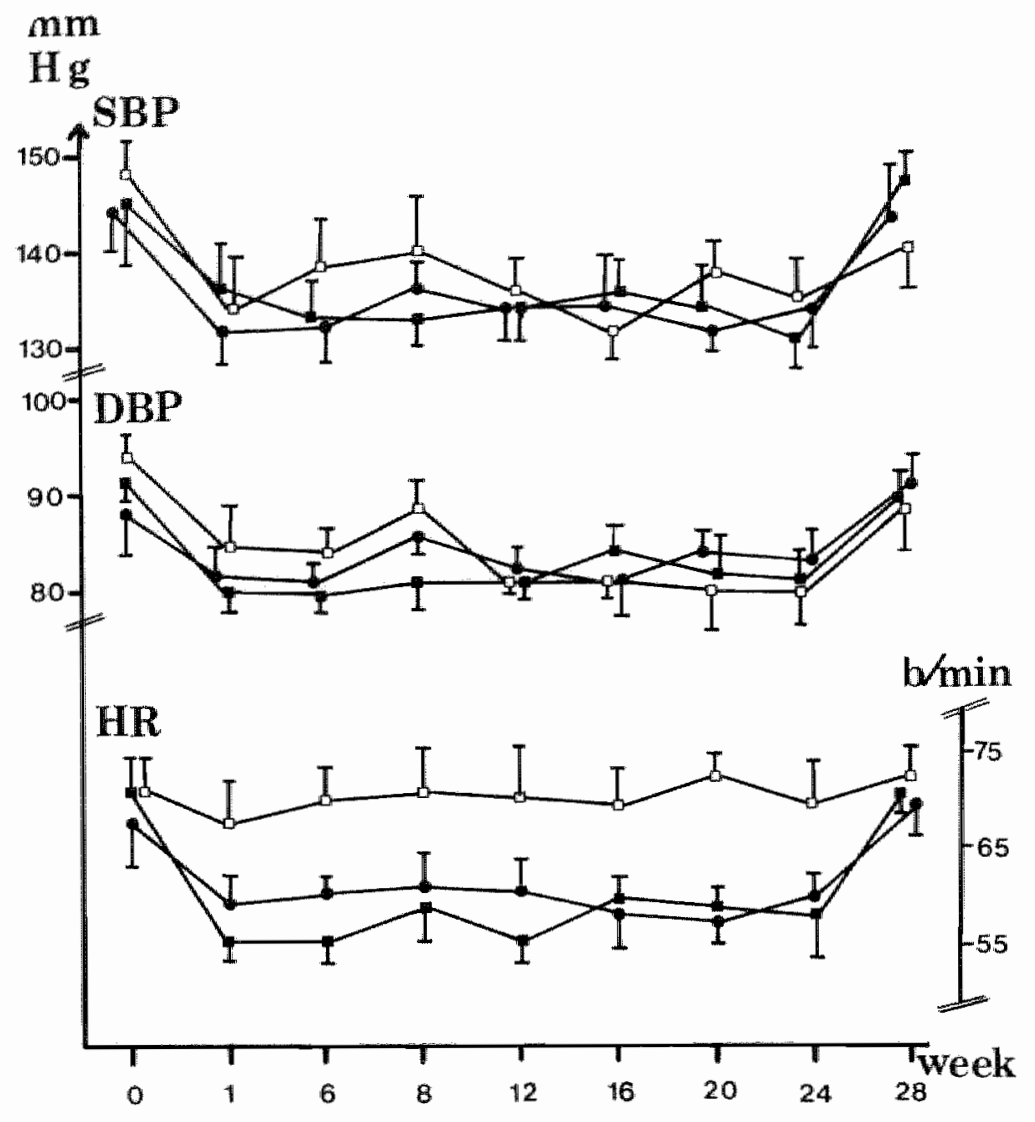

Plac Beta blocker treatment

Plac

Figure 1: Suplne systolic (SBP), diastollc (DBP) blood pressure and heart rate (HR; b/min) during placebo (Plac) and chronic treatment with propranolol $(\bullet)(n=7)$, metoprolol $(\mathbf{\theta})(\mathrm{n}=7)$ and pindolol (口) $(n=6)$. Mean values \pm SEM a re given.

4.4.3 PNA and PRA at rest

Table 1 shows PNA levels at rest during the placebo and the treatment perlods with the 3 beta blackers. After 6 weeks, PNA during $\mathrm{Pr}$ showed a decrease $(p<0.05)$, whereas the 5 th/6th month treatment value showed no slgniflcant difference with placebo. Me had no statistilically significant effect on resting PNA throughout the wholle treat- 
Table 1: Plasma noradrenaline levels at rest (ng/mi) during treatment with propranolol ( $\mathrm{Pr}$ ), metoprolol (Me) and pindolol (PI). Data represent mean values $\pm S E M$.

Plac Week 6 Week 20 Week 24

\begin{tabular}{|c|c|c|c|c|}
\hline $\operatorname{Pr}(n=7)$ & $0.26 \pm 0.04$ & $0.15 \pm 0.01^{*}$ & $0.23+0.05$ & $0.21+0.03$ \\
\hline Me $(n=7)$ & $0.24 \pm 0.02$ & $0.21+0.03$ & $0.22+0.02$ & $0.22+0.03$ \\
\hline Pi. $(n=6)$ & $0.29 \pm 0.03$ & $0.11 \pm 0.01^{* *}$ & $0.16+0.02^{* *}$ & $0.26 \pm 0.10$ \\
\hline
\end{tabular}

ment period. During $\mathrm{Pi}_{\text {, a }}$ a significant decrease was found in the $6 \mathrm{th}$ week and the 5 th month of treatment $(p<0.01)$. The value in the 6 th month was not significantly different from placebo.

PRA leve1s at rest were significant 1 y decreased during treatment with all 3 beta blockers when compared with placebo. PRA fell from $1.38+0.28$ to $0.68 \pm 0.11 \mathrm{ng} A I / \mathrm{h} . \mathrm{ml}$ during $\operatorname{Pr}(\mathrm{p}<0.01)$, from $1.24 \pm 0.14$ to $0.67 \pm 0.09 \mathrm{ng} A I / \mathrm{h} . \mathrm{ml}$ during Me $(\mathrm{p}<0.001)$ and from $1.43 \pm 0.28$ to $0.86+0.14 \mathrm{ng} A I / h . m 1$ during P1 $(p<0.05)$ in the $5 \mathrm{th} / 6 \mathrm{th}$ month of treatment.

\subsubsection{Exerclse BP and MR}

The patients performed their exercise tests at a mean work load of $131 \pm 13 \mathrm{~W}$. Exerclse SBP and DBP at the point of exhaustion chenged from $184+4 / 87 \pm 3$ to $167 \pm 4 / 89+3 \mathrm{~mm} \mathrm{Hg}$ during $\mathrm{Pr}$, from $185 \pm 5 / 84 \pm 2$ to 168 $\pm 6 / 85 \pm 3$ min $\mathrm{Hg}$ during $\mathrm{Me}$ and from $180 \pm 4 / 86 \pm 3$ to $162 \pm 4 / 84+3 \mathrm{~mm} \mathrm{Hg} \mathrm{durIng}$ Pi (Fig. 2). Simllar results were obtalned at the end of the first exercise perlod $(30 \mathrm{mIn})$. Exercise SBP was decreased signiflcantly by al1 3 beta blockers $(p<0.01)$, whereas exerclse DBP showed no signif1cant change. No statistically significant difference in exercise SBP was found between the 3 beta blockers. The SBP increase from rest to exercise was only blunted significantly under P1 (p<0.05) (Fig. 1+2).

Exercise HR at the point of exhaustion was decreased signifi- 


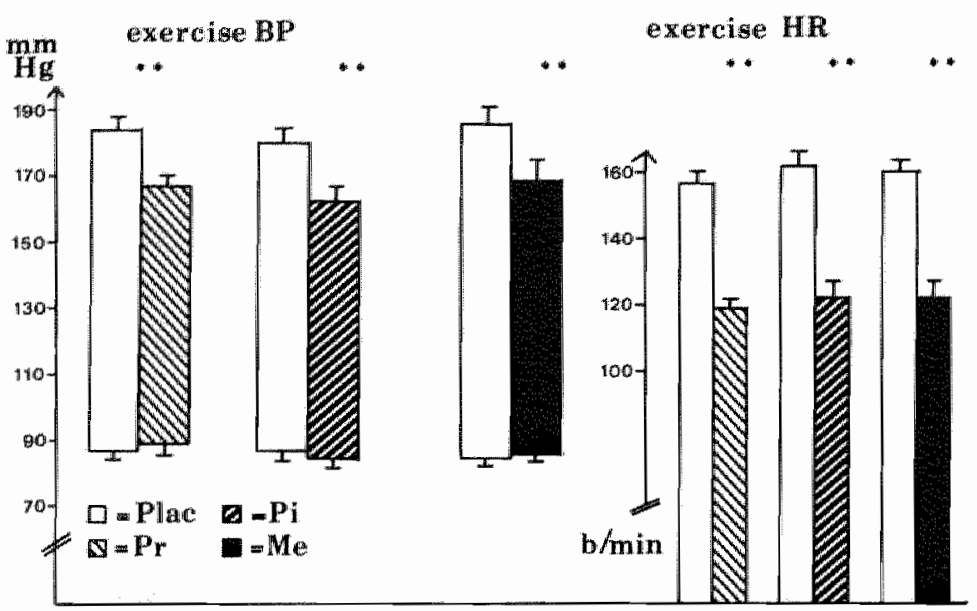

Figure 2: Exercise systollc and diastolic bload pressure and heart rate (HR) at exhaustion during chronlic treatment with propranolo1 ( $\mathrm{Pr} ; \mathrm{n}=7$ ), metoprolo1 $(\mathrm{Me} ; \mathrm{n}=7$ ) and pindolol ( $\mathrm{P}$; $\mathrm{n}=6$ ). Mean values of placebo (Plac) are compared with the mean of the 20 th and 24 th week of treatment. Mean values $\pm S E M$ are given. $*_{\mathrm{p}}<0.05 ; * * \mathrm{p}<0.01$.

cantly $(p<0.01)$ by all 3 beta blockers. HR fell from $157 \pm 4$ to $119+2$ beats/min during $\mathrm{Pr}$, from $160+3$ to $118+4$ beats/min during Me and from $162 \pm 4$ to $122 \pm 4$ beats/min during P1 (Fig. 2). No significant difference was found between the 3 beta blackers in exerclse HR at exhaustion nor after $10 \mathrm{~min}$ of exercise.

\subsubsection{PNA and PRA during exercise}

Values of PNA and PRA during exercise are presented in Table 2. When compared with placebo, $\mathrm{Pr}$ and Me had no significantly different effect on PNA during exercise. PNA during Pi was decreased at the end of the first exercise perlod and during recovery when compared to placebo values $(\mathrm{p}<0.05)$.

On placebo, exercise resulted in a rise of PRA. Although values of PRA after the beta blockers tended to decrease, the reduction was not significant durfing $\mathrm{Pr}$ and only at the point of exhaustion $(\mathrm{p}<0.05)$ and durting recovery during $M e$ and $P 1(p<0.05)$. It must be pointed out that PRA values of one patient increased systematically durlng exercise after all 3 beta blockers: there was a two-fold rise when compared with placebo. When the values of this patient were excluded, 
Table 2: Plasma noradrenaline levels (PMA) and plasma renln activity (PRA) during exercise. Propranolol (Pr), metoprolol (Me) and pindolol (Pi) levels refer to mean $20 / 24$ th week. Data represent mean values $\pm \mathrm{SEM}$.

\begin{tabular}{|c|c|c|c|c|c|}
\hline $\begin{array}{l}\text { End of } \\
\text { period }\end{array}$ & t exercise & Exhaus & & Recove & \\
\hline $\begin{array}{l}\mathrm{PNA} \\
\mathrm{ng} / \mathrm{ml}\end{array}$ & $\begin{array}{l}\text { PRA } \\
\text { ng AI/mL.h }\end{array}$ & $\begin{array}{l}\text { PNA } \\
\mathrm{ng} / \mathrm{m} 1\end{array}$ & $\begin{array}{l}\text { PRA } \\
\text { ng AI/m1.h }\end{array}$ & $\begin{array}{l}\mathrm{PNA} \\
\mathrm{ng} / \mathrm{ml}\end{array}$ & $\begin{array}{l}\mathrm{PRA} \\
\mathrm{ng} A \mathrm{C} / \mathrm{ml} \cdot \mathrm{h}\end{array}$ \\
\hline
\end{tabular}

$\begin{array}{lllllll}\mathrm{PLac} & 1.44 \pm 0.18 & 3.36 \pm 0.61 & 1.47 \pm 0.18 & 4.78+0.85 & 0.26 \pm 0.02 & 3.25+0.55 \\ \mathrm{PE} & 1.49 \pm 0.22 & 2.24 \pm 0.75 & 1.67 \pm 0.23 & 3.31 \pm 1.98 & 0.29 \pm 0.05 & 2.90 \pm 1.60 \\ (\mathrm{n}=7) & & & & & \end{array}$

Plac $1.68 \pm 0.40 \quad 3.52 \pm 0.45 \quad 1.95 \pm 0.51 \quad 5.11 \pm 0.74 \quad 0.35+0.04 \quad 3.19 \pm 0.42$

Me $1.76 \pm 0.422 .46 \pm 1.34 \quad 1.76 \pm 0.462 .63 \pm 1.18 * \quad 0.30 \pm 0.04 \quad 1.80 \pm 0.67 *$ $(n=7)$

P1ac $\quad 1.94+0.26 \quad 3.55 \pm 0.70 \quad 2.18 \pm 0.40 \quad 5.27 \pm 1.24 \quad 0.34+0.05 \quad 3.20+0.62$

$\begin{aligned} & P 1 \\ & (n=6)\end{aligned} \quad 1.58+0.15 * 2.26 \pm 0.92 \quad 1.77 \pm 0.19 \quad 1.87 \pm 0.63 * \quad 0.23 \pm 0.05 * 1.38+0.34 *$

$* \mathbb{p}<0.05 ; * * p<0.01$ when compared with placebo.

mean PRA Levels were decreased signiflcantly at all tine polnts during Pr, Me and Pi $(p<0.05)$.

\subsubsection{Endurance time}

There was a statistically significant decrease of endurance time during treatment with all 3 beta blockers. During Pr, exercise time was reduced from $69+10 \mathrm{~min}$ to $52 \pm 6 \mathrm{~min}(p<0.05)$, during Me from $69 \pm 10$ min to $58 \pm 9$ min $(p<0.01)$, and during $P 1$ from $62+9$ to $38+10$ min ( $p<$ 0.05). However, differences in reduction of exercise time between the 3 beta blockers were not statistically significant. The average reduction of exercise time after one week of treatment was $10+13 \%$ and $22 \pm 10 \%$ in the 5 th and 6 th month of treatment $(\mathrm{p}<0.03)$. 


\subsection{DISCUSSION}

\subsubsection{Effects on $\mathrm{HR}$ and $\mathrm{BP}$ at rest and during exercise}

No differences in the BP lowering effect at rest between the 3 beta blockers were found, which indicates that equieffective anthypertensive doses of $\mathrm{Pr}$, Me and PI were used in our study. Supine HR was lowered signiflcantly during $\mathrm{Pr}$ and Me, whereas P1 did not affect $\mathrm{AR}$ as has also been found in other studies (Velasco et al., 1980; Gavras et al., 1981; Svensson et a1., 1981; Franz et a1., 1982). The pronounced ISA of $\mathrm{PI}$ is held responsible for the absence of a decreased HR at rest (Kostisi and DeFelice, 1983). SBP during exercise was lowered slgnificantly and similarly by all 3 beta blockers. The same 1s true for HR durlng exerclse. Exercise DBP was slightly increased or unchanged during beta blocker treatment when compared with placebo, which 1 is in agreement with other studies (Leenen et al., 1980; Morrison et al., 1982). In contrast, decreased values of DBP have also been reported (Franz et all., 1980; Svensson et al., 1982; Virtanen et al., 1982; Van Hooff et al., 1984b). However, both measurement and interpretation of exerclse DBP are very difficult (Rasmussen et al., 1985).

\subsubsection{Effects on PNA and PRA at rest and during exercise}

There are conflicting reports on the influence of beta blockers on resting plasma catecholamines (Rahn, 1980; DeQuattro and Hamad, 1985). In general, no changes have been found. In our study, PNA levels during Me at rest showed no consistent changes, during Pr only after 6 weeks of treatment. PNA levels during $P i$ tended to decrease more consistently. This is in agreement with studies by Brecht et al. (1976) and Franz et al. (1980), but in contrast with reports by Gavras et all. (1981) and Floras et a1. (1985). The PNA level is detemined by the rate of release of noradrenaline into and the removal from plasma. Esler et al. (1981c) reported reduced plasma noradrenaline clearance during Pr suggesting that the unchanged PNA levels are the result of a decreased release and a decreased clearance. Since P1 does not reduce cardlac ouput and hepatic blood flow at rest, one would not expect PNA clearance to be reduced (Man in 't Veld and Schalekamp, 1983). The de- 
creased PKA levels during PI could then be interpreted as a reduction of noradrenaline release, this effect being masked with other beta blockers by their conconitant effects on PNA clearance (struthers and Dollery, 1985). During exerclse PNA levels during $\mathrm{Pr}$ and Me did not differ from those during placebo, which is in agreement with other studies (Watson et al., 1980b; Lehmann et a1., 1982; Van Hooff et al., 1984b), whereas during P1 PNA was decreased at the end of the first period of exercise. However, no significant difference was found at the moment of exhaustion. Since the HR reduction during exercise was similar with all 3 beta blackers, there is mo evidence for differences in hemodynamics which could explain the tendency for lower PNA levels during Pi.

PRA was decreased during treatment at rest and during exercise as in other studies (Hansson et al., 1977a,b; Lifnen et al., 1979; Leenen et al., 1980, 1983; Van Hooff et al, 1984b). Although in most studies no decrease of resting $P R A$ is found during $P i$ treatment (Man in 't Veld and Schalekamp, 1983), a significant reduction of resting PRA was found in our study. The reason for this finding is not clear.

\subsubsection{Effects on submaximal exercise tolerance}

In our patients, submaximal exercise time was decreased during treatment with all 3 beta blockers. Galbo et al. (1976), Lundborg et al. (1981), and Kindermann et al. (1984) also found limpalment of submaximal exercise performance in healthy subjects after acute beta blockade. No signiflcant differences in exercise time between the 3 beta blockers were found in our patients. Furthermore, the statement that during chronic beta blocker therapy effects of decreased exercise performance tend to disappear (Fellenius, 1983) is in disagreement wh our findings which show an even more reduced exercise performance after 6 months of beta blocker treatment than after the first week. $A$ possible explanation for the impaired exercise performance after beta blockade could be a decreased leg blood flow (Frisk-Holnberg et al., 1985) and/or the metabolic effects of beta blockers (Lohmann, 1981; Fellenlus, 1983). These results could have consequences in prescribing beta blockers for physically active hypertensive patients. 


\section{Chapter 5}

LONG-TERM ANTIHYPERTENSTVE THERAPY

WITH THREE DIFFERENT BETA BLOCKERS :

METABOLIC EFFECTS

AT REST AND DURING SUBMAXIMAL ENDURANCE EXERCISE

M.A. van Baak ${ }^{1,4}$, R.O.B. Böhm ${ }^{1}$, B.G. Arends ${ }^{1}$, G.M.E. Janssen ${ }^{2,4}$, M.E.J. van Hooff ${ }^{1}$, and K.H. Rahn ${ }^{3}$

Dept. of Phamacology ${ }^{1}$, Dept. of Human Blology ${ }^{2}$, Dept. of Medlclne, Division of Nephrology, Hypertension and Clinical Pharmacology ${ }^{3}$, University of Limburg, and Institute for Sports Medicine Limburg 4 , Maastricht, The Netherlands 


\subsection{STMMARY}

The effects of long-tem (6 months) antihypertensive treatment wth three different types of beta blockers (propranolol, non-selective without ISA; pindolol, non-selective with ISA; metoprolol beta selective whout ISA) on metabolic variables at rest and during submaximal bicycle ergoneter exercise at $70 \%$ of estimated $\dot{V}_{2}$ max were studied in 7 subjects th essential hypertension.

Similar reductions of blood pressure and exercise heart rate were obtained with the three beta blockers. Apart from an increase in total and LDL+WLDL serum triglyceride concentrations during propranolol treatment, no effects on serum 1ipoprotein profile were found. During exercise, the reduction of plasma glycerol and non-esterified fatty acid concentrations was more pronounced during non-selective than during beta ${ }_{1}$-selective blackade. Plasma glucose concentrations were largely unaffected. No consistent effects on plasma lactate levels were found. These data, in combination with a slightly decreased oxygen uptake and 1 ncreased respiratory ratio, are suggestive for a decreased utilization of non-esterified Eatty actis and increased carbohydrate combustion during beta blocker treatrent.

Plasma potasslum concentrations during exercise were significantly increased and the increase was more pronounced during non-selective than during beta ${ }_{1}$-selective blockade.

The effects on the variables during exercise were simllar after 1 week and during long-tern (20/24 weeks) beta blocker treatment.

\subsection{INTRODUCTION}

Over the past years, it has become evident that beta-adrenoceptor blocking agents reduce submaximal exercise capacity (Galbo et a1., 1976; Kalser et al. . 1981; Lundborg et al., 1981; Kindemann et all., 1984). The effects of beta blockade on the metabolic adjustments to exerclse are probably involved in this reduction of exercise tolerance. Since beta ${ }_{1}$-selective blockers have less influence on beta $2^{-}$ receptor-mediated metabolic adfustments to exercise than non-selective 
blockers (Lundborg et al., 1981; Laustiola et al., 1983) a difference between the effect of beta, - selective and non-selective blockers on metabolism and exercise tolerance seems likely. Indeed, in number of studies such differences have been found (Kaiser et a1., 1981; Lundborg et al., 1981; Kindermann et al., 1984). However, all of these studies have been performed in young, healthy, usually well-trained subjects after acute or short-tern beta blocker administration. For practical purposes, i.e. for the treatment of physically active hypertensive patients, it is important to know whether similar differences between beta,-selective and non-selective beta blockers are also present in this group of patients, and whether they are maintained during long-tem chronic therapy.

It has also been suggested that differences in the metabolic effects of beta ${ }_{1}$-selective and non-selective blockers with and without intrinsic sympathicominetic activity (ISA) may lead to different Ifpoprotein profiles during treatment (van Brummelen, 1983; Weidmann et al. , 1983).

Therefore, a study was designed to compare the metabolic effects of three different types of beta blockers (propranolol (non-selective, without ISA), pindolol (non-selective, with ISA) and metoprolol (beta ${ }_{1}$-selective, without $I S A$ ) at rest and during submaximal endurance exercise during long-term treatment in patients with essential hypertension.

\subsection{SUBJECTS AND METHODS}

\subsubsection{Subjects}

Inftially, 9 subjects were included in the study. Two of them dropped out: one developed overt coronary heart disease and one subject could not be motivated to continue after one treatment perlod. Thus 7 subjects (6 males, 1 female; age $29-48$ years) with mild to moderate essential hypertension completed the study. They were all physically active on a recreational level. The protocol of the study was approved by the Ethical Committee of the University of LImburg and all subjects gave their informed consent. 


\section{3 .2 Destign of the study}

At the end of a 4-week wash-out perlod, when all antihypertensive medication had been withdrawn, standing blood pressure (BP) was $>140 / 90$ but $<170 / 110 \mathrm{~mm} \mathrm{Hg}$ in all subjects. Then placebo treatment was started for 6 weeks. In the 3 rd week, maximal oxygen uptake ( $\mathrm{VO}_{2}$ max) was estimated by a submaximal blcycle ergometer test ( $A$ strand, 1960). Submaximal endurance tests at $70 \%$ of the estimated $\mathrm{vo}_{2}$ max were performed in the $4 \mathrm{th}$ and 6 th week of the placebo perlod. The first test was wised for habituation purposes and is not included in the results. The subjects were then treated orally in a single-blind randomized manner with propranolol, metoprolol and pindolol for 6 months each. A placebo period of 4 weeks followed each 6 months of active treatment. The dose of the beta blocker was adjusted to attain a standing diasto$11 \mathrm{BP}<90 \mathrm{mmHg}$. After 5 and 6 months of active treatment and at the end of each placebo period, the subjects performed a submaximal endurance test at $70 \%{ }^{*} \mathrm{w}_{2} \max$ (protocol, see below).

In half of the treatment periods, randomized over the three drugs, an additional endurance test was performed after 1 week of beta. blocker treatment.

At the end of each active treatment and placebo period, blood was sampled after an overnight fast for determination of the lipoprotein profile and other metabolic varlables at rest.

\subsubsection{Protocol of the submaximal endurance test}

Exerclse tests were performed $2-4$ h after intake of the last tablets, at least $2 \mathrm{~h}$ after the last meal. The subjects were asked not to consume alcohol, coffee or nicotine on the day of the test and to avold strenuous physical exerclse. After insertion of a short catheter In the $v$. cubitalis, subjects rested in suplne position for $30 \mathrm{~min}$. During the last 10 min of this perliod, explratory air was collected in Douglas bags for determination of minute ventilation $\left(\dot{V}_{\mathbb{E}}\right)$, oxygen consumption $\left(\mathrm{VO}_{2}\right)$ and respiratory ratio $(R)$. During the last min, blood was draw for determination of plasma glucose, glycerol, lactate, $\mathrm{Na}^{+}$, $\mathrm{K}^{+}$, and non-esterified fatty acid (NEFA) concentrations. Subsequently, the exercise test was started. The subjects exercised in a temperature-controlled laboratory $\left(18-21^{\circ} \mathrm{C}\right)$ on a lode bicycle ergometer at 
$70 \%$ of estimated $\mathrm{VO}_{2}$ max until exhaustion. Maximal duration of the cest was $3 \times 30 \mathrm{~min}$ with $10 \mathrm{~min}$ rest in between, a protocol similar to that described by tumbborg et al. (1981). During the last 5 min of ach 30 min exercise bout, just before exhaustion, and after $15 \mathrm{~min}$ recovery in supine position, expiratory air was collected, blood was drawn and heart rate determined.

\subsubsection{Methods}

Heart rate was determined electrocardiographically. Fractions of $\mathrm{O}_{2}$ and $\mathrm{CO}_{2}$ in expiratory air were measured with an Ergoscreen system (Fenyves and Gut, Base1), and expiratory volume was measured with a dry gasmeter (Meterfabriek Schlumberger). From these data $\dot{V}_{E}$, $\dot{V}_{2}$, $\dot{\mathrm{V}}_{2}$ and $\mathrm{R}$ were calculated by standard methods. Blood samples for determination of plasma glucose, glyceral, lactate, $\mathrm{Na}^{+}$and $\mathrm{k}^{+}$(heparinized) and for NEFA (no anti-coagulant added) were centrifuged immediately for 1 min at high speed. Plasma for glycerol, NEFA, $\mathrm{Na}^{+}$ and $\mathrm{K}^{+}$determinations was rapidly frozen in dry ice and stored at $-70^{\circ} \mathrm{C}$ until futher processing. Glucose and lactate were determined immediately.

Plasma lactate, glycerol and glucose concentrations were measured enzymatically (Roche lactate analyzer 640, glucose test comblnation Compur, and a modification of the triglyceride (Neutralfett) test combination Boehringer Mannhelm, respectively). Plasma $\mathrm{Na}^{+}$and $\mathrm{K}^{+}$ were determined by flame photometry (Instrumentation Laboratory 243). Hemolytic samples were excluded. Plasma NEFA concentrations were determined colorimetrically (non-esterlfed fatty acids test combination Boehringer Mannheim). Serum 1lpoprotein fractions we separated by density gradient ultracentrifugation (Terpstra et a1., 1981). Cholesterol and triglycerldes were detemined enzymatically (Catalase kit Boehringer Mannheim, and test comblnation Triglyceride vollenzymatisch (Neutralfett) Boehringer Mannheim, respectively).

\subsubsection{Data analysis}

Results are presented as means $\pm S$ S. For the sake of clarlty, results of the exercise test during the placebo period before and after each active treatment period were averaged and so were the 
results of the exercise tests in the 5 th and 6 th month of active treatment. This was considered acceptable since no statistically significant differences in exercise heart rate within those pairs of tests were found. This suggesti that no consistent changes in cardiorespiratory futness had accurred between the two tests.

Statistical analysis was performed by Wilcoxon's signed ranks tests and by analysis of variance for a randomized blocks design (zerbe, 1979). The level of significance was set at p<0.05.

\subsection{RESULTS}

One subject was withdrawn from pindolol treatment after 2 weeks because of severe headache. In another subject, the pindolol treatment period was shortened to 3 months because of complaints about fatigue. In all subjects, the alm of the antlhypertensive treatment, standing diastolic $B P<90 \mathrm{~mm} \mathrm{Hg}$, was attained and $B P$ reductions we re comparable with the three beta blockers. Average standing BP was $135 \pm 3 / 88+2$ during propranolol, $133+4 / 89+2$ during pindolol and $136+3 / 88+3 \mathrm{~mm} \mathrm{Hg}$ during metoprolol treatment. The average value during placebo treatment was $145+3 / 97 \pm 2 \mathrm{mrn} H \mathrm{Hg}$. The average dally doses used were $108 \pm 17 \mathrm{mg}$ propranolol, $150+31 \mathrm{mg}$ metoprolol and $14 \pm 2 \mathrm{mg}$ pindolol. The subjects exercised at a mean work load of $131+13 \mathrm{~W}$.

\subsubsection{Cardioresplratory variables}

Exerctse heart rate was slgnificantly and to a similar extent reduced during treatment with all three beta blockers $(p<0.01)$ (Fig. 1). At rest and during recovery, heart rate was significantly lowered during propranolol and metoprolol ( $p<0.01)$, but not during pindolol treatment. $\mathrm{VO}_{2}$ at rest and during recovery was unaffected by beta blacker therapy (F1g. 2). During exerclse, $\overline{\mathrm{V}}_{2}$ tended to be lower during non-selective beta blockade (propranolol: $p<0.05$; pindolol: $\mathrm{p}=0.06)$. $\mathrm{R}$ showed a tendency to increase during beta blocker administration (Fig. 3). However, consistent significant differences were only found during plndolol treatment ( $p<0.05)$. Minute ventillation was unaffected by beta blockade. There was no signiflcant difference in 


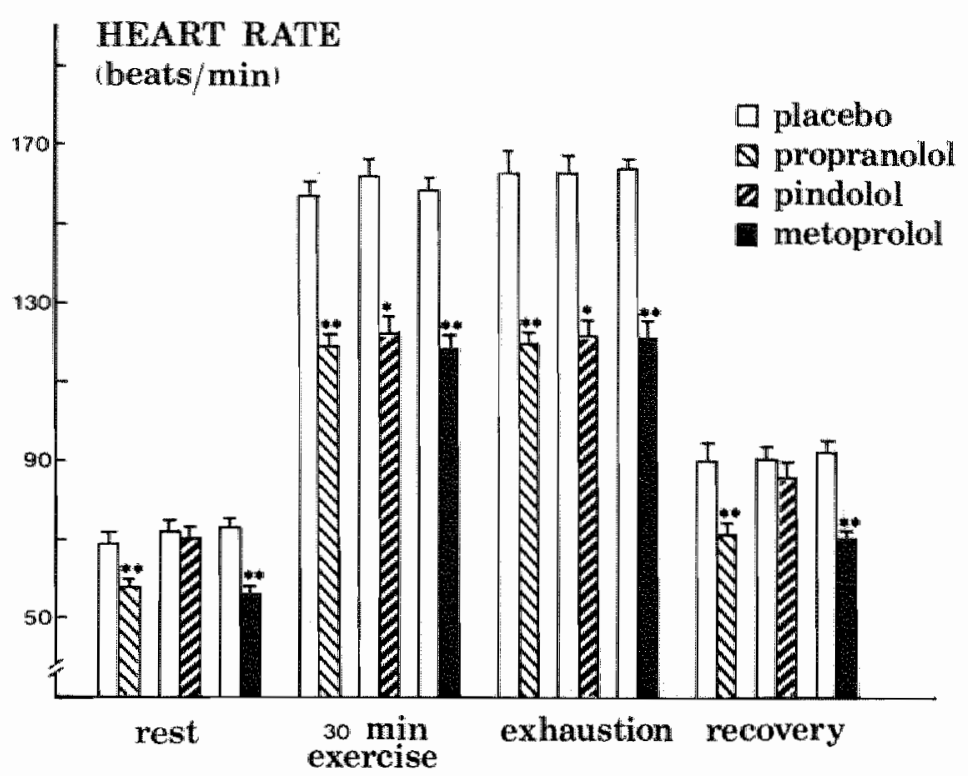

Figure 1: Heart rate (at rest, during exercise and during recovery) during placebo and beta blocker treatment (mean \pm SEM). * significant difference with placebo $(* p<0.05 ; * *<<0.01)$.

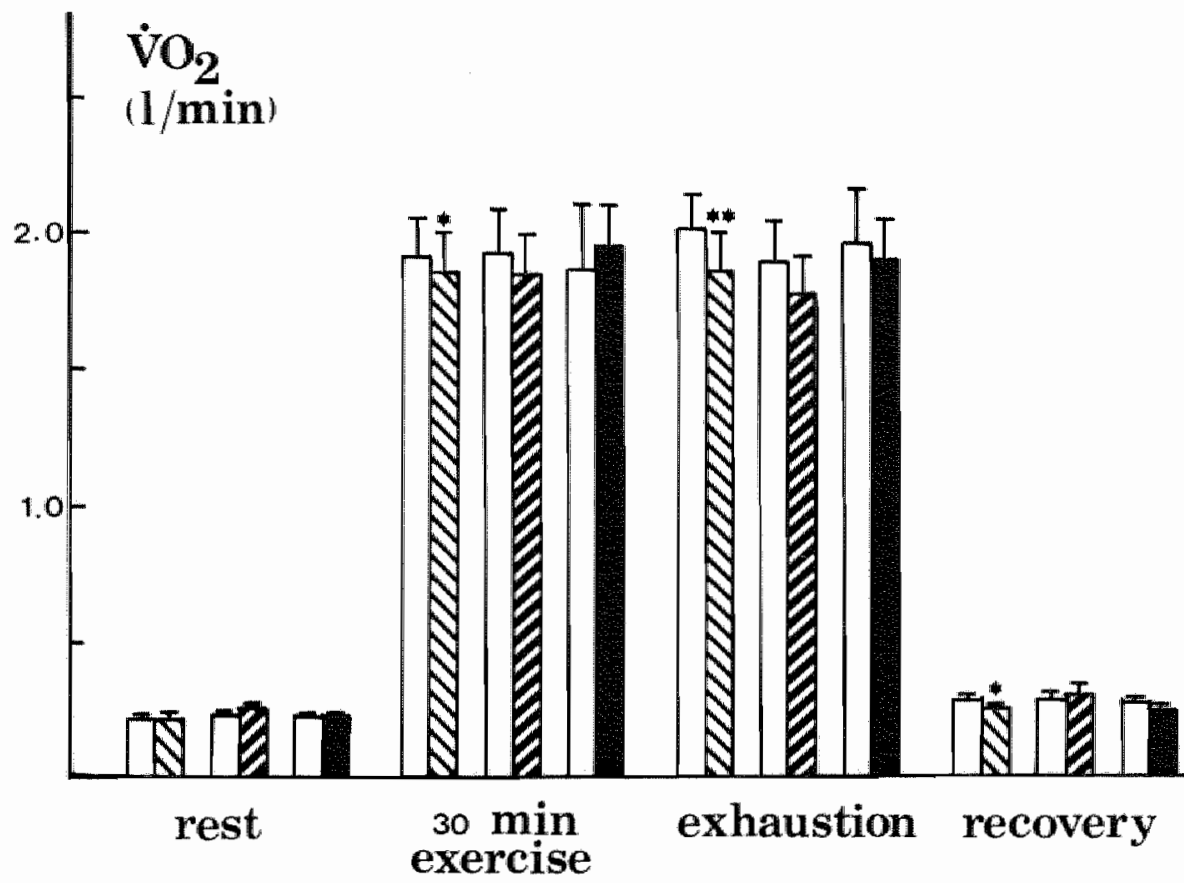

Figure 2: Oxygen consumption $\left(\dot{\mathrm{V}}_{2}\right)$ (at rest, during exercise, and during recovery) during placebo and beta blocker treatment (mean $\pm S E M)$. For symbols, see legend to figure 1 . 
exercise heart rate and $\mathrm{VO}_{2}$ after 1 and $20 / 24$ weeks of beta blocker treatment (Table 1 ). R was higher after long-term treatment than after 1 week.

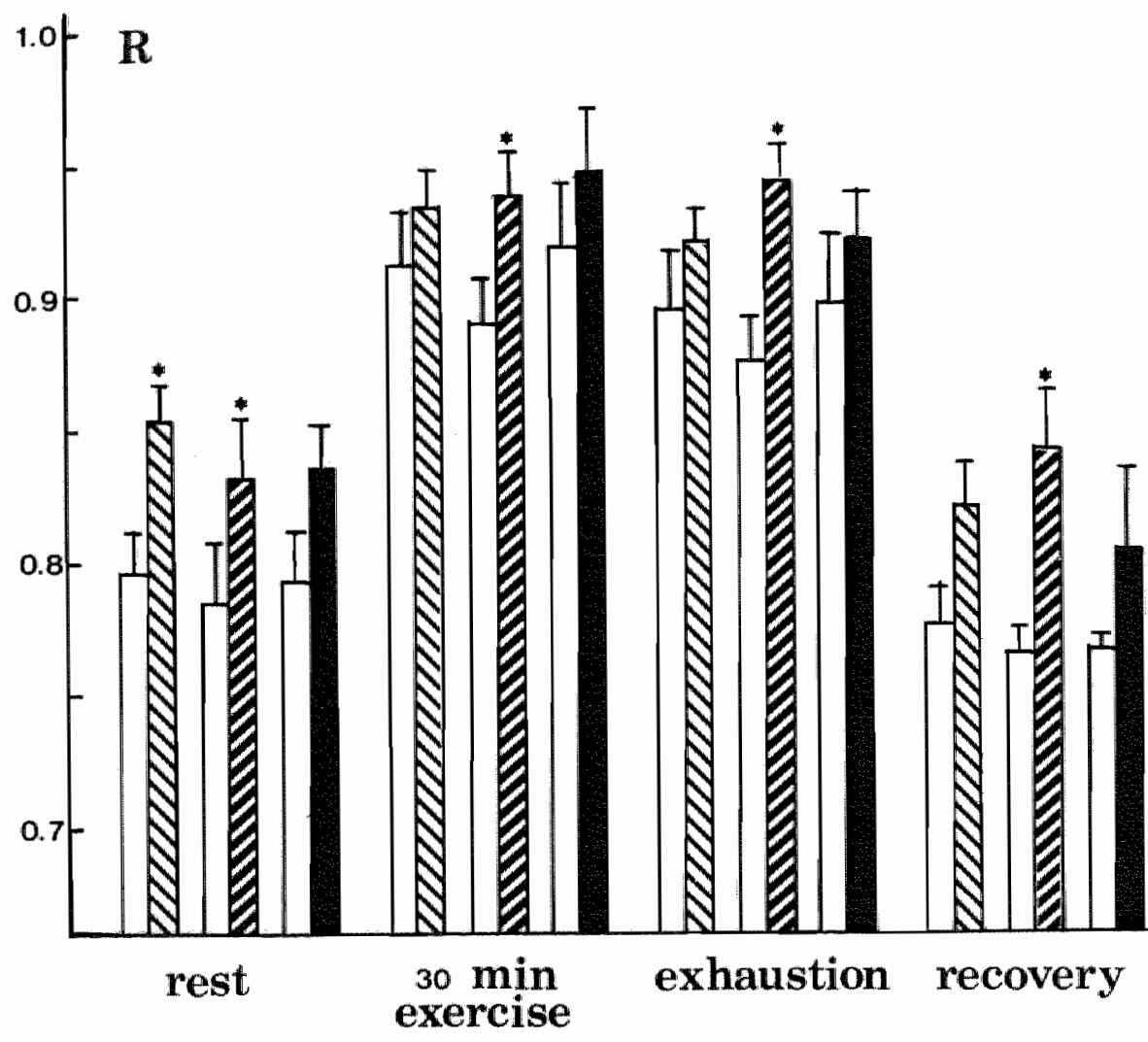

F1gure 3: Resplratory ratio (R) (at rest, during exercise, and during recovery) durting placebo and beta blocker treatment (mean \pm $\mathrm{SEM})$. For symbols, see legend to figure 1 .

\section{4 .2 Metabolic variables}

Fasting plasma glucose, lactate and NEFA levels were unaffected during beta blocker therapy (Table 2). Fasting plasma glycerol concentration was lower during treatment with all three beta blockers than during placebo treatment. Total serum triglyceride content was signiflcantly increased during propranolol treatment, malnly due to an increase in LDL+VLDL-triglycerides. No significant changes in total cho- 
Table 1: Variables (mean \pm SM) after 30 min exercise after 1 and $20 / 24$ weeks of beta blocker treatment.

Beta blocker treatment

Week 1

Week $20 / 24$

HR $(b / m i n)$

$118.4+2.4$

$119.7+2.5$

$\dot{v o}_{2}(1 / \mathrm{min})$

$1.71+0.14$

$1.79+0.10$

R

$0.91 \pm 0.01$

$0.94 \pm 0.02 *$

Glucose (mmol/1)

$3.59+0.21$

$3.97 \pm 0.19$

Lactate (mol/1)

$6.00+0.71$

$6.11+0.76$

Glycerol (mol/1)

$0.11 \pm 0.01$

$0.1 \pm 0.02$

NEFA (moll/1)

$0.19+0.02$

$0.18+0.02$

$\mathrm{K}^{+}(\mathrm{mmol} / 1)$

$5.42 \pm 0.09$

$5.35+0.08$

$* p<0.05$

lesterol or division of cholesterol over the lipoprotein subfractions we re seen.

Plasma glucose levels at rest and during exercise were not signiflcantly different during placebo and beta blocker treatment ( $F 1 g$. 4). Plasma lactate levels tended to be higher durting beta blocker treatment than during placebo (F1g. 5), although the difference was only significant during pindolol therapy ( $<<0.05)$. Plasma glycerol levels were signiflcantly reduced during exerclse and recovery by beta blocker therapy $(p<0.05)(F 1 g$. 6). The decrease was alignificantly more pronounced during propranolol and pindolol than during metoprolol treatment $(p<0.05)$. Non-esterified fatty acld concentrations were significantly reduced during exercise and recovery by propranolol and pindollol administration $(p<0.05)$, but not by metoprolol treatment (FIg. 7). However, the placebo values corresponding with the metopro- 
Table 2: Fasting metabollc vartables (in mol/1) during placebo, propranolo1, pindolol and metoprolol treatment (mean \pm SEM).

$$
\text { Placebo Propranolol Pindolol Metoprolol }
$$

Total cholesterol $\quad 5.44+0.40 \quad 5.11+0.49 \quad 5.05 \pm 0.22 \quad 5.61+0.58$

VLDLELDL chol $\quad 3.97 \pm 0.39 \quad 3.97 \pm 0.43 \quad 3.62 \pm 0.30 \quad 3.72 \pm 0.56$

HDL chol $\quad 1.15+0.12 \quad 1.10 \pm 0.10 \quad 1.03 \pm 0.21 \quad 1.32 \pm 0.18$

Total triglycerides $\quad 1.51 \pm 0.34 \quad 2.26 \pm 0.38 * * \quad 1.63+0.23 \quad 1.31 \pm 0.28$

VLDL+LDL triglyc $\quad 1.08+0.19 \quad 1.74+0.29 * * 1.19+0.23 \quad 1.00 \pm 0.28$

HDL triglyc $\quad 0.11+0.01 \quad 0.15+0.02 \quad 0.14+0.02 \quad 0.16+0.02$

Glucose

$4.63 \pm 0.18 \quad 4.64+0.26 \quad 4.76 \pm 0.20 \quad 4.63 \pm 0.19$

Lactate

$1.21+0.15 \quad 1.06 \pm 0.14 \quad 1.18 \pm 0.14 \quad 1.21 \pm 0.11$

NEFA

$0.29+0.03 \quad 0.28+0.03 \quad 0.27 \pm 0.03 \quad 0.26 \pm 0.04$

Glycerol

$0.12+0.01$

$0.08+0.01 * 0.09 \pm 0.01 * * 0.08 \pm 0.01 * * *$

* Significant difference with placebo $(* * p<0.01 ; * * * p<0.001)$

1.01 treatment period were lower than the other placebo values. Differences between metoprolol and pindolol or propranolol were not statistically significant.

There were no statistically signiflcant differences between the metabolic variables during exerclse after 1 and $20 / 24$ weeks of treatment (Table 1). 


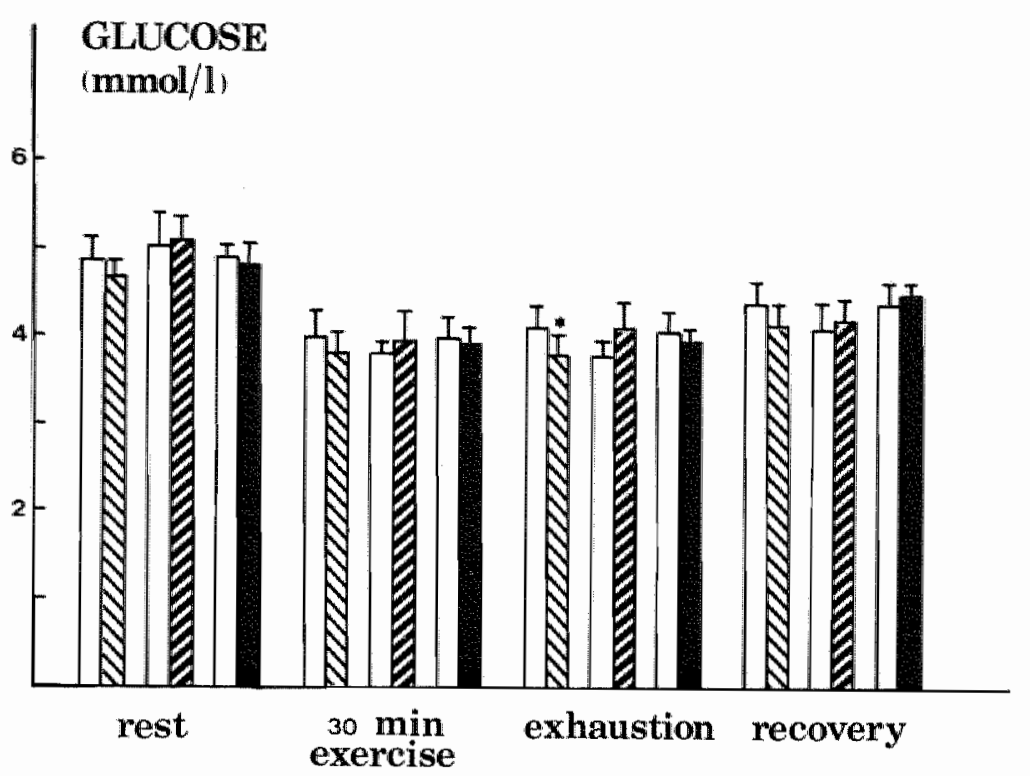

Figure 4: Plasma glucose concentration (at rest, during exercise, and during recovery) during placebo and beta blocker treatment (mean $\pm S E M)$. For symbols, see legend to figure $\mathbb{1}$.

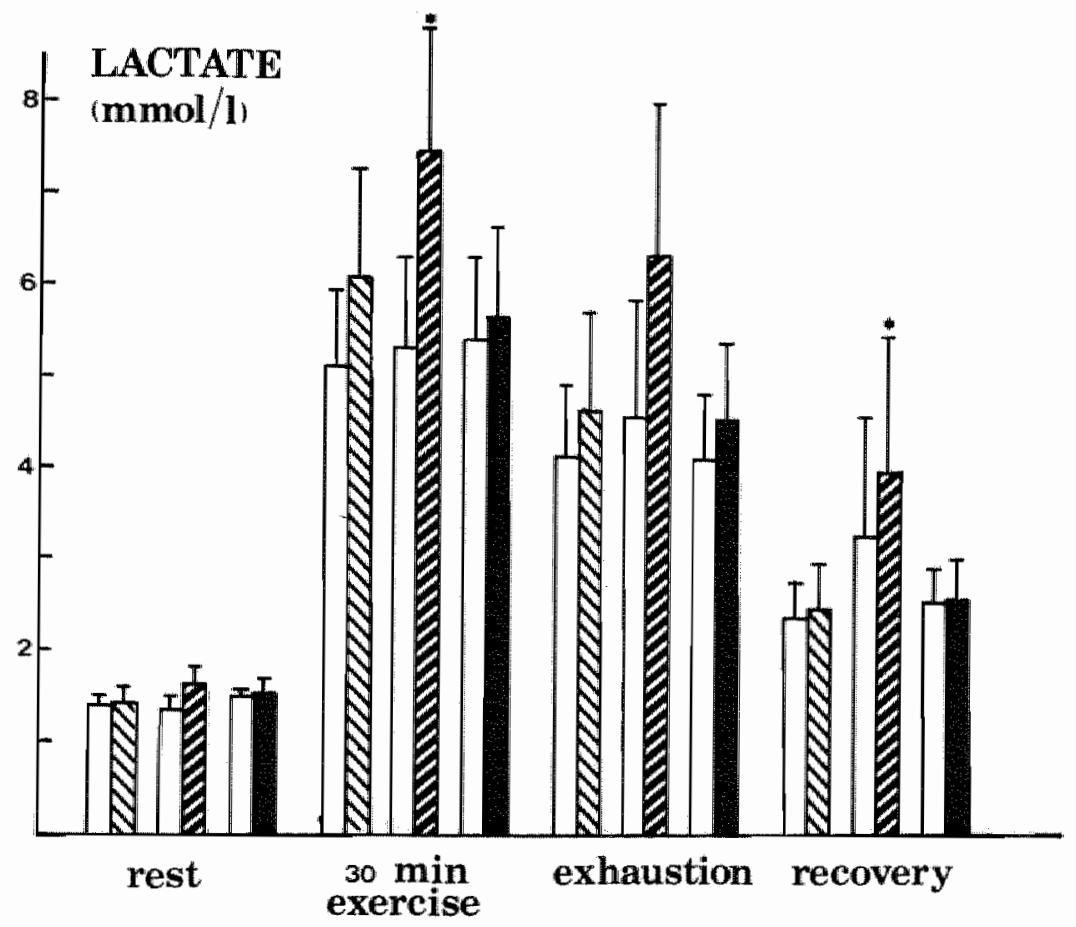

Figure 5: Plasma lactate concentration (at rest, during exercise, and during recovery) during placebo and beta blocker treatment (mean $\pm S E M)$. For symbols, see legend to flgure 1 . 


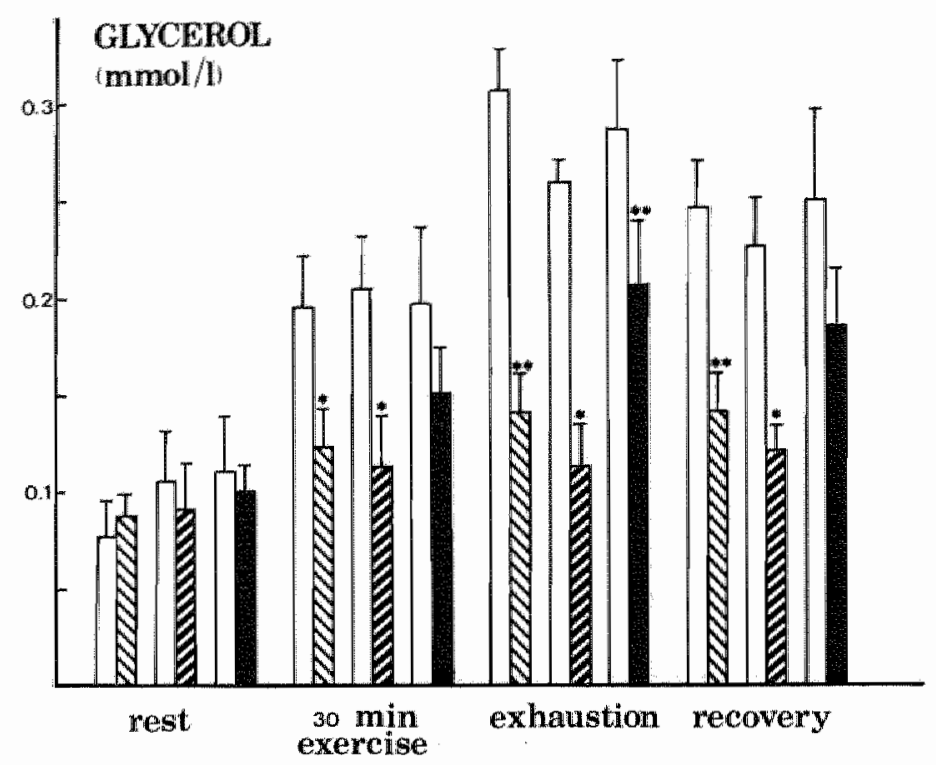

Figure 6: Plasina glycerol concentration (at rest, during exercise, and during recovery) during placebo and beta blocker treatinent (mean $\pm \mathrm{SEM})$. For symbols, see legend to figure 1 .

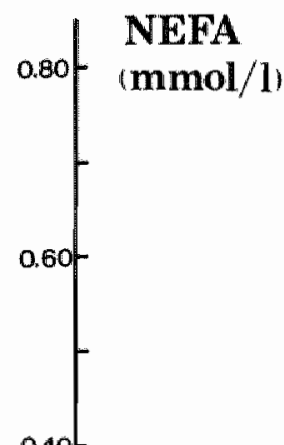


5.4.3 Plasma $\mathrm{Na}^{+}$and $\mathrm{K}^{+}$

There was no significant difference between plasma $\mathrm{Na}^{+}$levels during placebo and beta blocker treatment, neither at rest nor during exercise or recovery. In contrast, plasma $\mathrm{K}^{+}$levels were significantly increased during treatment with all three beta blackers ( $<<0.05$ ) (Fig. 8). The increase was significantly more pronounced during propranolol and pindolol than during metoprolol therapy $(p<0.05)$. Plasma $\mathrm{K}^{+}$levels were similar after 1 and $20 / 24$ weeks of treatment (Table 1 ).

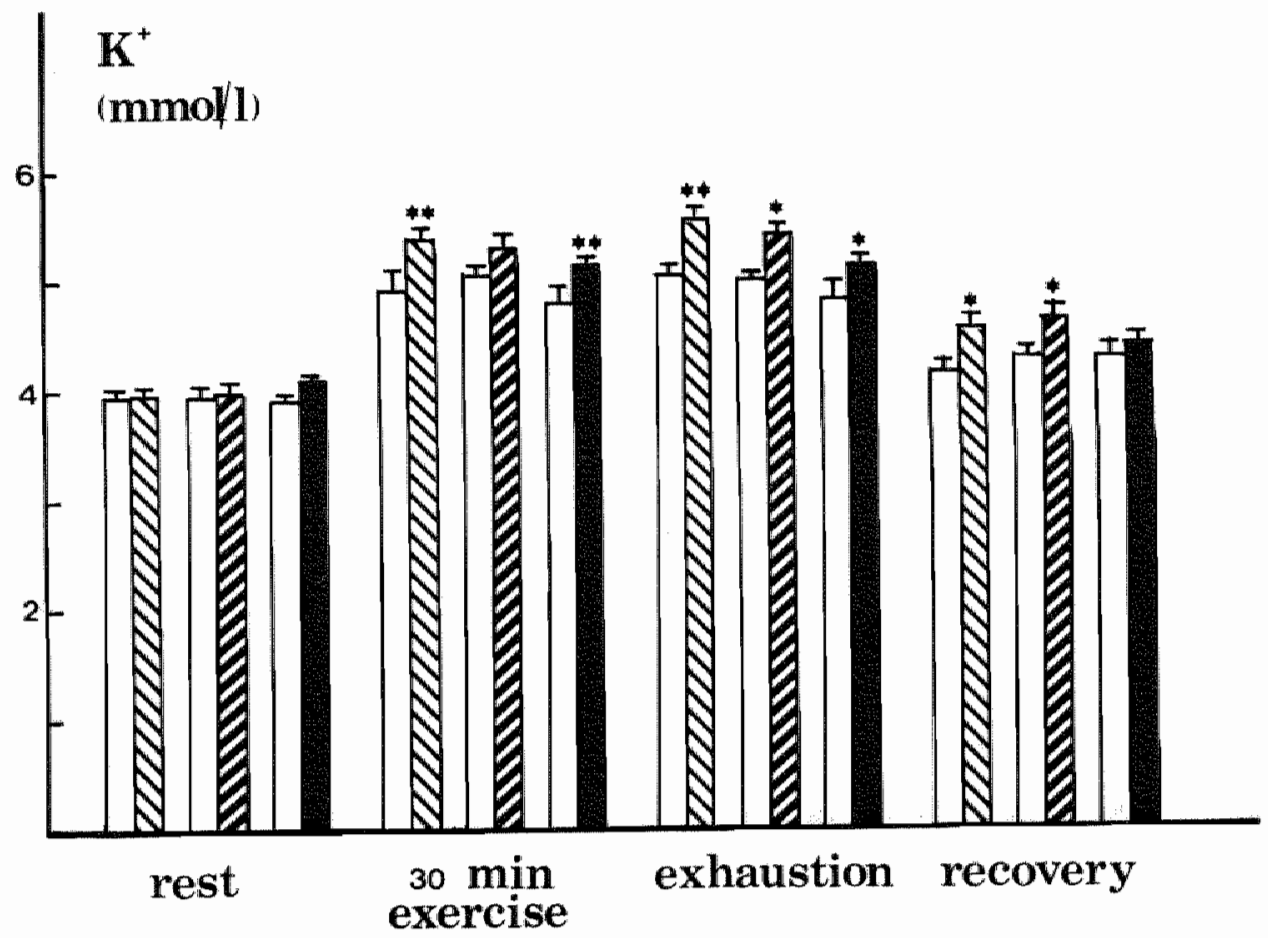

Figure 8: Plasma potassium concentration (at rest, during exercise, and during recovery) durling placebo and beta blocker treatment (mean $\pm \mathrm{SEM}$ ). For symbols, see legend to figure 1 . 


\subsection{DLSCUSSION}

The administered dally doses of the three beta blockers reduced blood pressure simllarly and were thus equieffective in their antihypertenslve effect.

The influence of beta blocker treatment on serum lipoprotein proflle was not very clear. The only significant change was an increase of total and LDL+VLDL triglyceride concentrations during propranolol treatment, which has also been found in other studies (Van Brummelen, 1983; Weidmann, et al., 1983). No slgnificant changes in total cholesterol or cholesterol content of lipoprotein subfractions were found. This may be due to the small number of subjects $\mathbb{1 n}$ our study and to the variability of serum lipoprotein walues. Reviews form the avallable 11terature show that significant patterns become only evident when results of a large number of studies are combined (Van Brummelen, 1983; Weldmann et al., 1983).

During treatment with all three beta blockers, a silmilar reduction of submaximal exercise heart rate was found. This suggests that there were probably no important hemodynamic differences during exercise between the three trials. Moreover, Frisk-Holmberg et al. (1981, 1985) showed that the oxygen uptake of exercising muscle was

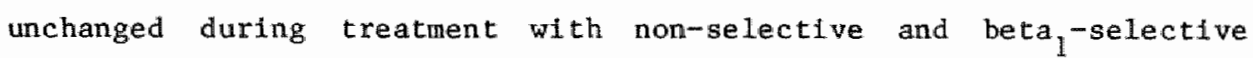
blockers despite a reduction of muscle blood flow. This at least suggests that differences between placebo and beta blocker treatment and between the three different beta blockers are not due to differences in oxygen dellivery to the working muscles, although the effects on muscle blood flow and oxygen extraction during exerclse of long duration and high intensity are not known.

A11 three beta blockers reduced plasma glycerol concentrations during exercise. The reduction was more pronounced during non-selective than during beta, ${ }_{1}$-selective blockade, which is in contrast with findings by Franz et al. (1983). However, a nore pronounced reduction of plasma glycero1 and NEFA levels during exercise during non-selec-

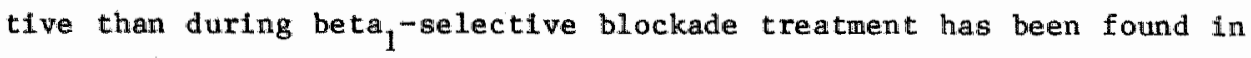
other studles as we11 (Lundborg et al., 1981; Uusitupa et al., 1982; Laustiola et al., 1983) which suggests that beta ${ }_{2}$-receptors are also 
involved in lipolysis (Juhlin-Dannfelt, 1983). The results of our study indicate that lipolysis during exercise is reduced during treatment with all three beta blockers and that the reduction is more pronounced during treatment with non-selective blockers. Thus, the supply of NEFA to the working muscles is probably impaired. Studles of IriskHolmberg et al. (1985) indeed show a reduction of the uptake of NEFA by the working muscle during beta blockade.

In view of a decreased supply of NEFA an Increased break-down of carbohydrates is to be expected. The decrease of $\mathrm{V}_{2}$ and increase of $R$, although not always statistically significant, are conpatible with this expectation. Decreases in $\dot{V}_{2}$ and increases in $\mathrm{R}$ have also been found in other studfes (Pearson et al., 1979; Tesch and Katser, 1983; Wilmore et al., 1985) although not in all (Franz and Lohmann, 1979; Smyth et al., 1984; Wilmore et al., 1985). Discrepancies may be due to differences in exercise protocol (duration, intensity) and the fact that the differences that have been found are usually quite small $(<10 \%)$.

An increased carbohydrate utilization may result from ari increased blood glucosie uptake, and/or an 1 ncreased muscle glycogen break-down, and/or an increased lactate utilization. Plasma glucose concentrations were hardly affected during beta blocker therapy, but an increased uptake of blood glucose may have been compensated by a concomitant increase in hepatic glucose output. On the other hand, studies by Frisk-Holmberg et al. (1977, 1985) have shown no changes in muscle glucose uptake during non-selective and beta ${ }_{1}$-selective blockade, although at a lowe $r$ work load. An fncreased glycogen utilization is not directly evident from studies in which muscle blopsles have been taken and which generally have shown that glycogen break-down was similar during exercise with and whout beta blockade (Frisk-Holmberg et al., 1979; Uusitupa et a1., 1982; Kalser et a1., 1985). At low work rates, a substantial reduction of lactate output from exercising muscle has been found during beta blocker treatment (Erisk-Holmberg et a1., 1977, 1985) which may suggest an increased utllization within the muscle. In our study, no consistent effect on plasma lactate concentrations was found during beta blocker treatment. In the 11terature 1ncreased. (Kaiser and Tesch, 1983; Katz et a1., 1985), unchanged 
(Franz and Lohmann, 1979; Laustola et al., 1983; Rindermann et a.., 1984; Smyth et al., 1984; Frisk-Holmberg et al., 1985) and decreased (Frisk-Holmberg et al., 1977; Kaiser et al., 1985) 1actate concentrations can be found. These discrepancies are probably due to differences in exercise intensity and duration, and to the dose of the drug. However, from changes in plasma lactate levels nothing can be said about the cause of the change: changes in lactate formation, lactate output and lactate utilization may all contribute.

In agreement with other studies (Lundborg, 1983; Katz et al., 1985; Kullmer and Kindermann, 1985), we found increased plasma potasslum concentrations during exerclse under the influence of beta blockade, which was more pronounced durling non-selective than during beta, selective blockade. Supposedly, this increase is due to an inhibition of potassitum uptake by blockade of beta ${ }_{2}$-receptors (Lundborg, 1983 ; Katz et al., 1985; Kullmer and Kindermann, 1985). As indicated in a previous paper (Böhm et al., submitted), the average exercise time was reduced from 69+10 min to $52+6 \mathrm{~min}$ during propranolol ( $p<0.01)$, from $62 \pm 9$ to $38+10 \mathrm{~min}$ during pindolol $(\mathrm{p}<0.05 ; \mathrm{n}=6)$ and from 69110 to $58+9$ min during metoprolal $(p<0.01)$. Although the reduction tended to be more pronounced during propranolol and pindolol than during metopro101, the difference was not statistically significant. The reduction of exercise time during beta blocker treatment seems to be related to changes in substrate avallability and utilization during exercise. From muscle blopsy studies, it seems unlikely that the reduction in exercise time is due to a more rapid glycogen depletion which is the factor limiting exercise duration of this type in trained subjects (Holloszy, 1982). Maybe the Increased fatigue is due to an increased number of muscle flbers that has to be recruted to deliver the same amount of work (due to a reduction of NEFA supply and to a reduction In the maxtmal rate of glycogen degradation by beta blocker administration (Chasiot 1 s et al., 1983)), or to increased muscular fatigue due to hyperkalemia. Although effects on metabolism and potassium were more pronounced during non-selective than during beta,-selectlve blockade, thls did not result in statistically significant differences In submaximal exercise performance in this group of hypertenstue subjects, although the tendency was present. 
Similar values for the hemodynamic and metabolic variables after $30 \mathrm{~min}$ exercise were obtained after 1 and $20 / 24$ weaks of beta blocker treatment. The same was true for the values at rest, at exhaustion and during recovery. These results indicate that no adjustments to beta blocker therapy of these varlables occcur between $\mathbb{d}$ week and 6 months of treatment. Only $\mathrm{R}$ was higher during long-term treatment than after 1 week, which is suggestlve for an increased carbohydrate combustion. However, no support for this possibility colld be found in other metabolic changes. Exercise time was reduced from $64 \$ 8$ min during placebo to $53 \pm 7 \mathrm{~min}$ after 1 week of beta blocker treatment $(\mathrm{p}<0.05)$ and to $46+6 \mathrm{~min}$ after $20 / 24$ weeks of treatment $(\mathrm{p}<0.05)$ (Böhn et a1., submitted). The reduction was more pronounced after $20 / 24$ weeks than after 1 week $(p=0.05)$. The reason for the slightly lower exercise tolerance after long-term treatment is not clear. 
Chapter 6

STUDIES OF THE ANTIHYPERTENSIVE EFFECTS

OF THE ANGIOTENSIN CONVERTING ENZMME INHIBITOR

RAMIPRIL (HOE 498) TN MAN

R.O.B. Böhm ${ }^{1}$, M.A. van Baak ${ }^{2}$, K.H. Rahn ${ }^{1}$

Department of Medicine ${ }^{1}$, Division of Nephrology, Hypertension, Clinical Pharmacology, and Department of Pharmacology ${ }^{2}$

University of Limburg

Maastricht (The Netherlands)

Eur J Clin Pharmacol (in press) 


\subsection{SUMMARY}

The time course of the blood pressure lowering effect and the dose-response relationship of the new angiotensin converting enzyme Inhibitor ranipril (HOE 498) were studied in 8 patients with essential hypertension. As compared with placebo, a single oral dose of $2.5 \mathrm{mg}$ ranipril lowered systollc and diastolic blood pressure. The antihypertensive action of single doses of $5,7.5$ and $10 \mathrm{mg}$ ramipril orally was more pronounced. No change in heart rate occurred. Angiotensin converting enzyme activity was suppressed after all doses of ramipril studied. Plasma renin activity increased after $2.5 \mathrm{mg}$ and $5 \mathrm{mg}$ ramipri1. Plasma aldosterone was not affected after $2.5 \mathrm{mg}$, but it fell after $5 \mathrm{mg}$ ramipril. Thus, ramipril produced prolonged inhtbition (more than 12 hours) of anglotenstn converting enzyme activity and lowered blood pressure in patients with essential hypertension.

\subsection{INTRODUCTION}

At present, two angiotensin converting enzyme (ACE) inhibitors are avallable for therapeutic use, namely captopril and enalapril. Both drugs markedly inhibit the conversion of anglotensin $I$ to the vasoactive peptide angiotensin II resulting in a decrease of blood pressure (Brunner et al., 1979; Brunner et al., 1981 ; Johnston et al., 1984; Davies et al., 1984; Frohlich et al., 1984). Because of certaln ade effects of captopril and enalapril, the search for new orally active ACE-inhibitors has continued. 2-[N-[(S)-1-Ethoxycarbony1-3-phenylpropy1]-L-alany1]-(1S, 3S, 5S)-2-azabicyclo[3.3.0] octane-3-carboxylic acid (HOE 498), ramipri1, is a new, potent orally active drug, belonglng to the group of non-sulphydryl prodrug ACE-1nhibitors. Studies in spontaneously hypertensive rats demonstrated a prolonged blood pressure lowerting effect, as well as long-lasting inhibition of tissue converting enzyme following oral treatment with ramipril (Unger et a1., 1984). Becker et al. (1983) and Sichölkens et al. (1984) described an antihypertensive effect of ramipril in conscious rats with spontaneous hypertension and in rats with renal hypertension. Studies in 
healthy normotensive men showed exther a slight decrease in systolic and diastolic blood pressure after $5 \mathrm{mg}$ ramipril (Witte et al., $1984 \mathrm{~b}$; Manhen et al., 1985) or no significant effect (Bussien et al., 1985). Felder and Witte (1984) have suggested an antihypertensive effect in patients with essential hypertension.

The time course and the dose-response relationship of the antihypertensive action of ramipril have been now been studied in patients with mild to moderate essentlal hypertension, as well as several paraweters of the renin-angiotensin system.

\subsection{PATIENTS AND METHODS}

\subsubsection{Patients}

Eight patients ( 6 males, 2 females) with essential hypertension participated in the study. In all patients high blood pressure was difficult to treat with conventional antihypertensive drugs, e.g. propranolol, hydrochlorothiazide and/or hydralazine. Secondary forms of hypertension were excluded by history, physical examination, appropriate laboratory tests and intravenous pyelography. The ages of the patients ranged from 40-66 years (mean 56 years), and the weight from $67-98 \mathrm{~kg}$ (mean $82 \mathrm{~kg}$ ). The patients had recelved no diuretics in the month preceding the study. Al1 other antlhypertensive drugs were discontinued for at least 2 weeks prior to entrance into the study * Except for one female patient, who received medroxyprogesterone acetate, the patients were given no drug other than ramipril during the study. Four patients were hospltalized for the study, and the others participated as outpatients. At least 6 months prior to the study the patients were advised to reduce salt intake, but otherwise they ate a normal diet. All subjects gave their informed written consent. The study was approved by the Ethical Commttee of the Undversity of luimburg.

\subsubsection{Protocol}

The antihypertenstve effect of single oral doses of ramipril was studied in 8 patients. On the first day, each patient recelved a 
placebo capsule. Then, for a total of 48 hours, serial measurements of blood pressure (BP), heart rate (HR), plasma renin activity (PRA), plasma aldosterone and angiotensin converting enzyme (ACE) activity were perfomed after 15 min rest in supine position. BP and HR were again deternined after standing for $2 \mathrm{~min}$. Thereafter, 6 patients recelved a single dose of $2.5 \mathrm{mg}$ ramipril and 5 patients 5.0 mg ramipri1 and the measurements were repeated. 24-h urine samples were collected during the 4 days of the study for measurement of the renal excretion of creatinine, sodium and potassium. In the 4 patients who recelved both doses of the drug, the interval between the studies ranged from $1-2$ weeks.

Subsequently the dose-response relationship of the anthypertensive action of ranipril was studied in 8 hypertensive subjects. At flrst, all patlents were glven placebo. BP and HR, both suplne and after standing for $2 \mathrm{~min}$, were repeated $1 \mathrm{y}$ measured over $9 \mathrm{~h}$. Thereafter, the patlents recelved fncreasing single oral doses of ramipril starting with $2.5 \mathrm{mg}$. The maximum dose was $10 \mathrm{mg}$. The serial measurements of $\mathrm{BP}$ and HR were repeated. The interval between 2 doses ranged from $1-2$ weeks. If in a given patient a dose of ramipril decreased supine BP to levels lower than $140 / 90 \mathrm{~mm} \mathrm{Hg}$ no further dose was glven. Prior to the first dose and after admintstration of the last dose the following laboratory data were obtained from all patients: complete examination of the peripheral blood as we 11 as sodium, potassium, calclum, chloride, blitrubin, urea, creatinine, uric acid, alkallne phosphatase, SGOT, SGPT in serum, and blood glucose, urinalysL and ECG . Liver function tests were nomal at the start of the study. Serum creatintine was normal in all patients except for one male subject in whor it was $142 \mu$ mol/1.

\subsubsection{Methods}

Blood pressure (BP) and heart rate (HR) were measured with an automatic recorder (DINAMAP, Applied Medical Research Corporation, Tampa, USA). A11 blood samples were collected via an indwelling cacheter in an antecubital vein. The samples were immediately centrifuged and the plasma frozen at $-20^{\circ} \mathrm{C}$ until analyzed. Plasma renin activity (PRA) was measured by radiolmmoassay (Henquet et al., 1981). Plasma 
aldosterone was detemined without extraction by a direct radiolmunoassay (Lijnen et al., 1978), using antibody of International CIS (St. Quentin, France). The interassay coefficient of varlation was $7 \%$. Anglotensin-converting enzyme (ACE) activity was detemined radionetrically using the $A C E$ radioassay system of Ventrex Laboratories (Portland, USA). $\left.\mathrm{P}-\mathrm{[}^{3} \mathrm{H}\right]$ benzoylglycylglycylglycine served as substrate. The ${ }^{3}$ H-labelled hippurate formed was extracted with ethyl acetate (Ryan et a1., 1977). The coefficlent of variation of the assay always was lower than $8 \%$.

Urine was collected in plastic bottles. Sodium and potassium in urine were determined by flame photometry, and creatinine in urfne by spectrophotometry.

Results are glven as mean \pm SEM unless otherwise indicated. Differences were tested by analysis of variance or using the paired t-test when appropriate. The level of statistlcal significance was aet at $\mathrm{p}<0.05$.

\subsection{RESULTS}

\subsubsection{Time course of the anthypertensive effect of ramipril}

Systolic and diastolic $B P$ and $H R$ in the standing position after placebo and after $2.5 \mathrm{mg}$ rampril p.o. In 6 patients are shown in F1g. 1. Systollc BP after ramipril was slightly lower than after placebo. The difference was statistically signiflcant $(p<0.01$, analysis of variance) and so was that in diastalic BP $(p<0.001)$. Thils dose of ramipril had no influence on $H R$ in the standing position $(p>0.1)$. Suplne systolic and diastolic BP were also slightly reduced (p<0.01). Ramlpri1 did not change suplne $M R(p>0.5)$.

The Influence of $5 \mathrm{mg}$ ramiprt $1 \mathrm{p} .0$. on $B P$ and $H R$ in the standing posttion in 5 hypertensives is 11lustrated in F1g. 2. The drug $81 \mathrm{~g}-$ niflcantly ( $<<0.001$, analysis of variance) lowered standing systollc and diastollc BP. HR was not changed $(\mathrm{p}>0.1)$. BP stated to decrease as early as $30 \mathrm{~min}$ after treatment, and the maximal reduction in $B P$ accurred after $6 \mathrm{~h}$. The reafter BP gradually rose to reach 1 ts control. levels after $24 \mathrm{~h}$. In 3 patients standing BP was also determined $12 \mathrm{~h}$ 


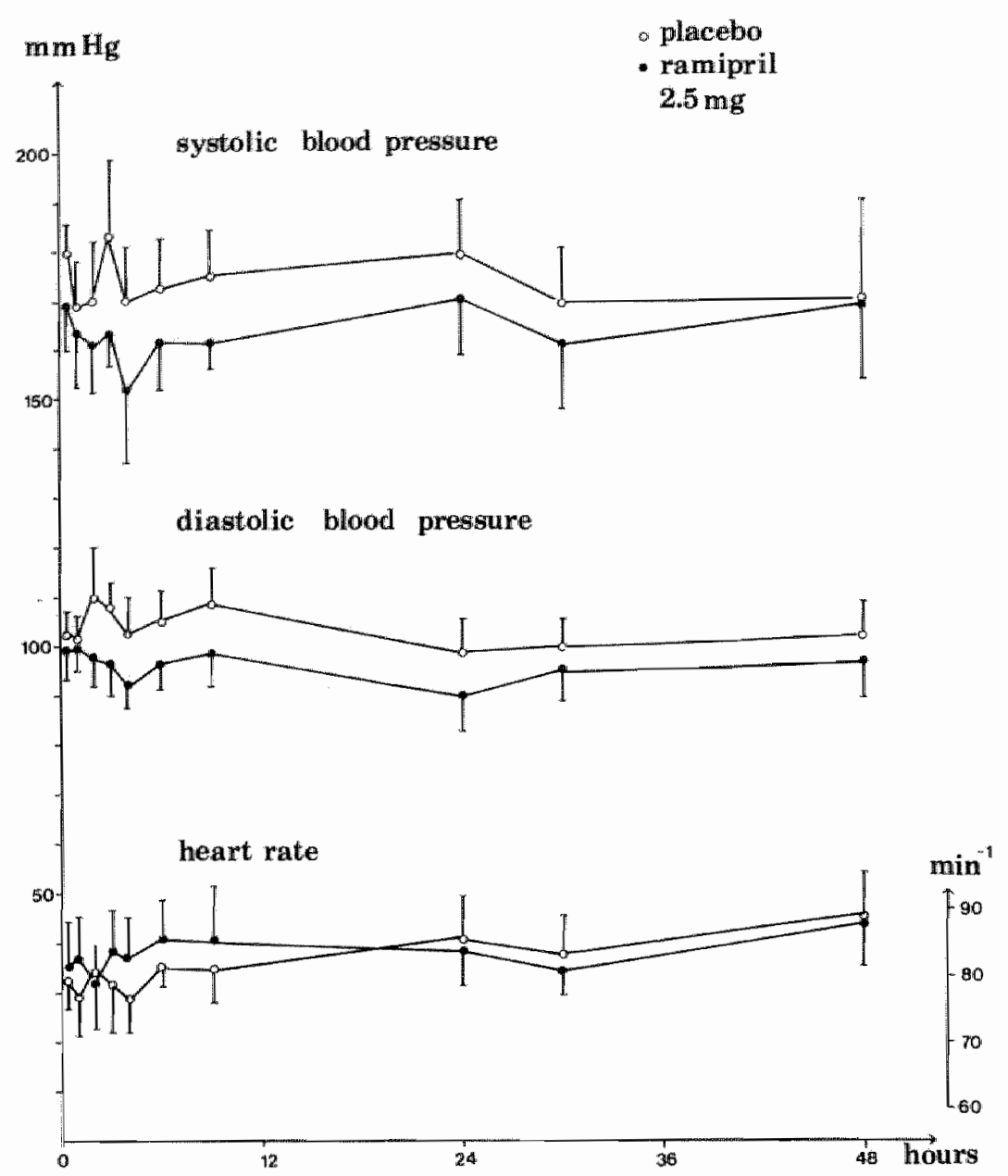

Flgure 1: Influence of $2.5 \mathrm{mg}$ ramiprt1 on standing blood pressure and heart rate in 6 patients with essential hypertension. Mean values $\pm S E M$ are given.

after dosing. In them, standing $B P$ was $182 \pm 15 / 95+4 \min \mathrm{Hg}$ prior to the drug. It was $163+7 / 90 \pm 3 \mathrm{~mm} \mathrm{Hg}$ after $12 \mathrm{~h}$, and $181 \pm 14 / 94 \pm 4 \mathrm{~mm} \mathrm{Hg}$ at 24 h. Ramipril $5 \mathrm{mg}$ also lowered suplne systolic and diastollc $\mathrm{BP}$ (p< 0.001). The time course was comparable to that described for standing BP.

6.4 .2 Influence of ramfprt1 on plasma anglotensin converting enzyme (ACE) activity, plasma renin activity (PRA) and plasma aldosterone

Single oral dose of $2.5 \mathrm{mg}$ and $5 \mathrm{mg}$ ramipril affected plasma 

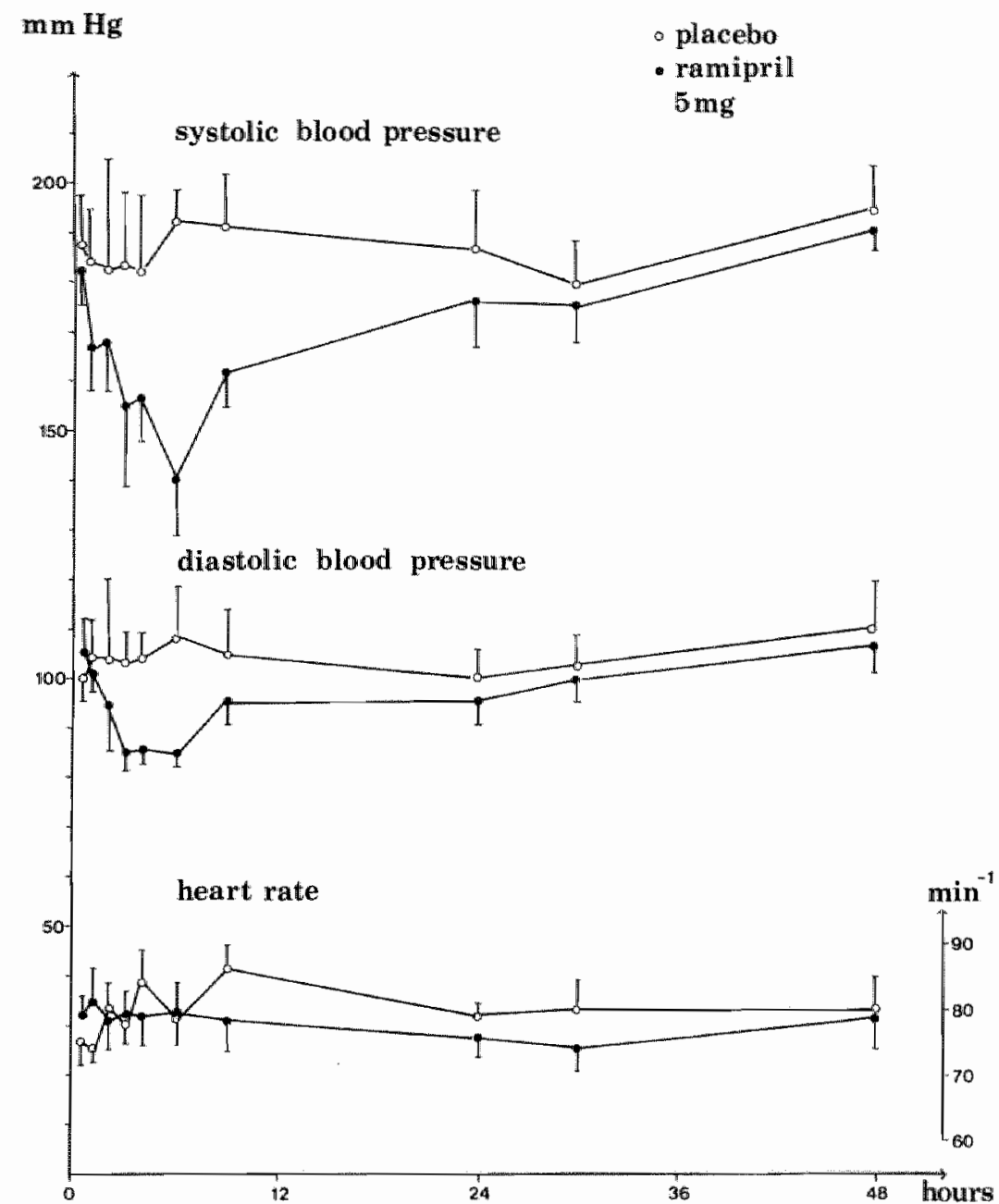

Figure 2: Influence of $5 \mathrm{mg}$ ramipril on standing blood pressure and heart rate in 5 patients with essential hypertension. Mean values \pm SEM are given.

ACE-activity (Fig. 3). It significantly ( $<0.001$, analysis of variance) lowered plasma ACE-activity compared to placebo. The effect was more pronounced with the $5 \mathrm{mg}$ than with the $2.5 \mathrm{mg}$ dose. The maximal. fall in ACE-activity occurred 1.5-9 hours after ramipril; the decrease was $96+0.1 \% 3 \mathrm{~h}$ after $2.5 \mathrm{mg}$ and $98 \pm 0.01 \% 3 \mathrm{~h}$ after $5 \mathrm{mg}$ of the drug. Thereafter, ACE-activity began to rise slowly.

Bath doses increased PRA (Table 1), but the change was signiflcant only $6 \mathrm{~h}$ after the $5 \mathrm{mg}$ dose. Plasma aldosterone was not altered by $2.5 \mathrm{mg}$, whereas $1 \mathrm{t}$ fell after the $5 \mathrm{mg}$ dose (Table 1 ). 

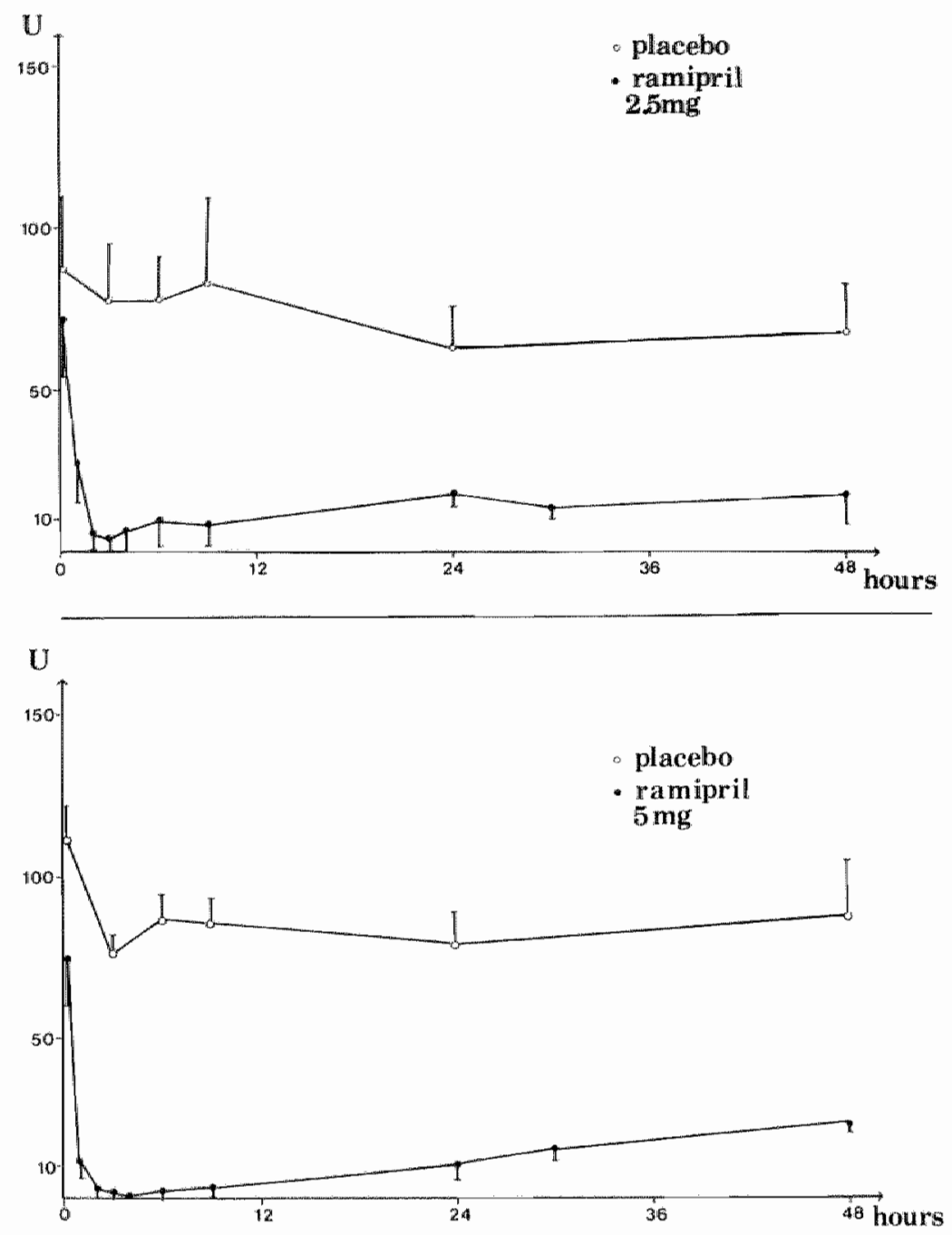

Plgure 3: Influence of ramipril on plasma angiotensin converting enzyme activity. Upper pane1: effect of $2.5 \mathrm{mg}$ ramipri1 orally In 4 patients with essential hypertension. Lower pane1: effect of $5 \mathrm{mg}$ ranipril orally in 5 patients. Mean values \pm SEM are glven. Absclssa: time after application of the drug $1 \mathrm{n}$ hours. Ordinate: plasma anglotensin converting enzyme activity in unts.

Urinary sodium excretion by the patients averaged $129+30$ mol// day. Neither dose of ramipril affected it. Ramipril also did not alter the urinary excretion of creatinine or potassium. 
Table 1: Influence of a single oral dose of ramipril on plasma renin activity (PRA) and plasma aldosterone levels.

Time after dose (h)
2.5 mg ramipri1 PRA $(\mathrm{ng} A \mathrm{M} / \mathrm{mI} \cdot \mathrm{h})$
Aldos te rone $(\mathrm{ng} / \mathrm{ml})$

\author{
5.0 mg ranipril \\ PRA \\ (ng AI/mI.h) \\ Aldosterone \\ ( $\mathrm{ng} / \mathrm{m} \mathbb{1})$
}

$\begin{array}{lllll}0 & 0.7 \pm 0.2 & 111 \pm 9.5 & 2.0 \pm 0.6 & 141 \pm 21.0 \\ 3 & 1.7 \pm 0.4 * & 120 \pm 10.3 & 3.3 \pm 0.6 & 84 \pm 19.1 * \\ 6 & 2.2 \pm 0.6 * & 114 \pm 10.5 & 3.3 \pm 0.8 * & 86 \pm 10.8 * * \\ 9 & 1.8+0.5 * * & 107 \pm 3.5 & 2.3 \pm 0.7 & 84+13.1 * *\end{array}$

The data represent mean \pm SEM of $4(2.5 \mathrm{mg}$ ramipril) and $5(5 \mathrm{mg}$ ramipril) patients.

${ }^{*} \mathrm{p}<0.05 ; * \mathrm{p}<0.01$ when compared with values at time 0 (palred $t$-test).

rog ramipril. The effect on supine and standing BP 6 h after each Individual dose is shown in Table 2. This time was chosen as other studies had indicated that that was when the maximum hypotensive action occurred. The influence of ramipril on suptne BP was clearly dose-dependent in the dose-range studied. The effect of $7.5 \mathrm{mg}$ ramipril on standing BP was not more pronounced than that of $5 \mathrm{mg}$.

Three bypertensives were given increasing doses of $2.5 \mathrm{mg}, 5 \mathrm{mg}$, $7.5 \mathrm{mg}$ and $10 \mathrm{mg}$ ramiprt1; the effects on supine and standing systollc and dlastollc BP are listed in Table 3. Agaln, doses up to $7.5 \mathrm{mg}$ had an increasing effect on supine BP, but no further decrease occurred with $10 \mathrm{mg}$ ramipril. The maximum effect on standing BP in these patlents was already obtalned with the $5 \mathrm{mg}$ dose.

No dose of ranipril altered heart rate in the suplne or standing positions. The drug was well tolerated by all patients. The hematological parameters and the 11 ver and renal function tests did not change during treatment. The electrocardiogram was not affected. Body weight remained unaffected during treatment with rampri1. 
Table 2: Blood pressure lowering effect of $2.5 \mathrm{mg}, 5 \mathrm{mg}$ and $7.5 \mathrm{mg}$ ramipril in 4 patients 6 hours after application of the drug.

Dose

Decrease of supine $\mathrm{BP}$ (mm Hg)

$2.5 \mathrm{mg}$

$5 \mathrm{mg}$

$7.5 \mathrm{mg}$
$10+8 / 5+4$

$25+8 * * / 18+9 *$

$30+9 * * / 19+6 * *$
Decrease of standing BP (mm $\mathrm{Hg}$ )

$13+7 / 7+3 *$

$37+10 * * / 16+6 *$

$32+13 * / 15+7 *$

Data represent mean \pm SEM.

*p<0.05; **p<0.01 when compared with placebo values at 6 hours (palred t-test).

Table 3: Blood pressure lowering effect of $2.5 \mathrm{mg}, 5 \mathrm{mg}, 7.5 \mathrm{mg}$ and 10 mg ramipril in 3 patients 6 hours after application of the drug.

Dose

$\begin{array}{lll}\text { Decrease of } & \text { Decrease of } & \text { Decrease of } \\ \text { suptne } & \text { supine } & \text { standing } \\ \text { systollc BP } & \text { diastolic BP } & \text { bystollc BP }\end{array}$

Decrease of

systolle BP diastolle BP

Bystolle BP

standing

diastolic BP

$\begin{array}{llclc}2.5 \mathrm{mg} & 11 \pm 11 & 3 \pm 4 & 13 \pm 9 & 4 \pm 1 * * \\ 5 \mathrm{mg} & 18 \pm 4 * * & 12 \pm 8 & 29+8 * * & 11+4 * \\ 7.5 \mathrm{mg} & 23 \pm 9 * & 16 \pm 7 * & 20 \pm 5 * * & 8+3 * \\ 10 \mathrm{mg} & 17 \pm 5 * * & 10 \pm 5 & 19 \pm 3 * * & 12 \pm 6\end{array}$

SBP systollc blood pressure; DBP = diastollc blood pressure. Data represent mean + SEM.

${ }^{*} \mathrm{p}<0.05 ; * * \mathrm{p}<0.01$ when compared with placebo value at 6 hours (palred t-test). 


\subsection{DISCUSSION}

Captopril was the first orally active ACE-inhibitor avallable for therapeutic use. It has the rather short duration of action of 6-8 h (Heel et al., 1980; Johnston et al., 1984). Subsequently, attempts have been made to develop ACE-Inhibitors with a longer lasting antihypertensive effect. Ramipril causes prolonged plasma ACE-inhibition, a substantial effect still being present up to $72 \mathrm{~h}$ after a single dose in healthy subjects (Witte et al., 1984b, Bussien et al., 1985). An active metabolite is formed in vivo from the drug, which inhibits the angiotensin converting enzyme (Becker et al., 1984).

So far, there has been $1 i t t l e$ experience with ramipril in hypertensive patients. Felder and Witte (1984) showed that repeated admintstration led to some antihypertensive activity and the present study has demonstrated that single oral doses of ramiprill as compared to placebo defintively decreased supine and standing BP in patients with essential hypertension. Ramfpril $2.5 \mathrm{mg}$ had a slight hypotensive effect, and $5-10 \mathrm{mg}$ ramipril led to a substantial fall in $\mathrm{BP}$. In the few patients who received $10 \mathrm{mg}$ ramipril, the antihypertensive effect was not more pronounced than that of $7.5 \mathrm{mg}$. In a.ll the present patients, BP had been poorly controlled by other antihypertensive drugs. Considerable interindividual differences in the efficacy of ranipril as an antihypertensive agent were found. In some patients, a decrease in BP to below $140 / 90 \mathrm{~mm} \mathrm{Hg}$ followed $2.5 \mathrm{mg}$ ramipril, but in other hypertensives, this effect was not produced by the $10 \mathrm{mg}$ dose.

The antihypertensive effect of captopril and enalapril starts 1-2 hours after oral application of the drugs (Johnston et al., 1984 ; Riley et al., 1985). The duration of the hypotensive action $1.6-8 \mathrm{~h}$ with captopril (Heel et al., 1980; Johnston et al., 1984) and about 24 $h$ with enalapril (Ferguson et al., 1982; Johnston et all., 1983; Riley et al., 1985). In the present study, the antihypertensive effect of ramipril became apparent 1 h after swallowing the dose. The maximum antihypertensive effect was obtalned after $6 \mathrm{~h}$, and the BP was sill decreased after $12 \mathrm{~h}$. The $\mathrm{BP}$ had returned to $1 \mathrm{ts}$ pretreatment level 24 $h$ after the single dose of ramipril.

It significantly decreased plasma ACE-activity ith a time 
course in hypertensive patients comparable to that seen in nomotensives (Hitte et al., $1984 a, b$; Bussien et al. 1985; Manhern et al. 1985). The period of action of enalapril on plasma ACE-activity is Blulax (Jackson et al., 1982; Johnston et al., 1983). In cantrast, captopr11 hes a shorter effect on plasma ACE-activity (Waeber et al., 1980).

Rampri1 2.5 and $5 \mathrm{mg}$ here increased PRA in hypertensive patlents. Rampril $5 \mathrm{mg}$ decreased plasma aldosterone. Similar observations were made in nomotensive subjects (Witte et a1., 1984b; Manhem et a1., 1985). Captopril and enalapril also increase PRA and decrease plasma aldosterone in man (heel et al. . 1980; Johnston et a1., 1984; Riley et al., 1985).

Ramipril here did not alter the urinary excretion of "sodiun, potassium and creatinine in patients with essential hypertension. There was a simflar result when it and enalapril were given to normotensfve volunteers (Brunner et al., 1981; Shoback et al., 1983; WItte et al., 1984b), and to subjects with essential hypertension (Ferguson et al., 1982).

Ramipril 2.5-10 mg p.o. did not alter supine or standing HR in the hypertensive patients. Apparently, hypotensive doses of the drug do not cause reflex tachycardia. Similar findings have been reported wth captopril (Johnston et al., 1984) and enalapril (Riley et al., 1985).

In conclusion, the present study has shown that ramipril is an orally effective antihypertensive agent with a long duration of actian. 
Chapter 7

CONCLUDING REMARKS 
For obvicus reasons, it is difficult to define the earliest phase of essential hypertension. As was outlined in the introduction (chapter 1), wost patients present themselves at a time when essential hypertension is already established. However, at this moment secondary changes persist which make it extremely difficult to assess the possible role of the (hypothetical) inducing factor(s) which led to the symptom hypertension. Furthermore, patients with essential hypertension have been described to be a heterogeneous group, indicating that a mult tude of factors has been deslgnated to play a role in the etiology and the pathogenesis of essential hypertension (Hansson, 1983; Peart, 1983). Anticlpating the pathophysiologic changes in the course of hypertension, early phases of human essential hypertension have been studied with the alm of identifying mechanisms which could be held responsible for laitfation of hypertension. Normotensive offspring of hypertensive patients and subjects with borderline hypertension represent the most easily identifiable groups of future hypertensives, but not all of them develop hypertension as different studies have shown (Julius and Schork, 1971; Hedstrand and \&berg, 1975; Sasakawa et a1., 1983).

The study performed in the group of borderline hypertensive subjects and normotensive age-matched controls which is presented in chapter 2, can be descrlbed as quite unlque. In 1986, some subjects have been followed for 9 years already. Despite some voluntary and forced (hypertensive) drop-outs, still the majority of the subjects of both groups is interested in participating. Other longitudinal studies 1 in borderline hypertensive subjects are scarce and have reported years of follow-up ranging from 3 to 10 years (Jullus, 1977; Hedstrand and Rberg, 1975; Falkner et a1., 1981; Sasakawa et al., 1983; Ueda et al., 1983). However, in some studies the age of the investigated borderline subjects is conslderably higher than in our study (mean age 40 years in Ueda et al., 1983) or the studies differ in the definition of borderline hypertension (casual sitting blood pressure in Kubo et al., 1983). Kaplan and Lieberman (1982) proposed to label borderline hypertensive patients as clearly hypertensive. In contrast, during the 7 
years of follow-up in this study, the progression to hypertension occurred only in the minority of the subjects with borderline hypertension (19\%). This percentage confirms other reports and studies ( Iulius and Schork, 1971; Julius, 1977; Julius et a1., 1980; Julius and Hansson, 1983). This progression of borderline hypertenstion to essential hypertension underlines also that borderline hypertensive subJects could serve as a madel to study possible factors which could lead to essential hypertension. The phenomenon of blood pressure decrease was also seen in a number of borderline hypertensive subjects who became nomotensive. This is confirmed by other authors (Hedstrand and Aberg, 1975; Kubo et al., 1983; Sasakawa et al., 1983). It must be noted, however, that the factors causing spontaneous reversion towards nomal blood pressure levels have not been fully identified. Taken together, this shows that the group of borderline hypertensive subjects is rather heterogeneous as far as development of blood pressure Is concerned.

At rest, the heart rate is higher in subjects with borderline hypertension than in normotensive subjects; this was repeated1y reported by Julius et al. (1980), Julius and Hansson (1983) and confirmed in this study. As was described in chapter 3, the results support the assumption for a decreased parasympathetic tone at rest in subjects with borderline hypertensilon when compared to the normotensive subjects. This finding confirms the reduced parasympathetic tone in borderline hypertensive subjects reported by Julius et al. (1971a). Komer et al. (1973) found also in essential hypertensive patients a reduced parasympathetic influence on heart rate. "The "intrinstc" heart rate after complete cardiac block is the same in both nomotensive subjects and hypertensive patients, as was found by Jose and Taylor (1969). Thus, assuming that the action of the intrinsic pacemaker off the heart is comparable in normotensive and essential hypertensive subjects, no reports oppose this assumption, too, in borderline hypertension. In a study by Henquet et al. (1982), noradrenaline was infused intravenously in borderline hypertensive and normotensive subjects, the same population as described in chapter 2. It was found that less exogenous noradrenaline was required to induce a rise of systolic blood pressure by $10 \mathrm{~mm} H \mathrm{Hg}$ in the borderline hypertenstue 
subjects than in the nomotensive control subjects. It was concluded that an increased vascular responslveness was the cause for this finding. This tncreased reactivity in borderline hypertensive subjects was also found by Weldmann et al. (1980), in contrast to Kawano et al. (1982). Furthermore, structural vascular changes were described in young borderline hypertensive subjects by Takeshita and Mark (1983), Mark (1984) and Egan and Julius (1985), but the cause for these changeg is not clear. A higher sympathetic drive might also contribute to vascular hypertrophy. As was outlined in chapter 1, sympathetic nervous overactivity can lead to hypertension and plasma levels of noradrenaline at rest can be taken as an index of the overall activity of the sympathetic nerwous system, as was described by different authors (DeChampla1n, 1977; Weldmann, 1981; Agabiti-Rosei et al., 1983; Folkow et al., 1983; Goldstein et al., 1983a; Conway, 1984; Esler et al., 1985). Borderline hypertenslve subjects have been reported to have nomal resting plasma catecholamines (Jullus et al., 1980). This confirms the finding of the study in chapter 2 that plasma levels of noradrenaline at rest in borderline hypertensive subjects who stayed borderline hypertensive are not different from those in the normotensive control group. However, in the analysis of different studies by Goldstein and lake (1984) a part (26\%) of the analyzed borderline hypertensive groups had higher mean plasma noradrenallne levels than the groups with normotension. An explanation for the discrepant finding could be that some studles did and some studies did not measure plasma noradrenaline at a time close to hypertension. Furthermore, most of the studies are not set up to follow subjects during a longer period of time and the definition of borderline hypertension often includes labile hypertension.

Th1s longitudinal study (chapter 2) showed for the first time that consistently high plasma noradrenallne levels at rest were found in borderline hypertenslve subjects who developed definite hypertenston when compared to those age-matched subjects who stayed borderline hypertensive and the mormotenstve control subjects. However, plasma noradrenaline levels at rest in the borderline hypertensive subjects, whether consldered as a whole group or as the subgroup which stayed borderline hypertensive, were not different from the levels of plasma 
noradrenaline at rest in the normotensive controls. But blood pressure is not requilred to rise through high plasma noradrenaline levels, normal plasma noradrenaline levels could induce the blood pressure rise as wel1. One explanation is an enhanced vascular responsiveness on noradrenaline, as was shown in the borderline hypertensive subjects by Henquet et al. (1982). For the blood pressure rise no elevated plasma noradrenaline levels are needed. It cannot be excluded that increased vascular sensitivity despite normal noradrenaline levels at rest could explain the higher blood pressure in borderline hypertensive subjects when compared to normotensives. But local activity of the sympathetic nervous system could be increased as well, but is not reflected by and/or measured by overall elevated plasma noradrenaline levels. A selective activation of the sympathetic nervous system involving the heart and kidneys in essential hypertension is suggested by Esler et al. (1985). Due to similar responsilveness in cardiac receptors in borderline hypertensive and normotensive subjects as reported by Henquet et al. (1982), the higher heart rate at rest is most likely caused by the decrease of the parasympathetic tone. The exact cause for the elevated levels of plasma noradrenaline in those borderline hypertensive subjects whose levels were consistently elevated and who developed definitive hypertension is not clear, but suggests a sympathetic nerwous system overactivity, whether or not combined with adrenal overactivity. Maybe a gradual tncrease in sympathetic activity occurs during a longer time in borderline hypertenston and becomes measurable on $1 y$ in an advanced stage. An altered noradremaline clearance is less likely since no differences in age between the groups and subgroups exist and all had nomal 11 ver and kldney function.

As mentloned in the introduction, obesity could play tale in the development of hypertension. In the defintively hypertensive subjects (subgroup 4), the body mass Index was statistically significantly higher than in the normotensive subgroup 1 . There was no statistically significant difference between the borderline hypertensive and the definttively hypertenslve subgroup. However, it is unlikely that overwelght was the inducing factor for hypertension in all subjects of this subgroup 4. Two subjects were clearly obese at 
the time when excluded due to hypertension, whereas the body mass index of the others ranged from lean to overwelght and was comparable to the mean of the nornotensive and borderline hypertensive subgroups. As was described in Chapter 1.8 , studies of plasma catecholamine in obese and overwelght hypertensive subjects when compared with lean normo- and hypertensive subjects are not wholly conclusive. A possible role of the hyperinsulinemia, whether or not additional to an increased sympathetic nervous system activity, cannot be wholly excluded in the overweight subjects.

The levels of plasma renin activity at rest in the borderlime hypertensive subjects who became hypertensive only tended to be higher than in the group of borderline hypertenstve and normotensive subjects. The reason for this could be the small number of subjects in subgroup 4 which makes $1 t$ difficult to obtain statistical significance. Furthermore, levels of plasma renin activity depend upon more factors than upon the sympathetic nervous system only (Davis and Freeman, 1976).

During exercise, when the influence of the parasympathetic nervous systern is abolished, the differences in heart rate and levels of plasma noradrenaline between the borderline hypertensive and nomotensive subjects disappear. This finding confirms a study by Jullus et al. (1980) who report that plasma catecholamine levels in subjects with borderline hypertension do not behave differently during exercise when compared to normotensive subjects. ObvHously, exercise leads to an increased activity of the sympathetic nervous system and small changes found at rest are no longer detectable during exercise due to the strong hemodynamic and metabolic stimulit.

All in al1, the 1 increased index of the overall activity of the sympathetic nervous system supports the assumption of a sympathetic overactivity in those borderline hypertensive subjects who become definitively hypertensive. The precise mechanism(s) or the origin remalin to be identifled. Julius and Johnson (1985) reported evidence for a relation with stress in the early phase of essential hypertension (borderline). This hypothesis of an excessive sympathetic drive which induces hypertension does not exclude a genetic or an acquired e.g. envirommental origin, or other simultameous factors such as 
vascular defects (e.g. defects of the sodium pump), receptor changes at different sites or centrally mediated changes. It is intented to continue the study with the borderline hypertensive subjects and to perform further investigations.

\subsection{TREATMENT}

Beta blockers are prescribed in the treatment of mild hypertension, but the precise mechanism of their biood pressure lowering is not exactly known. It is generally accepted that their antihypertensive action depends upon competitive antagondsm of the beta-adrenoceptor. The effects of catecholamines at these beta receptors are attenuated. In the study presented in chapter 4 plasma noradrenaline levels tended to decrease at rest during long-term treatment with pindolol. The finding of decreased plasma noradrenaline levels at rest during long-term treatment with pindolol was also presented in an analysis of 17 different studies by Man in 't Veld and Schalekamp (1983). The beta blockers metoprolol and propranolol resulted in no consistent change of plasma noradrenaline at rest. It has been hypothesized that the difference in plasma noradrenaline concentratians between beta-blockers with and without ISA is due to differences in their hemodynamic effects. Beta blockers without ISA reduce cardiac output and resting liver blood flow. This reduction of hepatic blood flow leads to a reduction of catecholamine clearance (Esler et a1., 1981c). Thus, normal plasma noradrenaline levels during treatment wh beta blockers without ISA may reflect decreased catecholamine release from the sympathetic nerve endings. In contrast, during pindolol treatment no change in resting cardiac output and hepatic blood flow is found, which may explatn the reduced concentrations of plasma noradrenallne and confirms the hypothesis of reduced sympathetic activity during treatment with all types of beta blockers. However, our data during exercise do not correspond with this hypothesfs. The heart rate reduction during exercise was similar during all three beta blackers studied which suggests similar effects on cardlac output. Nevertheless, plasma noradrenaline concentrations still tended to be lower 
during plndolol than during propranolol and metoprolol treatment. Thus, reduced plasma noradrenaline levels appear to be spectfic for pindolol treatment. The mechanism of this phenomenon is not clear and needs further investigation.

Furthermore, the study presented in chapters 4 and 5 showed that mild hypertensive patients can benefit from the antihypertensive action of beta blockers at rest and in slituations of stress like phystcal exerctse in which blood pressure is increasing. The three beta blockers propranolol, metoprolol and pindolol, in the doses prescribed, had a comparable antihypertensive effect at rest during the treatment period of 6 months. The exercise induced increase of heart rate and blood pressure is attenuated by beta blockers through a blockade of cardiac beta-adrenoceptors, whereas the stroke volume stays unchanged or 1 is increased, the overall effect being a reduction in cardiac output (Pearson et al., 1979). The heart rate decrease and blood pressure lowering during exercise was comparable by all three beta blockers. It has been shown furthermore that beta blockers reduce exercise performance in hypertensive patients and in nomotensive subjects (for review, see Fellentus, 1983). However, the studies mentioned mostly investigated effects of beta blockers after acute or short-term treatment during maximal exercise. Long-term therapy and submaximal endurance (exercise) correspond more with actual situations in the datly life of essential hypertensive patients. This is the reason why this type of exercise was performed in this study. It has been further stated that non-selective beta blockers like propranalol result in more complalnts than beta, ${ }_{1}$ selective blockers 11 ke metopro101 (Fellenius, 1983). The results of the study in the chapters 4 and 5 show only a tendency of greater impairment of submaximal endurance tine durtng non-selective beta blockade than during beta -selective blockade. Furthermore, the results indicate no improvement of exercise endurance time during long-term therapy with beta blockers 1 n contrast to the clalm by Fellentus (1983) who states that the temporary rascular fatigue disappears as the therapy continues.

Durling exercise, several mechanlsins are thought to be the cause for the impalment during beta blocker therapy. The depression of cardiac output resulting in a reduced leg blood flow could play a 
role. Frisk-Holmberg et al. (1985) found a reduction in leg blood flow by $10 \%$ during atenolol treatment, but oxygen extraction by the working muscle was elevated and no impairment of oxygen uptake in the muscless was found. Another reason for the impalment of exercise performance is seen in the metabolic effects of beta blockers. It is a fact that during prolonged submaximal exercise, lipolysis plays an essential role in the energy supply of the skeletal muscle (Felig and Wahren, 1975; Juhlin-Dannfelt, 1982). The results of chapter 5 showed an inhibited lipolysis and indicated a more pronounced reductilon during

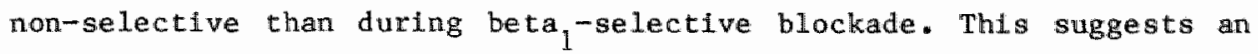
involvement of beta 2 -receptors in. lipolysis as well. This is confirmed by Juhlin-Dannfelt (1983) who reports both beta - and beta ${ }_{2}$-receptors with a predominance of beta ${ }_{1}$-receptors in adipocytes. Blood glucose levels were largely unaffected during exercise during treatment with the three beta blockers in the study performed (chapter 5), but an increased uptake by the working muscles because of a reduced supply of fat substrate may be compensated by an increased glucose output by the liver. Glucose levels measured during exercise are influenced by the intensity of exercise, the duration of the exercise, the beta blocker administered and the storage level of glycogen in the liver and skeletal muscle before exercise. These factors could explain partly the inconststent findings in literature. During prolonged exercise during beta blocker therapy, the decrease in cardiac output and the decrease in leg blood flow could also decrease the amount of substrate transported to the working muscles. Free fatty actds and glucose may be delivered in a lower amount than needed.

A third reason for the impaiment of exercise performance could. be the hyperkalemila during exercise. As was reported in chapter 5 , the hyperkalemila was more pronounced during non-selective than beta ${ }_{1}^{-}$ selective blockade. This was confirmed by others (Lundborg et al., 1983; Kullimer and Kindermann, 1985). Whether this rise in plasma potassium could result in changes of excitability in working muscles. and hereby increase muscular fatigue is not clear.

The metabolic changes were more pronounced during non-selective than during beta ${ }_{1}$-selective blockade. A tendency for a more pronounced impairment of endurance time during non-selective beta blockade was 
found. However, the difference was statistically not significant. But

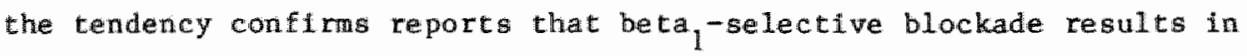
less Impalment of exercise than non-selective beta blockade (Fe1lenitu, 1983; Ople, 1985). Taken together, the results of chapter 5 suggest a lack of substrate avallability as a reason for the impalred endurance performance. It cannot be concluded that one speciflc factor Is the cause, it seems rather 11 kely that the complex interrelations of several factors have to be held responsible.

From the point of view of antihypertensive efficacy at rest and during exercise, these three beta blockers have proven their usefulness in patients wth wid hypertension. However, among their sideeffects ranges the Impairment of exercise performance and this could lint thelr use, espectally in younger and/or physically active patients durtig everyday activities. Limitation of occupational performance or lefsure time activity is netther needed nor desired. Being physically fit and performing endurance sports activities like running or blcycling has become a fashion and even a rage of late. Furthermore, the tmpalment of performance could have a negative effect on the compliance of the patient. Due to the limitation of physical performance durling treatment with beta blockers, other types of drugs could then be considered. As was recently shown in our group by Mooy et al. (1985), the calcium channel blocker verapamil, in contrast to propranolol, does not reduce submaximal endurance time in mild hypertensive patients. With the doses prescrubed, a comparable blood pressure decrease by both drugs was seen at rest and during exercise. So, calclum channel blockers could serve as an altemative in the treatment of mild hypertension in case stde-effects of beta blockers impair the petient's dally activities.

As was outlined in chapter 1 , the anglotensin converting enzyme inhibitors have been promoted already for monotherapy in mild to moderate essential hypertension. But captopril has a rather short duration of action which requires an intake of three times daily. Some side-effects are dose-dependent and Iimit its use. Therefore, the search for new anglotensin converting inhibltors was continued. The effects of single oral doses of the new anglotensin converting enzyme inhibitor ramipril have been studied in essential hypertensive pa- 
thents as described in chaper 6. Ramipril proved to be an effective anthypertensive agent when compared with placebo. The blood pressure lowering effect was obvious after single oral doges of 2.5 mig the effects of single oral doses of $5=10 \mathrm{mg}$ were mor pronounced. The antihypertensive effect was evaluated in patlents who were difficult to control by other antihypertensive drugs, e.g. diuretic and beta blocker and/or vasodilator. It seems that the effucacy can be at least with much caution, compared to that of enalaprll and captoprl. Salvett et al. (1985) reported in their review that emalapil and captopril had a comparable blood pressure lowering effect durthg chronic treatment as atenolol and chlorthalidone in patients with moderate essential hypertension. Effects of ramipril on parameters such as plasma renin activity, plasma aldosterone and anglotensin converting enzyme activity are largely comparable to those of captopril and enalapri1. Furthermore, the duration of the antihypertenstue action of a single dose of ramipril lasted for more than 12 hours. In comparison to the rather short-acting captopril, ramipril could have the advantage of the longer duration of the antihypettensive effect. This could mean an enhancement of compliance in patients during longterm therapy due to only once daily intake of the drug. No side-effects were reported after the single oral dose. No orthostatic hypotension was seen. The results presented in thisi study add important details about this new angiotensin converting enzyme inhibitor for further studies. Ramipril is a new drug which seems to be comparable to the other anglotensin converting enzyme inhibitors. It has antihypertensive effects and the advantage of a longer duration of action. However, the effects and the action of ramipril need confirmation and evaluation during further $10 \mathrm{~g}$-term studies.

In short, the studies presented in this thests have led to the following conclusions :

1. During 7 years of follow-up only a minority of borderilne hypertensive subjects became hypertensive. The group of borderilne hypertensive subjects who developed definitive hypertension had consistently high plasma noradrenaline levels at rest thoughout the observation period and as determined closest to the moment to 
exclusion because of hypertension than the group of normotensive subjects or the subjects who stayed borderline hypertensive. As a cause an oweractivity of the sympathetic nervous system is suggested. The results also support the assumption that at rest the parasymathetic influence on salivary glands is reduced in subfects wh borderline hypertension when compared to normotensive subjectsi *

2. Blood pressure at rest and during submaximal exercise 1 s lowered effectively during long-term treatment with the beta blockers propranolol, metoprolol and pindolol in patients with mild essential hypertension. During beta blockade submaximal exercise endurance time is impal red. The mechanism of reduced plasma noradrenaline levels at rest and during exercise during treatment with plndolol is not clear. Reduced substrate availability are suggested, among other factors, as a reason for impaiment of exercise endurance time during treatment with the beta blockers. The new anglotensin converting enzyme inhibltor ramipril lowers blood pressure effectively in patients with essential hypertension after single oral doses. Ramipril has an antihypertensive effect which lasts more than 12 hours. 
Chapter 8

LIST OF REFERENCES 


\section{LIST OF RERERENCES}

Abboud M. The sympathetic system in hypertension. Hypertension 4 (suppl II): 208-225, 1982 .

Abboud F. The sympathetic nervous system in hypertension. Ciln Exp Hypertens $46: 43-60,1984$.

Agabiti-Rosel $\mathrm{E}$, Allcandr1 C, Beschi M, Castellano M, Corea L, Beggi $P$, Motolese M, Mulesan G. Relationships between plasma catecholamines, renin, age and blood pressure in essential hypertension. Cardiology $70: 308-316,1983$.

Ahlquist RP. A study of the adrenotropic receptors. Am J Physiol 153 : $586-600,1948$.

Ambard Z, Beaujard E. Causes de 1 'hypertenston artérlelle. Arch Gén Med 1: $520-533,1904$.

Ames RP, H111 P. Antihypertensive therapy and the risk of coronary heart disease. J Cardiovasc Pharmacol 4 (suppl 2): 206-212, 1982.

Aol W, Kuramochi M, Hashiba K. Meurohumoral factors in borderline hyypertension. Jpn Circ J 47: 258-267, 1983.

Rstrand I. Aeroblc work capacity in men and women with special reference to age. Acta Physiol Scand 49 (suppl): 169, 1960.

Australlan Therapeutic Trial. The Autralian therapeutic trial in mild hypertension. Report by the management committee. The Lancet $\mathbb{1}$ (8181): $1261-1267,1980$.

Axelrod J, Weinshilboun R. Catecholamines. New Engl J Med 287: 237, 1972 .

Baak MA van, Struyker Boudier HAJ, Smits JFM. Antihypertensive mechanism of beta-adrenoceptor blockade: a review. Clin Exp Hypertens A 7: $1-72,1985$.

Becker RHA, Schölkens BA, Unger TH, Linz $W$. HOE 498: on orally active nonsulphydryl anglotensin-converting enzyme inhibitor. Naunyn Schmiedeberg's Arch Phamacol 324: R42, 1983.

Becker RHA, Schölkens BA, Metzger M, Schulze KJ. Pharmacological propertles of the new orally active anglotensin converting enzyme inhtbitor 2-(NI (S)-1-ethoxycarbony1-3-phenylpropy1]-L-alanyl]-(1S, $35,5 s)-2-a z a b i c y c 10$ [3.3.0] octane-3-carboxyl1c actd (HoE 498). Drug Res 34: $1411-1416,1984$.

Bengah H, Jackman G, Boblk A. Determination of plndolol in human plasma by high pressure liquid chromatography. I Chromatogr 183: $255-259,1980$.

Bergllund G, Wthelmsen $L$, We rkö L. Blood pressure development and characterlstics of subjects with moderate blood pressure elevation. Acta Med Scand 196: $301-306,1974$.

Bergllund 6 , Whelmsen L. Factors related to blood pressure in a general population of Swedish men. Acta Med Scand 198" 291-298, 1975.

Berglund $G$, Whelmsen L, Sannerstedt $R$, Hansson L, Andersson 0 , Sivertsion $R$, Wedel $H$, Wikstrand $J$. Coronary heart disease after treatment of hypertension. The Lancet 1 (8054): 1-5, 1978.

Berglund $G$. The role of salt in hypertension. Acta Med Scand 672 (supp1): 117-120, 1983.

Berglund $G$. Are we overtreating hypertenston? Acta Med Scand 216: $337-339,1984$. 
Berthelsen S, Pettinger WA. Functional basis for classification of alpha-adrenergic receptors. Life Sci 21: 595-606, 1977.

Beyer KH, Peuler JD. Hypertension: perspectives. Pharmacol Rev 34 : $287-313,1983$.

Blaustein MP. Sodium transport and hypertenston. Where are we going? Hypertension 6: 445-453, 1984.

Boehringer $k$, Beretta-Piccoll $C$, Weidmann $P$, Meier A, Ziegler W. Pressor factors and cardlovascular pressor responsiveness in lean and averwelght nomal or hypertensive subjects. Hypertension 4: $697-702,1982$.

Böhm R, Baak M van, Mooy J, Rahn KH. Studies of the antithypertensvie effect of the anglotensin converting enzyme inhibitor HOE 498 in man. Naunyn Schmiedeberg's Arch Pharmacol 330 (supp1): R47, 1985.

Böhm ROB, Arends BG, Hooff ME van, Rahn KH, Baak MA van. Chronic antihypertensive therapy with three different beta blockers: blood pressure and indices of sympathetic activity at rest and during exercise and the influence on submaximal exercise tolerance. Submitted for publication.

Boll1 P, Amann FW, Hulthén L, Kiowski W, Bühler FR. Elevated plasma adrenaline reflects sympathetic overactivity and enhanced alphaadrenoceptor mediated vasoconstriction in essential hypertension. C1in Sc1 51 (supp1 7): 161-164, 1981 .

Borst JGG, Borst-de Geus A. Hypertension explained by Staring's theory of circulatory homeostasis. The Lancet 1: 677-682, 1963 .

Brecht HM, Banthien $F$, Schoeppe $W$. Decrease in plasma noradrenaline levels following long-tern treatment with pindolol in patients with essential hypertension. K1in Wschr 54: 1095-1105, 1976.

Brody MJ. New developments in our knowledge of blood pressure regulation. Fed Proc 40:2257-2261, 1981.

Brooks McCC. Introduction: control of the autonomic nervous system and the multiple roles 1 t plays in regulating cardiovascular functions. $J$ Autonom Nerv Syst 4: 115-120, 1981.

Brown MJ, Causon RC, Bremnan P, Greenberg $G$. Adrenaline and noradrenaline excretion in placebo treated patients in the Medical Research Council Hypertension Trial and in matched nomotensive controls. J Hypertens 3 (suppl 3): $87-88,1985$.

Brummelen $\mathrm{p}$ van. The relevance of intrinsic sympathominetic activity for beta blocker induced changes in plasma liplds. J Cardiovasc Pharmacol 5 (suppl): $51-55,1983$.

Brumner HR, Laragh $J H$, Baer L, Newton MA, Goodwin Fid, Krakoff LR, Baro RH, Bihler FR. Essential hypertension: renin and aldosterone, heart attack and stroke. New Engl J Med 286: 441-449, 1972 .

Brunner HR, Gavras $H$, Waeber B, Kershaw GR, Turini AG, Vukovich RA, Mckinsky DN, Gavras J. Oral anglotensin converting enzyme lnhibitor in long-term treatment of hypertensive patients. Ann Int Med 90* $19-23,1979$.

Brunner DB, Desponds $G$, Biollaz J, Keller $T$, Eerber F, Gavras HJ, Brumer HR, Schelling JL. Effect of a new anglotensin converting enzyme inhibitor MK 421 and 1 ts lysine analogue on the components of the renin system in healthy subjects. Br $y$ clin Phamacol 11 : $461-467,1981$.

Bühler FR, Laragh $J$, Vaughan ED, Brunner HR, Gavras H, Baer L. Ant1hypertensive action of propranolol. Am J Cardiol 32:511-522, 1973. Bühler FR, Bolli $\mathrm{P}$, Erne $\mathrm{P}$, Kiowski $W$, Müller FB, Hult thén UL, $J I$ BH. 
Adrenoceptors, calcium, and vasoconstriction in normal and hypertensive humans. J Cardiovasc Pharmacol 7 (suppl 6): 130-136, 1985.

Bühlex FR. Pathophyslologie und Anwendung von Kalzium Antagonisten in der Hochdruck the raple. Theraplewoche $36: 1425-1430,1986$.

Bumstock $G$. Tholinergic, adrenerglc and purinergic neuromuscular transmission. Fed proc 36: 2434-2438, 1977.

Bussten JP, Nussberger $J$, Porchet $M$, Waeber B, Brumer HR, Perisic M, Tansey $M J K$, Botm $M$, Hadju $P$. The effect of the angiotensin converting enzyme inhibitor HOE 498 on the renin-angiotensin-aldosterone system in normal volunteers. Nauny Schmiedeberg's Arch Phamacol $329: 63-69,1985$.

Chaix RL, Dimitriu VM, Wagniart PR, Safar ME. A simple exercise test in borderline and sustained essential hypertension. Int $J$ Cardiol 1: $371-382,1982$.

Chalmers JP, Blessing WW, West MJ, Howe PRC, Costa M, Fumess JB. Inportance of new catecholamine pathways in control of blood pressure. C1in Exp Hypertens A3: 393-416, 1981.

Chalmers JP, West MJ. The nervous system in the pathogenesis of hypertension. In: Handbook of hypertension. Clinical aspects of essentlal hypertension (ed: Robertson JIS). Elsevier, Amsterdam, 64-96, 1983.

Chasiotis D, Brandt $R$, Harris RC. Effects of beta blockade on glycogen metabolism in human subjects during exercise. Am J Physiol 245: $\mathrm{E} 166-\mathrm{E} 170,1983$.

Christensen $\mathbb{N J}$, Galbo H, Hansen JF, Hesse B, Richter A, Trap-Jensen $J$. Catecholamines and exercise. Diabetes 28 (supp1 1): 58-62, 1979.

Christensen NJ. The role of the autonomic nervous system in borderline and mild hypertension. Acta Med Scand 686 (suppl): 35-40, 1984 .

Conway $J$. Hemodynamlc aspects of essential hypertension. Physiol Rev 64: $617-660,1984$.

Corvol L, Galen FX, Devaux C, Ménard J. Blochemical characteristics of human and animal renin. In: Hypertension (eds: Genest J, Kuchel 0 , Hamet $P$, Cantin M). McGraw Hi11, New York, 184-193, 1983.

Cost11 DL, Branam G, Fink W, Nelson R. Exercise-induced sodium conservation: changes in plasma renin and aldosterone. Med Sci Sports $8: 209-213,1976$.

Cousineau $\mathrm{D}$, DeChamplain $\mathrm{J}$, Lapointe $\mathrm{L}$. Clrculating catecholamines and systolic time intervals in labile and sustalned hypertenston. Cli Scl and Mo1 Med 55 (supp1 4): 65-68, 1978.

Cowley AW. The concept of autoregulation of total blood flow and its role in hypertension. An J Med 68: 906-916, 1980.

Cruz-Coke R. Genetlc aspects of essential hypertension. In: Clinical aspects of essential hypertension (ed: Robertson JIS). Elsevier, Amsterdam, 21-29, 1983.

Cryet PE. Physlology and pathophysiology of the human sympatho-adrenal neuro-endocrine system. New Engl J Med 303: 436-444, 1980 .

Dampney RAL. Functional organization of central cardiovascular pathways. C11n Exp Pharmacol Physiol 8: 241-259, 1981.

Davidson L, VanDongen R, Belilin LJ, Arkwright PD. Free and sulfate conjugated catecholamines during exercise in man. J Ciln Endocrinol Me tab 58: $415-418,1984$.

Davles Ro, Irvin JD, Kramsch DK, Walker JE, Moncloa F. Enalapril worldwide experience. Am J Med 77 (suppl): 23-35, 1984.

Davis JO, Freeman RH. Mechanlsms regulating renin release. Physiol Rev 
56: $1-56,1976$.

Dawber TR, Kannel WB. Current status of coronary prevention. Prev Med 1: $499-512,1972$.

Deboden A, Inagami T, Ganten D. Tissue renin. In: Hypertension (eds: Genest $J$, Kuchel 0 , Hamet $P$, Cantin M). McGraw Hi11, New York, $194-209,1983$.

DeChamplain J. The sympathet1c system in hypertension. Clin Endocrinol Metab 6: 633-655, 1977 .

DeChamplain $J$, Cousineau $D$, Ameringen $M-R$ van, Marc-Aurele $J$. The role of the sympathetic nervous system in experimental and human hypertension. Postgrad Med I 53 (supp1 3): 15-30, 1977.

DeChamplain $J$, Cousineau D, Lapointe L. Evidences supporting an increased sympathetic tone and reactivity in a subgroup of patients with essential hypertension. Clin Exp Hypertens A2: 359-377, 1980 .

DeChamplain $J$, Cousineau D, Lapointe L, Laval16e M, Nadeau R, Denis $G$. Sympathetic abnormalities in human hypertension. Clin Exp Hypertens A3: 417-430, $1981 \mathrm{a}$.

DeChamplain $J$, Nadeau RA, Lavallée M, Denis G. Autononic dysfunctions in human hypertension. Hypertension 3 (suppl II): $124-128,19816$.

Dequattro V, Chan $S$. Raised plasma catecholamines in some patients with primary hypertemsion. The Lancet 1 (7755): 806-809, 1972.

Dequattro $V$, Hamad $R$. The role of stress and the sympathettc nervous system in hypertension and ischemic heart disease: advantage of therapy with beta-receptor blockers. Clin Exp Hypertens A7: 907$932,1985$.

Dimsdale JE, Hartley HL, Guiney T, Ruskin IN, Greenbllatt D. Postexercise peril. JAMA 251: 630-632, 1984.

Dollery CT, Davies DS, Draffan GH, Dargie HJ, Dean CR. Clinical pharmacology and pharmacokinetics of clonidine. Clin pharmacol Ther 19 : $11-17,1976$.

Dominlak P, Grobecker H. Elevated plasma catecholamines in young hypertensive and hyperkinetic patients: effect of pindolol. Br $\mathrm{J}$ Clin Pharmacol 13 (suppl 2): 381-390, 1982.

Doyle AE. Morbidity and mortality in hypertension. Drugs 11 (suppl 1 ): $25-27,1975$.

Doyle AE. Future directions in mild hypertension research. In: Mild Hypertension (eds: Gross F, Strasser T). Raven Press, New York, $389-392,1983$.

Drayer JJM, Weber MA, Laragh JH, Sealey JE. Renin subgroups in esgential hypertension. Ciln Exp Hypertens A4: 1817-1834, 1982 .

Dustan HP. Physiologic regulation of arterlal pressure. Hypertension 4 (suppl III): $62-67,1982$.

Dustan HP. Mechanisms of hypertenston with obesity. Amm Intern Med 98 (part 2): $860-864,1983$.

Eckberg DL. Carotid baroreflex function in young men with borderline blood pressure elevation. Circulation 59: 632-636, 1979.

Edis AJ, Shepherd JT. Autonomic control of the peripheral vascular system. Arch Int Med 125: 716, 1970.

Egan B, Jullus $S$. Vascular hypertrophy in borderline hypertension: relationship to blood pressure and sympathetic drive. Clin Exp Hypertens A7: $243-255,1985$.

Eliasson K, Hjemdah1 P, Kahan T. CArculatory and sympatho-adrenal responses to stress in borderline and established hypertension. I Hypertens 1: 131-139, 1983. 
Ellasson $K$. Borderline hypertension: Circulatory, sympatho-adrenal and psychological reactions to stress. Acta Med Scand 692 (suppl): 190,1984 .

Eliasson $K$, Hjemdah1 $P$, Wahan $T$. Circulatory and sympatho-adrenal responses to stress in borderline and established hypertension. I Hypertens 3 (suppl 4): $11-17,1985$.

Engelinan $K$, Portnoy $B$. A siensitive double-isotope derivative assay for norepinephrlne and epinephrine: nomal resting human plasma levels. Circ Res 26: 53-57, 1970 .

Epstein FH. The epidemiology of essential hypertension. In: Handbook of hypertension. Clinical aspects of essential hypertenstion (ed: Robertson JIS). Elsevier, Amsterdam, $1-21,1983$.

Esler MD, Julius $S$, Randall $O T, E I 11 \mathrm{~S} C N$, Kashima $T$. Relation of renin status to neurogenic vascular resistance in borderline hypertension. Am J Cardiol 36: 708, 1975.

Esler M, Julius $S$, Zweifler A, Randall O, Harburg E, Gardiner H, Dequattro $V$. Mild high renin essential hypertension, neurogenic human hypertension? New Engl J Med 296: 405-411, 1977a.

Esler M, Zwelfler A, Randali $O$, Julius $S$, DeQuattro V. Agreement among three different indices of sympathetic nervous systen activity in essential hypertension. Mayo Clin Proc 52: 379-382, $1977 \mathrm{~b}$.

Esler M, Skews $\mathbb{H}$, Lenonard $P$, Jackman $G$, Bobik A, Korner $\mathbb{P}$. Age dependence in noradrenaline kinetics in nomal subjects. Clin Sci 60 : 217-219, 1981a.

Esler M, Jackman $G$, Bobik A, Leonard $P$, Kelleher $D$, Skews $H$, Jennings $G$, Komer P. Norepinephrine kinetics in essential hypertension. Defectlve neuronal uptake of norepinephrine in some patients. Hypertension 3: 149-156, $1981 \mathrm{~b}$.

Esler M, Jackman $G$, Leonard $P$, Skews H, Bobik A, Jennings $G$. Effect of propranolol on noradrenaline kinetics in patients with essentilal hypertension. Br J Clin Pharmacol 12: 275-280, 1981C.

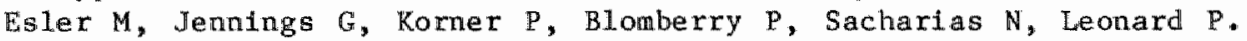
Measurement of total and organ-specific epinephrine kinetics in humans. Am J Physio1 247: E21-E28, 1984a.

Esler MD, Jennings GL, Johns J, Burke F, Little PJ, Leonard P. Estimation of "total" renal, cardiac and splanchnic sympathetic mervous tone in essential hypertension from measurements of noradrenaline release. J Hypertens 2 (supp1 3): 123-125, $1984 \mathrm{~b}$.

Esler M, Hasklng GJ, Willett TR, Leonard PW, Jennings GL. Noradrenaline release and sympathetic nervous system activity. J Hypertens 3: $117-129,1985$.

Furopean Working Party on High Blood Pressure in the Elderly Trial. Mortality and morbidity results. The Lancet 1 (8442): 1349-1354, 1985.

Falkner B, Kushner $H$, Onesti $G$, Angelakos ET. Cardiovascular characteristics in adolescents who develop essential hypertension. Hypertension 3: $521-527,1981$.

Felder $K$, Witte PU. Effects of the new oral anglotensin converting enzyme inhibitor 2-[N-[(S)-1-ethoxycarbonyl-3-phenylpropyl]-L-alanyl]-(1S,3S,5s)-2-azabicyc10[3.3.0] octane-3-carboxyl1c acid (HOE 498) in essential hypertension. Drug Res 34 (II, 10b): 1452-1454, 1984.

Felig P, Wahren J. Fuel homeostasis in exercise. New Engl J Med 21: $1078-1084 * 1975$. 
Fellenius $\mathrm{E}$. Muscle fatigue and beta blockers - a rewlew. Int I Sports Med 4: 1-8, 1983.

Ferguson RK, Vlasses $\mathrm{PH}$, Swanson BN, Mofaverian P, Hichens M, Irvin JD, Huber PB. Effects of enalapril, a new converting enzyme inhibitor in hypertension. Clin Phamcol Ther 32:48-53, 1982.

Floras JS, Hassan MO, Vann Jones J, Sleight P. Cardioselective and nonselective beta-adrenoceptor blocking drugs in hypertension: a comparison of thel $r$ effect on blood pressure during mental and physical activity. J Am Coll Cardiol 6: 186-195, 1985.

Folkow B. Physlological aspects of primary hypertension. Physiol Rev $62: 348-504,1982$.

Folkow B, DiBona GF, Hjendahl P, Thorén PH, Wallin BG. Measurements of plasma norepinephrine concentrations in human primary hypertension. A word of caution on their applicability for assessing neurogenic contributions. Hypertension $5: 399-403,1983$.

Frank E. Bestehen Beziehungen zwischen dem chromaffinmen System und der chronischen Hypertonie der Menschen? Ein kritischer Beftrag zu der Lehre von der playsio-pathologischen Bedeutung des Adrenalins. Dtsch Arch Klin Med 103: 397, 1911.

Franz $\mathbb{I}-W$. Untersuchungen über das Blutdruckverhalten während und nach Ergometrie bei Grenzwerthypertonikem in Vergleich $z u$ Nomalpersonen und Patienten mit stabiler Hypertonie. $Z$ Kardiol 68: 107-115, 1979.

Franz I-W (ed). Ergonetrie bei Hochdruckkranken. Springer Verlag, BerIin-Heidelberg-New York, 54-66, 1982.

Franz I-W. Assessment of blood pressure response during ergometric work in normotensive and hypertensive patients. Acta Med Scand 670 (supp1): $35-47,1983$.

Franz I-W. Ergometry in the assessment of arterial hypertension. Cardiology $72: 147-159,1985$.

Franz I-W, Lohmann FW. Der Einfluss einer chronischen sog. kardioselektiven und nichtkardloselektiven beta-Rezeptoren-Blockade auf den Blutdruck, die 0 -Aufnahme und den Kohlenhydratstoffwechsel. $Z$ Kardiol 68: 503-509, 1979.

Franz I-W, Lohmann FW, Koch G. Differential effects of long-tern cardloselectlve and non-selective beta-receptor blockade on plasma catecholamines during and after physical exercise in hypertensive patients. I Cardiovasc Pharmacol 2: 35-44, 1980.

Franz I-W, Lohmann FW, Koch G. Effects of chrondic anthypertentwe treatment with acebutolol and pindolol on blood pressures, plasma catecholamines and oxygen uptake at rest and during submaximal and maximal exercise. J Cardiovasc Pharmacol 4: 180-186, 1982 .

Franz I-W, Lohmann FW, Koch $G$, Quabbe H-J. Aspects of hormonal regulation of lipolysis during exercise: effects of chronic beta-receptor blockade. Int J Sports Med 4: 14-20, 1983.

Freeman RH, Davis Jo. Factors controlling renin secretion and metabolism. In: Hypertension (eds: Genest J, Kuche1 0 , Hanet $P$, Cantin M). MeGraw Hi11, New York, 225-249, 1983.

Freis ED. Salt volume and the prevention of hypertension. Circulation 53 : $589-595,1976$.

Frelis ED. Should mild hypertension be treated? New Engl J Med 307 : $306-309,1982$.

Frels ED. Hypertension: intelal treatment. J Cardiovasc Pharmacol 7 (supp1 1): $112-116,1983$. 
Frisk-Holmberg M, Jorfeldt L, Juhlin-Dannfelt A. Influence of alpreno101 on hemodynamic and metabolic responses to prolonged exercise in subjects with hypertension. Clin Pharmaco1 Ther 21: 675-684, 1977.

Frtsk-Holmberg M, Jorfeldt L, Juhlin-Danfelt A, Karlsson J. Metabollc changes in muscle on long-term alprenolol therapy. Clin Phamacol Ther 26: $566-571,1979$.

Erisk-Holmberg M, Jorfeldt $L$, Juhlin-Dannfe1t A. Metabolic effects in muscle during antihypertensive therapy with beta - and beta $/$ beta $_{2}$ adrenoceptor blockers. Clin Pharmacol Ther 30:611-618, 1981 .

Irik-Holmberg M, Juhlin-Dannfe1t A, Rström H. Hemodynamic and metabo$11 \mathrm{c}$ responses to prolonged exercise after chronlc beta-adrenoceptor blockade in hypertensive man. Clin Physiol 5: 231-242, 1985.

Frohlich ED, Kozul WJ, Tarazi RC. Physiological comparison of labile and essential hypertension. Clic Res 46 (suppl I): 55-69, 1970.

Frohlfch ED. The adrenergic nervous system and hypertension. Mayo Clin Proc 52: $361-368,1977$.

Frohllch ED, Cooper RA, Lewis EJ. Revlew of the overal1 experience of captopril in hypertension. Arch Int Med 144: 1441-1444, 1984.

Fujita $\mathrm{T}$, Henry WL, Bartter $\mathrm{FC}$, Lak $\mathrm{CR}$, Delea CS. Factors 1 influencing blood pressure in salt sensitive patients with hypertension. Am J Med 69: $334-344,1980$.

Galbo H, Holst JJ, Christensen NJ, Hilsted J. Glucagon and plasma catecholamines during beta-receptor blockade in exercising man. J Appl Physiol 40: 855-863, 1976.

Ganten D, Dietz R, Schömig A, Schölkens B, Bönner G. Early biochemical changes in hypertension. In: Mild hypertension (eds: Gross F, Strasser T). Raven Press, New York, 277-292, 1983.

Gavras $J$, Gawras $H$, Tifft $C h$, Kershaw GR, Bresnahan $M$. Effect of pindolol on blood pressure, plasma renin activity and catecholamines in hypertensive patients. J Clin Pharmaco1 21: 79-83, 1981.

Goldstein DS. Plasma catecholamines and essential hypertension - an analytical review. Hypertension $5: 86-99,1983$.

Goldstein DS, McCarty R, Polinsky RJ, Kopin JJ. Relationship between plasma norepinephrine and sympathetic neural activity. Hypertension 5; $552-559,1983 a$.

Goldsteln DS, Lake CR, Chernow B, Zlegler MG, Coleman MD, Taylor AA, MLtchell JR, Kopln JJ, Kelser HR. Age dependence of hypertenslvenormotensive differences in plasma norepinephrine. Hypertension 5: $100-104,1983 b$.

Goldstein DS, Lake R. Plasma norepinephrine and epinephrine levels in essentlal hypertension. Fed Proc 43: 57-61, 1984.

Gordon T. Blond pressure of adults by age and sex, United states 1960-1962. National Center for Health Statistics. Public Health Service Publication no. 1000, Series 11, no. 4, Washington DC, 1964.

Graefe KH, Henseling $M$. Neuronal and extraneuronal uptake and metabo1 ism of catecholamines. Gen Pharmacol 14: 27-33, 1983.

Guyton AC (ed). Textbook of medical physiology. WB Saunders, Philadelphila, 1981a.

Guytion AC. The relationship of cardiac output and arterial pressure control. Circulation 64: 1079-1088, 1981b.

Guyton AC, Hall JE, Lohmeier TE, Jackson TE, Kastner PR. Blood pressure regulation: basilc concepts. Fed Proc 40: 2252-2256, 1981.

Haber $E$, Carlson $W$. The blochemistry of the renin-anglotensin system. 
In: Hypertension (eds: Genest $J$, Kuchel 0 , Hamet $P$, Cantin $M$ ). McGraw H11, Wew York, 171-183, 1983 .

Halperin AK, Cubeddu LX. The role of calciun channel blockers in the treatment of hypertension. Am Heart J 111: 363-382, 1986.

Hansson $B-G$, Dymling $J-F$, Hedeland $H$, Hulthén VL. Long-tern treatment of moderate hypertenston with the beta, -receptor blocking agent netoprolol. I. Effect on maximal working capacity, plasma catecholamines and renin, urinary aldosterone, blood pressure and pulse rate under basal conditions. Eur I Clin Pharmacol 11: 239-245, $1977 \mathrm{a}$.

Hansson $B-G$, Dymlin J-F, Maukem P, Hökfelt $B$. Long-term treatment of moderate hypertension with the beta-receptor blocking agent metoprolol. II. Effect of submaximal work and insulin-induced hypoglycemia on plasma catecholamines and renin activity, blood pressure and pulse rate. Eur J Clin Pharmacol 11: 247-254, 1977b.

Hansson E, Eriksson BO, Sivertsson R. Baroreceptor reflexes after coarctectomy. Clin Physiol 1: 503-509, 1981.

Hansson L. Is mild hypertension an irreversible condition? In: Mild hypertension (Eds: Gross F, Strasser T). Raven Press, New York, $209-218,1983$.

Harlan WR, Hull AL, Schmouder RL, Landis RJ, Thompson FE, Larkin FA. Blood pressure and nutrition in adults. The National Health and Nutrition Examination Study. Am J Epidemiol 120: 17-28, 1984.

Hedberg A. Adrenergic receptors. Methods of determination and mechanilsms of regulation. Acta Med Scand 672 (supp1): 7-15, 1983.

Heel RC, Brogden RN, Speight TM, Avery GS. Captopri1: a preliminary review of its pharmacological properties and therapeutic efficacy. Drugs $20: 409-452,1980$.

Hedstrand H, \&berg H. A 3-year follow-up of middle-aged men with borderline blood pressure. Acta Med Scand 198: 389-395, 1975.

Helgeland A. Treatment of mild hypertension: a five year controlled drug trial (The 0slo Study). An J Med 69: 725-732, 1980.

Henquet JW. Het autonome zenuwstelsel bij borderline hypertensie. Thesis, Maastricht, 1980 .

Henquet $J W$, Kho $T$, Schols M, Thijssen H, Rahn KH. The gympathetlic nervous system and the remin-anglotensin system in borderifne hypertension. Clin Sic1 60: 25-31, 1981.

Henquet JW, Baak M van, Schols M, Rahn KH. Studies on the autonomic nervous system in borderline hypertension. Eur $J$ Clin phamacol 22 : $285-288,1982$.

Hiton PJ. Cellular sodilum transport in essential hypertenstion. New Eng 1 J Med 314: 222-229, 1986.

Hofman A, Valkenburg HA. Een epidemiologisch onderzoek naar risikoindikatoren voor hart- en vaatziekten (EPOZ). II. Voorkomen, opsporing en behandeling van hypertenste in een open bevolking. Ned Tijdschr Geneeskd 124: 189-195, 1980 .

Hökfelt T, Fuxe K, Goldstein M, Johansson 0 . Immunohistochemical evidence for the existence of adrenaline neurones in the rat brain. Brain Res 66: 235,1974 .

Hollander $W$. Role of hypertenstion in atherosclerosis and cardiovascular disease. Am J Cardiol 38: 786-800, 1976.

Holloszy Jo. Muscle metabolism during exercise. Arch Phys Med Rehabil 63: $231-234,1982$.

Hooff M van, Baak M van, Schols M, Rahn KH. Studies of salivary flow 
in borderline hypertension: effects of drugs acting on structures innervated by the autonomic nervous system. Clin Scl 66:599-604, $1984 \mathrm{a}$.

Hooff MEJ van, Rahn KH, Baak MA van. Effects of acute and chronic administration of propranolol during submaximal exercise in essential hypertension. Int J Sports Med 5 (supp1): 186-188, 1984b.

Horan MJ, Kennedy HL, Padgett NE. Do borderline hypertensive patients have labile blood pressure? Ann Intern Med 94: 466-468, 1981.

Houston MC. Sodium and hypertenstion. A review. Arch Int Med 146 : $179-185,1986$.

Hyman D, Kaplan M. Treatment of patients with mild hypertension. Hypertension $7: 165-170,1985$.

Hypertenstion Detection and Follow-up Program Cooperative Group (HDFP). Circ Res 40 (supp1 I): $106-109,1977$.

Hypertension Detection and Follow-up Program (HDFP). Five year findings of the HDEP. 1. Reduction in mortality of persons with high blood pressure, including mild hypertension. JAMA 242: 2562-2571, 1979.

Ibsen H. Borderline and mild hypertension - definitions and prevaLence. Acta Med Scand 686 (suppl): 7-9, 1984.

Iimura 0 , Kikuchi $K$, Salto $S$. Plasma noradrenaline concentration and pressor response to infused noradrenaline in patients with brorderline hypertension, and mild or moderate essential hypertension. Jpn Circ J 48: 159-167, 1984

Insel PA. Identiflcation and regulation of adrenergic receptors in target cells. Am J physiol 247: E53-E58, 1984.

Izzo JL. The sympatho-adrenal system in the maintenance of elevated arterlal pressure. J Cardilovase Pharmacol 6 (suppl 3): 514-521, 1984.

Jackson AS, Squires WG, Grimes $G$, Beard EF. Prediction of future resting hypertension from exercise blood pressure. J Cardiac Rehab 3: $263-268,1983$.

Jackson B, McGrath BP, Johnston CI. Correlation between angiotensin converting enzyme inhibition and the acute hypotensive response to MK 421 in essential hypertension. Clin Exp Pharmacol Physiol suppl $7: 99-104,1982$.

Johnson JG, Mulrhead EE. Vascular complications of the hypertensive state. In: Hypertension update (eds: Hunt JC, Cooper T, Bloomfleld $\mathrm{NJ})$. Health Leaming Systems, Bloomfield, 38-51, 1980.

Johnston $\mathrm{LC}$. The abnomal heart rate response to a deep breath in borderline labile hypertension: a sign of autonomic nervous system dysfunction. Am Heart J 99: 487-493, 1980 .

Johnston CI, Jackson B, McGrath B, Mathews G, Arnolda L. Relationship of antihypertensive effect of enalapril to serum MK 422 levels and anglotensin converting enzyme lnhibition. J Hypertens 1 (suppl 1 ): $71-75,1983$.

Johnston CI, Arnolda L, Hiwatari M. Anglatensin converting enzyme inhibitors in the treatment of hypertension. Drugs $27: 271-277$, 1984.

Joint National Comittee. Hypertension prevalence and the status of awareness, treatment and control in the United States. Hypertension $7: 457-468,1985$.

Jones DH, Hamilton CA, Reld JL. Cholce of control groups in the appraisal of sympathetic nervous activity in essential hypertension. 
Clin Sci $57: 339-344,1979$.

Jose AD, Taylor RR. Autonomic blockade by propranolol and atropine to study intrinsic myocardial function in man. J Clin Invest 48: 2019, 1969 .

Juhlin-Dannfelt A. Metabolic effects of beta-adrenoceptor blockade on skeletal muscie at rest and during exercise. Acta Med Scand 665 (supp1): $113-115,1982$.

Juhlin-Dannfelt A. Beta-adrenoceptor blockade and exercise : effects on endurance and physical training. Acta Med Scand 672 (suppl): 49-54, 1983.

Julius $S$, Conway $J$. Hemodynamla studies in patients with borderline hypertension. Crculation $38: 282-288,1968$.

Julius S, Schork MA. Borderline hypertension - a critical review. J Chron Dis 23: 723-754, 1971.

Julius $S$, Pascual AV, London $R$. Role of parasymathetic inhibition in the hyperkinetic type of borderline hypertension. Clrculation 44: 413-418, $1971 \mathrm{a}$.

Julius S, Pascual AV, Sannerstedt R, Mitche1l Ch. Relationshlp between cardiac output and peripheral resistance in borderline hypertension. Circulation 43: $382-390,1971$ b.

Iulius S, Pascual AV, Reilly K, London R. Abnormalteles of plasma volume in borderline hypertension. Arch Intern Med 127: 116-119, $1971 \mathrm{c}$.

Julius S, Hansson L. Hemodynamics of prehypertension and hypertension. Verh Dtsch Ges Inn Med 80: 49-58, 1974.

Jullus $S$, Esler $M$. Autonomic nervous cardiovascular regulation in borderline hypertension. Am J Cardiol 36: 685-696, 1975.

Jullus S, Randa11 0, Esler M, Kashima T, Ellis C, Bennett J. Altered cardiac responsiveness and regulation in the normal cardiac output type of borderline hypertension. Circ Res 36-37 (supp1 I): 199-207, 1975.

Julius $s$. Neurogenic component in borderline hypertension. In: The nervous system in arterial hypertension (eds: Julius S, Esler MD). CC Thomas, Springfield, 1976.

Julius S. Borderline hypertension - an overview. Med Clin North America $61: 495-511,1977$.

Julius S, Hansson L, Andrén, L Gudbrandsson T, Sivertason R, Svensson A. Borderline hypertenston. Acta Med Scand 208: 481-489, 1980.

Julius S, Hansson NL. Classification of hypertension. In: Hypertenslon (eds: Genest J, Kuchel o, Hamet P, Cantin M). McGraw Hill, New York, 679-683, 1983.

Jullus $S$, Weder AB, Egan BM. Pathophyslology of early hypertension: implication in epidemiological research. In: Mild hypertension (eds: Gross F, Strasser T). Raven Press, New York, 219-236, 1983.

Julius $S$, Johnson EH. Stress, autonomic hyperactivity and essential hypertension: an enfgma. I Hypertens $3($ suppl 4): 11-17, 1985.

Kaiser P, Rössner S, Karlsson J. Effects of beta-adrenerglc blockade on endurance and short-time performance in respect to individual muscle fiber composition. Int $J$ sports Med 2: 37-42, 1981 .

Kaiser P, Tesich PA. Effects of acute beta-adrenergic blockade on blood and muscle lactate concentration during submaximal exerclse. Int $J$ Sports Med 4: $275-277,1983$.

Kaiser P, Tesch PA, Thorsson J, Karlsson J, Kayser L. Skeletal muscle glycolysis during submaximal exercise following acute beta-adrener- 
glc blockade in man. Acta Physiol Scand 123: 285-291, 1985.

Kannel WB, Schwartz MJ, McNamara PM. Blood pressure and the risk of coronary heart disease: the Framingham study. Dis Chest 56: 43 , 1969.

Kanne1 WB. Role of blood pressure in cardiovascular morbidity and mortal1ty. Frogr Cardiovasc Dis $17: 5-24,1974$.

Kaplan NM, Lieberman $E$ (eds). Clinical hypertension. Williams and Wilkins, Baltimore, 1982.

Kaplan WM. The rapy for mild hypertension. JAMA 249: 365-367, 1983.

Katz A, Sahlin, $k$, Juhlln-Dannfelt A. Effect of beta-adrenoceptor blockade on $\mathrm{H}^{+}$and $\mathrm{K}^{+}$flux in exercising humans. I Appl Physiol 59: $336-341,1985$

Kawano Y, Fukiyama $K$, Takeya Y, Abe I, Omae T. Elevated plasma catecholamines without alteration in cardlovascular responsiveness in young men with borderline hypertension. Am Heart J 104: 1351-1356, 1982 .

Keil $U$, Dörring $A$, Stieber $J$. Communtty studies in the Federal Republic of Germany. In: Mild hypertension (eds: Gross F, Strasser T). Raven Press, New York, 63-84, 1983.

Keil U, Remmers A, Chamblers L, Hense HW, Hörtel U, Preuss KJ, Lauck A. Prevalence, awareness, treatment and control of hypertension 1 in Lïbeck. Results of the Lübeck blood pressure study (LBS, 1984). Hochdruck $6: 36,1985$.

Kelly J, o'Malley K. Adrenoceptor function and aging. Clin Sc1 66: $509-515,1984$.

Kindermann $W$, Scheerer $W$, Salas-Fraire $O$, Biro $G$, Wölfing A. Verhalten der körperlichen Lelstungsfahlgkelt und des Metabolismus unter akuter Beta - und Beta $/ 2$-Blockade. Z Kardiol 73: 380-387, 1984.

Kollai M, Koizuni $K$. Cardfovascular reflexes and interrelationships between sympathetic and parasympathetic activity. J Autonom Nerv Syst 4: 135-140, 1981 .

Korner PI, Shaw J, Uther JB, West MJ, McRltchie RJ, Rlchards JG. Autonomic and non-autonomic circulatory components in essential hypertension in man. Circulation 48: 107-117, 1973.

Korner PI. The present status of the autoregulation theory of the pathogenests of hypertenston. Clin Exp Pharmacol Physiol 7: 521$526,1980$.

Komer PL. The central nervous system and its operation in cardiovascular control. Clin Exp Hypertens A3: 343-368, 1981.

korner PT. The pathogenesis of hypertension: the Baker concerto. Clin Exp Hypertens A6: 565-586, 1984.

Kostis JB, DeFelice EA. The hemodynamic effects of pindolol. Cur Ther Res 33: 494-511, 1983.

Kosunen $\mathrm{KJ}$, Pekarinen $\mathrm{AJ}$. Plasma renln, angiotensin II, and plasma and urinary aldosterone in running exercise. J Appl Physiol 41: 26-29, 1976 .

Kotchen TA, Hartley LH, Mougey EH, Jones LG, Mason JW. Ren1n, norep1nephrine, and epinephrine responses to graded exercise. J Appl Phystol 31: 178-184, 1971 .

Kubo 5 . Predictors of future established hypertension and diurnal blood pressure variablitty in borderline hypertension. Jpn Circ J $47: 207-220,1983$.

Kubo SH, Cody RJ. Clinical phamacokinetics of the anglotensin converting enzyme inhibitors. C1in Phamacokin 10: 377-391, 1985. 
Kuchel 0 . The autonomic nervous system and blood pressure regulation In human hypertension. In: Hypertension (eds: Genest $J$, Kuchel 0 , Hamet P, Cantin M). McGraw Hil1, New York, 140-160, 1983.

Kullmer $T$, Kindermann $W$. Physical performance and serum potassium under chronic beta blockade. Eur J Appl Physiol 0ccup Physiol 54: $350-354,1985$.

Lake CR, Ziegler MG, Kopin IJ. Age-adjusted plasma noreplnephrine lewels are similar in normotensive and hypertensive subjects. New Engl J Med 296: 208-209, 1977.

Lancet Editorial. Blood pressure control at home and in hospital. The Lancet 1 (8065): 645-646, 1978 .

Lancet Editorial. Why does blood pressure rise with age? "The Lancet 1 $(8241): 289-290,1981$.

Lands AM, Arnolds A, McAuliff JP, Luduena FP, Brown TG. Differentation of receptor systems activated by sympathominetic amines. Nature $214: 597-598,1967$.

Langer $S 2$. Presynaptic regulation of catecholanine release. Biochem Pharmacol 23: 1793-1800, 1974 .

Laragh $J H$. Vasoconstriction volume analysis for understanding and treating hypertension: the use of renin and aldosterone profiles. Am I Med 55: 261-274, 1973.

Laustiola K, Uusitalo A, Kolvula T, Sovijärvi A. Divergent effects of atenolol, practolol and propranolol on the pertpheral metabollc changes induced by dynamic exercise in healthy men. Eur I Clln Pharmacol 25: 293-297, 1983.

Lavallée M, DeChamplain J, Nadeau RA, Yamaguchi N. Muscarinic inhtbition of endogenous myocardial catecholamine liberation in the dog. Can J Physiol Phamacol 56: 642, 1978.

Leenen FH, Coenen CHM, Zonderland $M$, Maas AHJ. Effects of cardioselective and nonselective beta-blockade on dynamic exercise performance in mildly hypertensive men. Clin Pharmacol Ther 28: 12-21, 1980.

Leenen FHH, Boer P, Dorhout Mees EJ. Antihypertensive effect of propranolol at rest and during exercise. Br J Clin Pharmacol 15: $361-365,1983$.

Lehmann $M$, Keul $J$, Wybitul $K$, Fisher H. Auswirkung eliner selektiven und nichtselektiven Adrenozeptorblockade wahrend körperarbelt auf den Energiestoffwechsel und das sympathoadrenerge Systen. Drug Reg 32 : $261-266,1982$.

Lees M. A hitch-hiker's guide to the galaxy of adrenoceptors. Br Med. J 283: 173-178, 1981.

Lefkowitz RJ. Direct binding studies of adrenergic receptors: biochemical, physlologlcal and clinical implications. Ann Intern Med 91: $450-458,1979$.

Lever AF, Beretta-Piccoll C, Brown $J J$, Davles DL, Fraser R, Robertson JIS. Sodium and potassium in essential hypertension. Br Med J 283: $463-468,1981$.

Levinson PD. Khatri IM, Freis $E D$. Persistence of normal blood pressure after withdrawal of drug treatment in mid hypertenstion. Arch Intern Med 142: 2265-2268, 1982.

Levitzki $A$. The beta-adrenerglc receptor and its mode of coupling to adenylate cyclase. CRC Crit Rev Bilochem 10: 81-112, 1981 .

Levy MN, Blattberg B. Effect of vagal stimulation on the overflow of norepinephrine into the coronary sinus during cardiac symathetic 
nerve stimulation. Circ Res $38: 81,1976$.

Levy RI, Moskowltz J. Cardiovascular research: a decade of progress, a decade of promise. Science 217: 121-129, 1982.

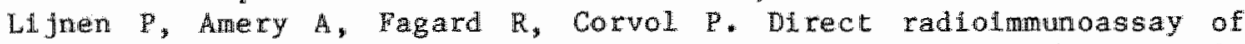
plasma aldosterone in nomal subjects. Clin Chin Acta 84: 305-314, 1978.

Lijnen PU, Amery AK, Fagard RH, Reybrouck $\mathrm{T}$. The effects of betaadrenoreceptor blockade on renin, anglotensin, aldosterone and catecholamines at rest and during exercise. Br J Clin Pharmacol 7: $175-181,1979$.

Lohmann FW. Die Beetnflussung des Stoffwechsels durch Beta-Rezeptoren-Blocker. KIIn Wschr 59:49-57, 1981 .

Louis WJ, Doyle AE, Anavekar SN, Johnston CI, Geffen LB, Rush R. Plasna catecholanine, dopanine-beta-hydroxylase, and renin levels in essential hypertension. Circ Res 341 (supp1 1): 57-61, 1974.

Lucas CP, Estigarribla JA, Derga LL, Reaven GM. Insulin and blood pressure in obesity. Hypertension 7: 702-706, 1985.

Lundborg $P$. The effects of adrenergic blockade on potassium concentrations in different conditions. Acta Med Scand 672 (suppl): 121$125,1983$.

Lundborg P. Aström H. Bengtsson C, Fellenius E, Schenck H von, Svensson L, Smith U. Effect of beta-adrenoceptor blockade on exercise performance and metabolism. C11n Sci 61: 299-305, 1981 .

Lund-Johansen $P$. Central hemodynamic effects of beta blockers in hypertension. A comparison between atenolol, metoprolol, timolol, penbutalol, alprenolol, pindolol and bunitrolol. Eur Heart $J 4$ (supp1 D): $1-12,1983$.

Lund-Johansen P. The hemodynamic pattern in mild and borderline hypertension. Acta Med Scand 686 (supp1): 15-21, 1984.

McAlister NFA. Should we treat "mlld" hypertension ? JAMA 249: 379-382, 1983.

MacDonald $\mathbb{L}$, Bennett $T$, Brown AM, Wilcox, RG, Skene AM. The effects of acute or chronic ingestion of propranolol or metoprolol on the metabolic and hornonal responses to prolonged, submaximal exercise in hypertensive men. Br J Clin Phamacol 17* 283-293, 1984.

McFate-Smith W. Treatment of mild hypertension. Circ Res 40 (suppl I): 98-105, 1977.

MeGrath JC. The variety of vascular alpha-adrenoceptors. Trends Pharmacol Scl $4: 14-18,1983$.

Mallnoff $P B$, Wolfe $B B$, Weiland GA. Quantitative analysis of drug receptor interactions. II. Deterninations of the properties of receptor subtypes. Life Sci $29: 427-443,1981$.

Malmejac J. Activity of the adrenal medulla and its regulation. Physiol Rev 44: 186-218, 1964.

Mancia G, Ferrarl A, Gregorini L, Parati G, Pomidossi G, Bertinieri G, Grassi G, DiRlenzo M, Pedotti A, Zanchetti A. Blood pressure and heart rate variabilities in normotensive and hypertensive human belngs. Cire Res 53: 96-104, 1983.

Manhem PJO, Ball SG, Morton JJ, Murray GO, Leckie BJ, Fraser R, Robertson JIS. A dose-response study of HOE 498, a new non-sulphydryl converting enzyme inibitor on blood pressure, pulse rate and the renin-anglotensin-aldosterone system in normal man. Br J Clin Pharmaco1 $20: 27-35,1985$.

Man in 't Veld AJ, Schalekamp MADH. Hemodynamic consequences of In- 
trinsic sympathomimetic activity in relation to changes in plasma, renin activity and noradrenaline during beta blocker therapy for hypertension. Postgrad Med J 59 (supp1 3): 140-158, 1983.

Man in "t Veld AJ. Betablokkers bij hypertensie. Hart Bulletin 16 (supp1): $5-10,1985$.

Mark AL. Structural changes in resistance and capacitance vessels in borderline hypertension. Hypertension 6(suppl 3): 69-73, 1984.

Medical Research Counct1 Working Party (MRC) trial of treatment of mild hypertension. The MRC trial: principal results. Br Med J 291: $97-104,1985$.

Mellander $S$, Johansson $B$. Control of resistance, exchange and capacitance functions in the peripheral circulation. Phamacol Rev 20: $117-196,1968$.

Memorandum WHO/ISH Meeting. Guldelines for the treatment of mild hy pertension. Hypertension 5: $394-397,1983$.

Ménard J, Degoulet P, Chatellier G, Corvol P. The assessment, investigation and care of the hypertensive patient. In: Handbook of hypertension. Clinical aspects of essential hypertension (ed: Robertson JIS). Elsevier, Amsterdam, 493-502, 1983.

Messerli FH, Frohlich ED, Suarez DH, Reisin E, Dreslinski GR, Dunn FG, Cole FE. Borderline hypertension: relationship between age, hemodynamics and circulating catecholamines. Circulation 64: 760-764, 1981 .

Messerl1 FH, Ventura HO, Reisin E, Dreslinski GR, Dunn FG, MacPhee AA, Frohlich ED. Borderline hypertension and obesity: Two prehypertensive states with elevated cardiac output. Circulation 66: 55-60, 1982 .

Metropolitan L1fe Insurance Company. Blood pressure: insurance expertence and its implications. Metropolitan life Insurance Co., New York, 1961.

Metropolitan Life Insurance Company. Statist Bu11 50: 1, 1969.

Miall WE, Love11 HG. Relation between change of blood pressure and age. Br Med J 2: 660, 1967.

Miall WE, Greenberg G, Brennan PJ. The medical research council's treatment trial for mild hypertension: a progress report. In: Mild hypertension (eds: Gross F, Strasser T). Raven Press, New York, $293-306,1983$.

Millar-Cralg MW, Bishop CN, Raftery EB. Circadian variation of blood pressure. The Lancet 1 (8068): $795-797,1978$.

Miura $Y$, Kobayashi $K$, Tomioka $M$, Adachi $M$, Yoshinaga K. Plasma noradrenaline concentrations and hemodynamics in the early stage of essential hypertension. Clin Sci Mol Med 55 (suppl 4): 69-71, 1978 .

Modan $M$, Halkin $H, A l m o g ~ S$, Lusky A, Eshkol A, Shefi M, Shttrib A, Fuchs $Z$. Hyperinsulinemia, a link between hypertension obestey and glucose intolexance. J Clin Invest 75: 809-817, 1985.

Mooy J, Böhm R, Petri H, Kemenade J van, Baak M van, Rahn KA. Fuxercise tolerance in hypertensive patients during treatment with verapamil and propranolo1. Naunyn Schmledeberg's Arch Pharmacol 332 (suppl): $\mathrm{R} 98,1986$.

Morgan $T$, Meyers $J$, Carney $S$. The evidence that salt is an important aetlological agent; if not the cause, of hypertension. Clin Sici 57 (suppl 5): 459-462, 1979.

Mörlin C. Wallin BG, Eriksson BM. Muscle sympathetlc activity and plasma noradrenaline in normotensive and hypertensive man. Acta 
Phystol scand 119: 117-121, 1983.

Morrison SC, Kumana CR, Rudnick KV, Haynes $B$, Jones NL. Selective and nonselective beta-adrenoceptor blockade in hypertension: responses to changes in posture, cold, and exercise. Circulation 65: 1171$1177,1982$.

Moser M. A decade of progress in the management of hypertension. Hypertension. 5: 808-813, 1983 .

Motulsky. MJ, Insel. PA. Adrenergic receptors in man. Direct identification, physlological regulation, and clinical alterations. New Engl. $J$ Med 307: 18-29, 1982.

Nahorski SR. Identifciation and significance of beta-adrenoceptor subtypes. Trends Pharmacol Sc1 2: 95-98, 1981.

NHS, National Center for health statistics. Blood pressure of adults. Serles 11: 4 and 5, Washington, 1964.

N1lsson A, Hansson B-G, Hokfelt B. Effect of metoprolol on blood glycerol, free fatty acids, triglycerides and glucose in relation to plasma catecholamines in hypertensive patients at rest and following submaximal work. Eur J Clin Pharmacol 13: 5-8, 1978.

O'Brien E, Fitzgerald D, O'Malley $\mathrm{K}$. Blood pressure measurement: current practice and future trends. Br Med J 290: 729-734, 1985.

Ohlsson 0, Henningsen NC, Malmquist I. Blood pressure, heart rate and plasma albumin in relatives of hypertensive patients. Acta Med Scand 209: 445-450, $198 \mathrm{\perp}$.

Ondett1 MA, Cushman DW. Anglotensin converting enzyme inhibitors: biochemical properties and biological actions. CRC Blochem 16: $381-411,1984$.

Opie LH. Effect of beta-adrenerglc blockade on biochemical and metabolic response to exercise. Am J Cardiol 55: 95D-100D, 1985.

Ostfeld A, Paul $O$. The inheritance of hypertension. The Lancet 3 : $575-579,1963$.

Ost1 RM, Trombini G, Magnani B. Stress and distress in essential. hypertension. Psychother Psychosom 33: 193-197, 1980.

Page LB, Dantion A, Moellering RC. Antecedents of cardiovascular disease in $\mathrm{s} 1 \mathrm{x}$. Solomon Island socleties. Circulation 49: 1132-1146, 1974 .

Page LB. Epldemlologic evidence on the etiology of human hypertension and 1ts possible prevention. An Heart J 91: 527-534, 1976 .

Page LB. Epldemiology of hypertension. In: Hypertension (eds: Genest $\mathrm{J}$, Kuchel O, Hamet P, Cantin M). McGraw Hill, Mew York, 683-699, 1983.

Pearson SB, Banks DC, Patrick JM. The effect of beta-adrenoceptor blockade on factors affecting exerclse tolerance in normal man. Br J Clin Phamacol 8: 143-148, 1979.

Peart WS. The problem of trement in mild hypertenston. Clin Sci 61 (supp1): $403-4 \mathbb{1}, 1981$.

Peart WS. General review of hypertenslon. In: Hypertension (eds: Genest J, Kuchel 0 , Hamet $P$, Cantin M). McGraw Hill, New York, $3-14,1983$.

Pedersen EB. Some aspects of kidney function, the renin-aldosterone system and sympathetic actlwity. Acta Med Scand 636 (suppl): 1-67, 1979.

pedersen EB, Christensen NJ. Catecholamines in plasma and urine in patients with essentlal hypertension deternined by double-isotope derivate techniques. Acta Med Scand 198: 373-377, 1975. 
Plckering G. Hyperpeisis: high blood pressure thout evident cause. Br Med J 2: 959, 1965.

Pickering G. Hypertension. Definitions, matural histories and consequences. Am J Med 52: 570-583, 1972.

Pickering TG. Treatment of mild hypertension and the reduction of cardiovascular mortality: The "of or by" dilemma. JAMA 249: 399$400,1983$.

Planz G, Gierlichs HW, Hawlina A, Planz R, Stephany W, Ratu KH. A comparison of catecholamine concentrations and dopamine-beta-hydroxylase activitles in plasma from nomotensive subjects and from patients with essential hypertension at rest and during exercise. Klin Wschr $54: 561-565,1976$.

Platt $\mathbb{R}$. Heredtty in hypertension. The Lancet 1: 899, 1963 .

Pohoreky LA, Wurtmann RJ. Adrenocortical control of eplnephrine synthesis. Pharmacol Res 23: 1, 1971.

The Pooling Project Research Group: Relationshlp of blood pressure, serum cholesterol, smoking hablt, relative weight and ECG abnomalities to incidence of major coronary events: final report about the Pooling project. J Chron Dis 31: 201, 1978.

Prineas RJ, Stephens WB, Lovell RRH. Blood pressure and its treatment in the community: the Albury blood pressure study. Med I Austr 1: $5,1973$.

Rahn KH, Gierlichs HW, Planz G, Planz R, Schols M, Stephany W. Studies on the effects of propranolol on plasma catechollamine levels in patients with essential hypertension. Eur J Clin Invest 8: 143-148, 1978.

Rahn $\mathrm{kH}$. The influence of beta-receptor blocking drugs on plasma catecholamine levels in patients with essential hypertension. Arch Int phamacodyn Ther suppi: $54-57,1980$.

Rahn KH, Baak M van, Hooff $M$ van, Schols M. Studies on salivary flow in borderline hypertension. J Hypertens 1 (suppl 2): 77-78, 1983.

Rand M.J, Majewski $\mathrm{H}$. Adrenaline mediates a positive feedback loop in noradrenergic transmission: its possible role in development of hypertension. Clln Exp Hypertens $A 6: 347-370,1984$.

Rapp JP. Genetics of experimental and human hypertenstion. In: Hypertension. (eds: Genest J, kuchel 0 , Hamet $P$, Cantin M). McGraw H11, New York, 582-598, 1983.

Rasmussen PH, Staats BA, Discroll DJ, Beck KC, Bonekat HW, Wilcox WD. Direct and indirect blood pressure during exercise. Chest 87 : $743-748,1985$.

Ribelro $A B$, Kohlmann 0 , Saragoca MAS, Marson 0 , Ramos OL. The renlnanglotensin system in the control of systemic arterial pressure. Drugs 30 (suppi 1): $6-12,1985$.

Riley LJ, Vlasses PH, Ferguson RK. Clinical phamacology and therapeutlc applications of the new oral converting enzyme lahlbitor enalapri1. Am Heart $J$ 109: 1085-1089, 1985.

Roberts J. Blood pressure levels of persons $6-74$ years. DHEW Publ No (HRA) 78-1648: 203, 1977 .

Robertson D, Shand DG, Hollifield JW, Nies AS, Fröllch JC, Oates JA. Alterations in the responses of the sympathetic nervous system and rentn in borderline hypertension. Hypertension 1: 118-124, 1979.

Robinson BF, Epstein SE, Beiser GD, Braunwald E. Control of heart rate by the autonomic nervous system. Studies in man on the Interrelation between baroreceptor mechanisms and exercise. C1rc Res 19: 
$400-411,1966$.

Roth JA, Rivett. J. Does sulfate conjugation contribute to the metabolic Inactivation of catecholamines in humans? Biochem Pharmacol 31 : $3017-3021,1982$.

Rowland $M$, Roberts J. Blood pressure levels and hypertension in persons ages 6-74 years in the United states 1978-1980. Hyattsullle M.D. National Center for Health Statistics. Advance data from vital and health statistics no 84 . DHHS publication no (PHS) 82$1250,1982$.

Rubin PC, Scott PJW, McLean $K$, Reld JL. Noradrenaline release and clearance 1 ri relation to age and blood pressure in man. Eur J Clin Invest $12: 121-125,1982$.

Ryan JW, Chung A, Amons $C$, Carlton ML. A simple radioassay for angiotensin converting enzyme. Biochem J 167: 501-504, 1977.

Salto $T$. Hemodyramics and baroreflex function in borderline hypertension. Jpn Circ J $47: 221-229,1983$.

Saito J, Takeshlta E, Saruta T, Nagano S, Sekihara T. Plasma prolactin, renin and catecholamines in young normotensive and borderline hypertensive subjects. J Hypertens 2: 61-64, 1984.

Salvetcl A, Pedrinelli R, Arzilli F, Hag-Abdel B. Angiotensin converting enzyme inhibitors in hypertension: a review. Int $J$ Clin Pharmacol Res 5: 429-438, 1985.

Sambhi MP. Prorenin and activators and inhibitors of renin. In: Hypertension (eds: Genest $J$, Kuchel 0 , Hamet $P$, Cantin M). McGraw Hill, New York, $210-224,1983$.

Sasakawa 0 , Fujli $\$$, Naji 0 , Shimura M, Tsumura $k$, Seki $\mathfrak{J}$, Wada M, Kobata D. A study of long-term observations in borderline hypertension. Jpn Circ J 47: 303-308, 1983.

Schalekamp MADH. Naar een rationele therapie. Hart Bul1 16 (suppl): $33-36,1985$.

Schneyer LH, Young JA, Schneyer ChA. Salivary secretion of electro1ytes. Physiol Rev 52: 720-777, 1972.

Schölkens BA, Becker RHA, Kaiser J. Cardiovascular and antihypertensive activities of the novel non-sulphydryl converting enzyme inhibt tor $2-[\mathrm{N}-[(\mathrm{S})]-1$-e thoxycarbony $1-3$-pheny 1 propyl $]-\mathrm{L}-\mathrm{alany} \mathrm{L}]-(1 \mathrm{~S}, 3 \mathrm{~S}$, 5s)-2-azablcyclo[3.3.0] octane-3-carboxyl1c acid (HOE 49.8). Drug Res $34: 1417-1425,1984$.

Schottstedt MF, Sokolow M. The natural history and course of hypertengion with papilledema (malignant hypertension). Am Heart J 45: 331 , 1953.

Seller H, Koizuni $K$, Brooks McC. Central control of the autonomic nervous system. J Autonom Nerv syst 3: 103-139, 1980.

Sever PS, Osibowsk B, Birch M, Turnbridge RDG. Plasma noradrenaline In essential hypertension. The Lancet 2 (8021): 1078-1081, 1977.

Shepherd JT, Vanhoutte PM. Neurohumoral regulation. In: The hunan cardlovascular system (eds: Shepherd JT, Vanhoutte PM). Raven Press, New York, 1979.

Shepherd JT, Vanhoutte PA. Local modulation of adrenergic neurotransmission. Ci rculation $64: 655-666,1981$.

Shoback DM, WIllians GH, Swartz SL, Davies RO, Kollenberg NK. Time course and effect of sodium intake on vascular and hormonal responses to enalapril (MK 421) in normal subjects. J Cardiovasc Pharmacol 5: 1010-1018, 1983.

Silverberg AB, Shah SD, Haymond MW, Deyer PE. Norepinephirine: homone 
and neurotransmitter in wan. Am J Physiol 234: E252-E256, 1978.

Simon ACH, Safar ME, Weiss $\mathrm{IA}$, London M, Milliez PL. Baroreflex sensitivity and cardiopulmonary blood volume in momotensive and hypertensive patients. Br Heart J 39: 799-805, 1977.

Simpson Fo. Salt and hypertension: a sceptical review of the evidence. Clin Sci 57 (suppl 5): 463-469, 1979.

Sims EAH. Mechantsms of hypertension in the averwelght. Hypertension 4 (suppl III): $43-49,1982$.

Smirk FH. Observations on the mortality of 270 treated and 199 untreated retinal grade $I$ and $I T$ hypertensive patients followed in all instances for five years. New Zealand Med J 63: $413,1964$.

Smith AD, Winkler $H$. Fundamental mechanisms in the release of catecholamines. In: Catecholamines. Handbook of experimental phamacology (eds: Blasko $H$, Muschol1 E). Springer Verlag, Berlin, 1972.

Smyth GA, Hughson RL, Walters DJ, Ranney DA. Short-versus long-term effects of oral beta blockers on exerclse performance. J Cardiac Rehabi1 4: 227-237, 1984.

Society of Actuaries and the Association of Life Insurance Medical Directors. Blood pressure study 1979. Society of Actuaries vol 2, november, 1980.

Sokolow M, Perloff D. The prognosis of essential hypertension treated conservatively. Circulation 23: 697-713, 1961 .

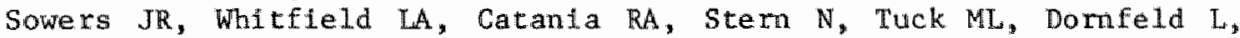
Maxwe $11 \mathrm{M}$. Role of the sympathetic nervous system in blood pressure maintenance in obesity. J clin Endocrinol Metab 54: 1181-1186, 1982.

Staessen J, cottaert A, Fagard R, Lifmen P, Hees L van, Amery A. Epidemiology of treated, compared to untreated hypertension. In: Hypertension (eds: Genest $J$, Kuchel 0 , Hamet P, Cantin M). McGraw Hi11, New York, 1069-1092, 1983.

Stamler J, Lindberg HA, Berkson DM. Epidemiological analysis of hypertension and hypertensive disease in the labor force of a Chicago utility company. Proc Commun High Blood Press Res 7: 23-52, 1958.

Stamler J. Research related to risk factors. Circulation 60: 1575$1587,1979$.

Steiner R, Lüscher T, Boerlin HJ, Slegenthaler W, Vetter W. Cllnical evaluation of semlautomatic blood pressure devilces for self-recording. J Hypertens 3 (suppl. 1): $23-25,1985$.

Stiles GL, Caron MG, Lefkowltz RJ. Beta-adrenerglc receptors: blochemical mechantsms of physiological regulation. Physiol Rev $64:$ $661-743,1984$.

Strasser $T$, Dowd JE. Mild hypertension in the communtty: findlags from the WHO Cooperative Hypertension Community Control Project. In: Mild hypertension: Recent advances (eds: Gross $\mathrm{F}$, Strasser $\mathrm{T}$ ). Raven Press, New York, 97-108, 1983.

Struthers AD, Dollery CT. Central nervous system mechanisms in blood pressure control. Eur J Clin Pharnacol 28 (suppl): 3-11, 1985.

Struyker Boudier HAJ, Rahn KH. Systeemanalyse van de bloeddrukregulatie; het sympathische zenuwstelsel en hypertensle. Ned THJdschr Geneeskd 123: 960-968, 1979.

Struyker Boudier HAJ, Smits JFM, Kleinjans JCS, Essen H van. Hemodynamic actlons of diuretic agents. Clin Exp Hypertens A5: 209-223, 1983.

Sullivan M, Ratts TE, Reed SW, Banna A, RIddle JC, Jordan C. Evidence 
for altered vascular reactivity in sodium-sensitive young subjects with borderline hypertension. Am J Med Sci 288: 65-73, 1984 .

Sullivan PA, Schoentgen S, DeQuattro V, Procci W, Levine D, Meulen 3 van der, Botnheimer $J$. Anxiety anger, and neurogenic tone at rest and in stress in patients with primary hypertension. Hypertension 3 (suppl 2): 119-123, 1981 .

Svardsudd $K_{\text {; }}$ Tibblin $G$. Mortallty and morbidity during 13.5 years" follow-up in relation to blood pressure. Acta Med Scand 205: 483$492,1979$.

Svension A, Gudbrandsson $T$, Sivertsson, R, Hansson $\mathbb{L}$. Metoprolol and pindolol in hypertenston: different effects on peripheral hemodynamics. Clin Sci 61 (suppl): 425-427, 1981 .

Svensson A, Gudbrandsson T, Sivertsson R, Hansson L. Mode of action of beta-adrenoceptor blocking agents in hypertension. A comparison between metoprolol and pindolol with special reference to peripheral vascular effects. Acta Med Scand 665 (suppl): 103-108, 1982.

Takeshlta $A$, Tanaka $S$, Kuroiwa $A$, Nakamura $M$. Reduced baroreceptor sensitivity in borderline hypertension. Circulation 51: 738-742, 1975.

Takeshita A, Mark AL. Structural vascular changes in young patients with borderline hypertension. Jpn Circ J 47: 256-257, 1983.

Tarazl. RC. Pathophystology of essential hypertension, role of the autonomic nervous system. Am $\mathbb{J}$ Med $75 ; 2-8,1983$.

Terpstra AHM, Woodward CJH, Sanchez-Mundz FJ. Improved techniques for the separation of serum lipoproteins by density gradient ultracentrifugation: visualization by prestalning and raptd separation of serum lipoprotelins from small volumes of serum. Anal Blochem 111 : $149-157,1981$.

Tesch PA, Kaiser P. Effects of beta-adrenergic blockade on oxygen uptake during submaximal and maximal exercise. J Appl Physiol 54: $901-905,1983$.

Thom T.J, Kannel WB. Downward trend in cardlovascular mortality. Am Rev Med 32: 427-434, 1981 .

Timmermans PBMWM, Zwieten PA van. Alpha, adrenoceptors: classification, Localization, mechanlsms, and targets for drugs. J Med Chem $25: 1389-1402,1982$.

Todd RA, Heell RC. Enalapri1. A review of its pharmacodynamic and pharmacokinetic properties, and therapeutic use in hypertension and congestive heart fallure. Drugs 31: 198-248, 1986.

Toretti J. Sympathetic control of renin release. Ann Rew Phamacol Toxicol 22: 167-192, 1982.

Toth PJ, Horwltz RI. Conflicting clinical trials and the uncertainty of treating mild hypertension. Am $J$ Med $75: 482-488,1983$.

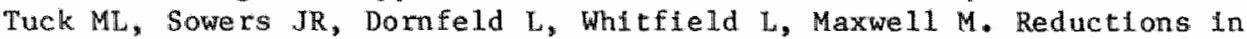
plasma catecholamines and blood pressure during welght loss in obese subjects. Acta Endocrinol 102: 252-257, 1983.

Ueda K, Omae $T$, Fujil J, Yamal T. Natural history of borderline hypertension in a communtty. An epidemiological aspect. Jpn Circ J 47: $199-206,1983$.

Unger $T$, Schü11 $B$, Hubner $D$, Yukimura $T$, Lang $R E$, Rascher $W$, Ganten $D$. Plasma converting enzyme activity does not reflect effectiveness of oral treatment with captopr11. Eur J Pharmaco1 72: 255-259, 1981 .

Unger T, Ganten D, Lang RE, Schölkens BA. Is tissue converting enzyme inhibition a determinant of the antihypertensive efficacy of con- 
verting enzyme inhibltors? Studies with the two different compounds HOE 498 and MK 421 in spontaneously hypertensive rats. J Cardiovasc Phamacol 6: 872-880, 1984 .

Uusitupa M, Siltonen O, Härkönen M, Gordin A, Aro A, Hersio K, Johansson $G$, Korhonen $T$, Rauramaa R. Metabollic and homonal response to physical exercise during beta -selective and non-selective beta blockade. Hormon Metab Res 14: $583-589,1982$.

Valkenburg HA, Hofman A, Klein F, Groustra FN. Een eplodemiologisch onderzoek naar risiko-indikatoren voor hart- en vaatziekten (EPOZ). I. Bloeddruk, serum cholesterolgehalte, quetelet-index en rookgewoonten in een open bewolking van vijf jaar en ouder. Ned Tijdschr Geneeskd 124: 183-188, 1980.

Vanhoutte PM, Webb RC, Collis MG. Pre- and postjunctional adrenergic mechanisms and hypertension. Clin Sei 59 (suppl): 211-223, 1980.

Vanhoutte PM, Verbeuren TJ, Clinton Webb R. Local modulation of adrenergic neuroeffector interaction in the blood vessel wall. Physiol Rev 61: 151-247, 1981 .

Vanhoutte $\mathrm{PM}$. Introductory remarks: alpha- and beta-adrenergic receptors and the cardiovascular system. J Cardiovasc Pharmacol 3 (suppl 1): $1-13,1981$.

Velasco M, Urbino-Quintana A, Morillo J, Guevara J, Ram1rez A, Hernandez-Pieretti 0 . Cardiac and systematic hemodynanlic effects of pindolol in hypertensive patients. Curr Ther Res 28: 972-979, 1980.

Venkata $C$, Ram S. Should mild hypertension be treated? Am I Int Med 99: $403-405,1984$.

Venter JC, Fraser $M$. The structure of alpha- and beta-adrenerglc receptors. Trends Pharmacol Scl 4: 256-258, 1983.

Veterans Administration Cooperative Study Group on Antihypertensive agents (VA). Effects of treatment on morbidity in hypertension. I. Results in patients with diastolic blood pressures averaging 115 through $130 \mathrm{~mm}$ Hg. JAMA 202: 1028-1034, 1967.

Veterans Administration Cooperative Study Group on antihypertenstve agents (VA). Effects of treatment on morbidity in hypertension. III. Results in patients with diastolic blood pressure averaging 90 through 114 mg HAMA 213: 1143-1152, 1970 .

Vetter $H$, Glänzer $K$, Vetter $W$. Essentlal hypertension: relationshlp between renin and blood pressure. Clin Exp Hypertens 2: 553-561, 1980.

Virtanen $K$, Jänne J, Frick MH. Response of blood pressure and plasma norepinephrine to propranolol, metoprolol and clonidine during isometric and dynamic exercise in hypertensive patients. Eur J Clin Pharmacol 21: 275-279, 1982 .

Volpe M, Trimarco B, Ricardelli B, Vigorito $C$, Deluca $\mathbb{N}$, Rengo $F$, Condorel1i $M$. The autonomic nervous tone abnormalities in the genesis of the impaired baroreflex responsiveness in borderilne hypertensive subjects. Clin Sci 62: 581-588, 1982.

Waeber $B$, Brunner HR, Brunner $C B$, Curtet $A L$, Turinf GA, Gavras H. Discrepancy between antihypertensive effect and anglotensin converting enzyme inhibition by captopril. Hypertension 2: 236-242, 1980.

Wallin BG, Sundlöf G, Erlksson B-M, Dominiak P, Grobecker H, Lindblad LE. Plasma noradrenaline correlates to sympathetic muscle nerve activity in normotensive man. Acta Physlol Scand 111: 69-73, 1981.

Wallin BG. Muscle sympathetic activity and plasma concentrations of 
noradrenal1ne. Acta Physiol scand 527 (suppl): $21-24,1984$.

Watson RDS, Stallard TJ, Flinn RM, Littler WA. Factors determining direct arterial pressure and its varlability in hypertensive man. Hypertension $2: 333-341$, 1980a.

Watson RDS, Eriksson BM, Hamilton CA, Reid JL. Stallard TJ, Littler WA. Effects of chronic beta-adrenoceptor antagonism on plasma catecholamines and blood pressure in hypertension. I Cardiovasc Pharmacol 2: 725-738, 1980b.

Watson RDS, Hamilton CA, Jones DH, Reid JL, Stallard TJ, Littler WA. sequential changes in plasma noradrenaline during bicycle exercise. Clin Sci 58: $37-43,1980 \mathrm{c}$.

Watt $G$. Design and interpretation of studies. Comparing individuals with and thout a family history of high blood pressure. I Hypertens $4: 1-7,1986$.

Weder $A B$, Jullus 5 . Behavior, blood pressure variability and hypertenston. Psychosom Med 47: 406-414, 1985.

Weldmann $P$. Interrelations among blood pressure, total blood volume, plasma renin activity and catecholamines $1 \mathrm{n}$ benign essential hypertension. Am J Med 62: 209-218, 1977.

Weldmann P, Keusch $G$, Flanner $J$, Ziegler WH, Reubi RC. Increased ratio between changes in blood pressure and plasma norepinephrine in essential hypertengion. J Clin Endocrinol Metab 48: 727-731, 1979.

Weldmann $\mathbb{P}$, Grimm M, Meler A, Glück 2 , Keusch G, Minder J, Berettaplccoll C. Pathogenic and therapeutic significance of cardiovascular pressor reactivity as related to plasma catecholamines in borderline and established hypertension. Clin Exp Hypertens 2: 427$449,1980$.

Weidmann P. Pressor factors and cardiowascular pressor responsivess in essent1a1 hypertension. Int $J$ Obes 5 (supp1 1): 51-67, 1981 .

Weidmann P, Gerber A, Mordasini R. Effects of antihypertensive therapy on serum lipoprotelns. Hypertension 5 (part II; suppl 3): 120-131, 1983.

Wettz W. Zur Atlologle der genuinen oder vascularen Hypertension. Z Klin Med 96: 15L, 1923.

Werning $C$, Fischer $N$, Kaip $E_{3}$ Stlel. $D$, Trübstein GK, Vetter $H$. Erhöhte Renlinstimulation nach Orthostase bei labiler oder Grenzwerthypertonde. Dtisch Med Wschr 97: 1038-1039, 1972.

Wesslau $C$. Coupling between the beta-adrenergic receptor and the adenylate cyclase - pathophyslologlcal Linplications. Acta Med Scand 672 (suppl): $17-20,1983$.

Westfall TC. Evidence that noradrenergic transmiter release is regulated by presynaptic receptors. Fed Proc 43: 1352-1357, 1984.

Whelmsen $L$, Berglund $G$, Werko $L$. Prevalence and management of hypertenston in a general population sample of Swedish men. Prev Med 2: $57-66,1973$.

Wilmore JH, Freund BJ, Joyner MJ, Hetrlck GA, Hartze1l. AA, Strother RI, Ewry GA, Faris Wf. Acute response to submaximal and maximal exercise consequent to beta-adrenerglic blockade: implications for the prescription of exercise. Am J Cardiol 55: 135D-141D, 1985.

Wlson NV, Meyer BM. Early prediction of hypertension using exercise blood pressure. Prev Med 10: 62-68, 1981.

Wite $\mathbb{P U}$, Irmisch R, Hajdu P, Metzger H. Pharmacokinetics and pharmacodynanics of a novel orally active angiotensin converting enzyme inhibitor (HOE 498) in healthy subjects. Eur J Clin Pharmacol 27 : 
$577-581,1984 \mathrm{a}$.

Witte PU, Metzger H, Eckert HG, Irnisch R. Tolerance and pharmacodynamics of the angiotensin converting enzyme inhibitor $2-[\mathrm{N}-[(\mathrm{S})]-$ 1-e thoxycarbony1-3-phenylpropyl]-L-alanyI]-(1S,3s, 5S)-2-azabicyclo [3.3.0] octane-3-carboxylic acid (HOE 498) in healthy volunteers. Drug Res $34: 1448-1451,1984 \mathrm{~b}$.

World Health Organization (WHO). Arterial hypertension. WHO Techn Rep Ser 628,1978 .

World Health Organfzation (WHO). 1986 Guldelines for the treatment of mild hypertension. Memorandum from a WHO/ISH Meeting * Bull WHO 64: $31-3.5,1986$.

Yamaguch $\mathbb{N}$, DeChamplain $J$, Nadeau $\mathbb{R}$. Correlation between the response of the heart to sympathetic stimulation and the release of endogenous catecholamines into the coronary sinus of the dog. Circ Res $36: 662-668,1975$.

Yamori $Y$. The genetics in essential hypertension. In: Mild hypertension: recent advances (eds: Gross F, Strasser $T$ ). Raven Press, New York, 187-196, 1983.

Yates FE. Dynamic regulation of mean arterial pressure: special. role of renal resistances. Fed Proc 42: $3143-3149,1983$.

Young JB, Rosa RM, Landsberg L. Dissociation of sympathetic nervous system and adrenal medullary responses. Am J Physiol 247: E35-E40, 1984.

Zanchetti AS. Neural regulation of renin release. Circulation 56: $691-698,1977$.

Zanchett A, Mancia $G$. Structural cardiovascular adaptation and the consequences for baroreflexes. Hypertension 6 (suppl 3): 93-99, 1984 .

Zanchetti A. A re-examination of stepped care: a retrospective and a prospective. J Cardlovasc Pharmaco1 7 (supp1): 126-131, 1985a.

Zanchetti A. Which drug to which patient? J Hypertens 3 (suppl 2): $57-63,1985 b$.

Zerbe GD. Randomization analysis of randomized blocks design extended to growth and response curves. Commun Statist Theor Meth A8: 191$205,1979$.

Zwieten PA van, Timmermans PBMW. Recent advances in the classfflcation of alpha-adrenoceptors. Phamaceut Wb1 Scl ted 2: 161-1.71, 1980.

Zwieten PA van, Jonge A de, Timmermans M. Inhibltors of the angioten sin $\mathbb{I}$ converting enzyme as antihypertensive drugs. Pharmaceut Wbl Sci Ed 5: 197-204, 1983 . 
Chapter 9 
The role of the sympathetic nervous system in the pathogenesis of essential hypertension is still controversial. Possibly an enhanced activity of this system causes chronic elevation of blood pressure in man. Borderline hypertension is a condition in man which could serve as a madel to study a progression to essential hypertension. A long1tudinal study in a group of borderline hypertensive subjects and normotensive controls could give insight in such a role of the sympathetic nervous system. Furthermore, a reduced parasympathetic tone could influence sympathetic activity at rest.

Patients with essential hypertension are often treated for a prolonged time with antihypertenstve drugs. They need a drug which lowers blood pressure at rest and during situations with increased sympathetic activity like stress and/or exercise. Lately, proposals have been made to add angiotensin converting enzyme inhibitors to beta blockers and diuretics used in monotherapy of essential hypertension. During beta blocker treatment patients often complain about muscular fatigue during exercise. It is suggested that some types of beta blockers behave differently during exercise. The effects of three different beta blockers at rest and during subnaximal exercise were investigated.

As mentioned before, angiotensin converting enzyme inhibitors are available for treatment of essential hypertenston. However, due to some side-effects and the short duration of action of the first generation of these drugs, new drugs of this type are being developed. Ramipril is such a new anglotensin converting enzyme inhibitor and was investigated in patients with essential hypertension.

Chapter 1 of this thesis gives a general outline of and introduction to the symptom hypertension in man. The attention is focused on the definition of high blood pressure (hypertension) as well as the consequences of this condition. Improvement of the prognosis through treatment is indicated and the clinical view on the condition hypertension is illustrated. The most important factors which control blood pressure in man are shortly described. Furthermore, the complex function and the role of the sympathetic nerwous system as a regulating 
and modulating mechanism in the control of the cardiovascular system and blood pressure is outlined. The description of the synthesis and the metabolism of the transmitters noradrenaline, adrenaline and acetylcholine follows. Several aspects among the theorles about the pathogenesis of essential hypertension wil be considered, like genetical and environmental factors and salt intake. The possible role of the renin-angiotensin system and the sympathetic nervous system in the pathogenests of hypertension are reviewed. The role of the parasympathetic nervous system is outlined. A description of the zone between nomotension and hypertension, i.e. borderline hypertension, follows. The prevalence rate, including the risks of borderline hypertension with respect to the possible progression towards hypertension reminds the reader that borderline hypertension is a zone which should not be overlooked. Furthemore, a number of physiological abnormalities of borderline hypertenslon are described. The motive to investigate subjects with borderline hypertension in a longitudinal study is explained. At the end of the first chapter, the benefits of treatment of mild hypertension and the difficult decision whether to treat or not to treat are recalled. A short description of the avallable drugs concludes this chapter.

Chapter 2 contains the results of the longitudinal study performed in a group of 26 borderline hypertensive subjects and 24 agematched normotensive controls. The aim was to investigate plasma catecholamine levels and plasma renin acitivity (PRA) at rest and durting ergonetry exercise during several years of follow-up. Another Important aspect was to observe the possible progression to essential hypertension. Normotension was defined as $\leqslant 125 / 85 \mathrm{~mm} \mathrm{Hg}$ (mean arterial pressure (MAP) $\leqslant 98 \mathrm{mmHg}$ ) and borderline hypertension as $\geqslant 140 / 90$ $<160 / 100 \mathrm{~mm} \mathrm{Hg}$ (MAP $\geqslant 107-<120 \mathrm{mmHg}$ ), both after $2 \mathrm{~min}$ standing (Korotkoff IV). Hypertension was defined as $\geqslant 160 / 100 \mathrm{mmiHg}$ (MAP $\geqslant 120$ mintg) after 2 min standing at two successive measurements and the subjects beling hypertensive dropped out of the study to recelve antihypertensive treatment. The study started in 1977 and was finished in 1984. During this period 3 subjects were lost to follow-up. At the end of the study (1984), the nomotensive and borderline subjects were subdivided. 15 subjects from the nomatensive group (subgroup 1) 
stayed normotensive and 10 subjects (subgroup 3 ) of the borderline group remained borderline hypertensive. During the 7 years of follow up 5 subjects of the originally borderline hypertensive subjects became hypertensive (MAP $2120 \mathrm{mmHg}$ ) (subgroup 4) and were excluded from further follow-up in order to recelve antibypertensive treatment. There were no differences in plasma noradrenaline levels at rest and during exercise between the total group of normotensive subjects and subjects with borderline hypertension at repeated measurements in 1977, 1979 and 1984. However, when considering the subgroups separate1y, subgroup 4 had consistently high plasma noradrenaline levels at rest. In contrast, subgroup 3 and subgroup 1 had relatively high resting noradrenaline levels only at entrance iato the study; at successive measurements the plasma noradrenaline levels were considerably lower than in subgroup 4. Plasma adrenaline and PRA at rest as well as plasma noradrenaline, plasma adrenaline and PRA during exercise did not differ between the groups and the subgroups. It is concluded that $20 \%$ of borderline hypertensive subjects become definitively hypertensive. The consistently high plasma noradrenaline levels at rest in these subjects suggest an enhanced sympathetic activity.

Chapter 3 deals with a study of salivary flow in the same borderline and normotensive subjects. Salivary flow at rest, which is predominantly under the influence of the parasympathetic nervous system, was measured in both groups during adrenergic blockade and stimulation and during parasymathetic stimulation and blockade. Plasma moradrenaline levels in the borderline and nomotensive group, which were determined as well, were not different. At rest, sallvary flow was significantly higher in the normotensive group than in the borderline hypertensive group. Intravenous propranolol, phentolamine and noradrenaline had no influence on sallvary flow. Atropthe decreased salivary flow in both groups. The effect of parasympathetic stimulation with neastigmine on salivary flow was more pronounced in the normotensives than in the borderline hypertensive subjects. The data of this study support the assumption that in subjects with borderline hypertension the parasympathetic influence on the sallvary glands is reduced.

In chapter 4 , a study 18 described which was performed to com- 
pare the effects of three beta-adrenoceptor blocking agents (propranolol, metoprolol, pindolol) during long-term treatment ( 6 months) in 7 mild to moderate hypertensive patients. Among the parameters investigated were plasma noradrenallne levels at rest and during submaximal ergonetry exerctse. Possible differences between the three beta blockers concerning exercise endurance time were a further polnt of interest. Al1 three beta blackers reduced systollc blood pressure in supine position and during exercise, whereas diastollc blood pressure fell only significantly in supine position. As was expected, suplne heart rate fell durling treatment with metoprolol and propranolol, but stayed unchanged during pindolol. During submaximal exercise, a comparable decrease of heart rate was found during all three beta blockers. Plasma noradrenaline levels at rest and during exercise tended to be decreased during pindolol; no consistent changes were found during propranolol and metoprolol. Endurance time was reduced similarly by all three drugs and no statistical differences between the beta blockers was found, although the tendency of more reduced endurance time during non-selective beta blockade was found. Furthermore, the impaiment of endurance time was more pronounced after 6 months than after 1 week.

In chapter 5, the metabolic varlables at rest and during exercise from the same study are presented. During propranolol an increase in total and LDL+VLDL serum triglyceride concentrations was found. During exerctse, non-selective beta blockade reduced plasma glycerol and non-esterifled fatty acid concentrations more than during beta ${ }_{1}^{-}$ blockade. Plasma glucose and lactate levels were largely unaffected at rest and during exercise during treatment with all three beta blockers. However, oxygen uptake was decreased slightly and respiratory exchange ratio was increased. These data suggest a decreased utilization of non-esterifled Fatty acids and increased carbohydrate combustion during treatment with the three beta blockers. Plasma potassium increase during exercise was more pronounced during non-selective than during beta-selective blockade. In this study no effects on these parameters during exercise were found when comparing the first week and the $20 / 24$ th week of treatment.

The study presented in chapter 6 deals with the time course of the blood pressure lowering effect and the dose-response relationship 
the new angiotensin converting enzyme inhibitor rampril (HOE 498). Eight patients with essential hypertension were studied and single doses of $2.5 \mathrm{mg}$ up to $10 \mathrm{mg}$ ramipril orally were given. As compared with placebo, a single dose of $2.5 \mathrm{mg}$ ramipril lowered suplne and standing systolic and diastolic blood pressure, but the effects of single doses of $5,7.5$ and $10 \mathrm{mg}$ ramipril were more pronounced. A blood pressure lowering effect was still found after 12 hours. No reflex tachycardia occurred after administration of the drug. Anglotensin conwerting enzyme activity was suppressed after all doses of ramipril studied. No side-effects were reported. This study shows that the new angiotensin converting enzyme inhibitor rampril is an orally effective agent and has a long duration of action.

The concluding remarks about the different studies are presented in chapter 7. The difficulty of analyzing and investigating factors which could induce hypertenston is depicted. It is underlined that not all borderline hypertensive subjects will develop definitive essential hypertension. The relationship between a reduced parasympathetic tone and a sympathetic nervous overactivity at rest and/or increased responsiveness to noradrenaline is described to explain blood pressure and heart rate differences at rest between borderline hypertensive and normotensive subjects. The possibility of an overactivity of the sympathetic nervous system in those borderline hypertensive sybjects who developed definite hypertension is suggested.

The cause for decreased plasma noradrenaline levels at rest and during exercise during treatment with plndolol is not clear and needs further investigation. The reduced submaximal endurance time during treatment with all three beta blockers and the possible metabolic causes are discussed. The suggestion for prescription of calclum channel blockers is made for those patienta treated with beta blockers who complain about impaired exerche performance. Finally, the results of the study with single oral doses of the new angiatensin converting enzyme Inhibitor ramipril are shortly depicted in comparison with the ather related drags. The need for further studies to investigate long-term effects is proposed.

A 1 ist of the references of this thesis $1 \mathrm{~s}$ given in chapter 8 . 


\subsection{SAMENVATTING}

De rol van het sympathische zenuwstelsel in de pathogenese van essentiele hypertensle 1 s tot op heden nog niet geheel duidelijk. Bij de mens zou een verhoogde aktivitelt wan het sympathische zenuwstelse1 een verhoging van de bloeddruk teweeg kunnen brengen. Borderline hypertensie bij de mens kan als model gebruikt worden on de ontwikkeling naar essentiële hypertensie te bestuderen. Een longitudinale studie van personen met borderline hypertensie en normotensieve kontrole personen zou de wraag naar de invloed van het sympathische zenuwstelsel op deze ontwikkeling kunnen beantwoorden. Bovendien kan een verlaagde tonus van het parasympathische zenuwstelsel in rust de aktivitelt van het sympathische zenustelsel befnvloeden.

Patienten met essentiele hypertensie worden valk gedurende langere tijd met antihypertensieve geneesmiddelen behandeld. Een voorwarde voor een dergelljk antihypertensief geneesmiddel is dat het de bloeddruk zowel in rust als ook tijdens verhoogde sympathische aktivitelt, bijwoorbeeld tijdens stress en/of lichamelijke inspanning, verlaagt. Vaak klagen patienten onder beta-blokker behandeling over vermoeldheid, met name tijdens lichamelijke belasting. De verschillende soorten beta-blokkers zouden verschillende effekten tijdens lichamelifke inspanning teweeg kumen brengen. On dit te onderzoeken werden drie verschillende beta-blokkers op hun effekten tijdens rust en submaximale lichamelijke inspanning onderzocht.

Zoals vermeld worden angiotensin converting enzyme remers toegepast bij de behandeling van essentiële hypertensie. De latate tijd zijn er voorstellen gedaan om aan de als monotherapie te gebruiken anthypertensiva ook anglotensin converting enzyme remers toe te voegen. De bifwerkingen en de korte werkingsduur van de middelen van de eerste generatie hebben ertoe geleid dat nieuwe middelen ontwikkeld werden. Ramlpril behoort tot de nleuwere anglotensin converting enzyme remuers en werd bij patiënten met essentiele hypertensie onderzocht.

In hoofdstuk 1 van dit proefschrift wordt een overzlcht gegeven van en een inlelding tot het symptoom hypertensie bij de mens. De aandacht wordt gevestigd op de definitie van hoge bloeddruk en de konsekwenties van dit beeld. De verbetering van de prognose door 
behandeling van hypertensie wordt uiteengezet. De belangrijkste faktoren die een rol spelen bij je kontrole van de bloeddruk bij de mens worden kort beschreven. De modulerende en regulerende komplexe invloeden van het sympathische zenuwstelsel op het kardiowaskulaire systeem en de bloeddruk worden bellcht. Aansluitend volgt de beschrijving van de synthese en het metabolisme van de transmitterstoffen noradrenaline, adrenaline en acetylcholine. De verschillende theorieën, die voor de pathogenese van essentiële hypertensie zijn opgesteld, zoals de genetische en omgewingsfaktoren en het zoutgebrulk, worden kort belicht. De mogelijke rol van het renin-angiotensin systeem en het sympathische zenuwstelsel in de pathogenese van hypertensie wordt beschreven. De invloed van het parasymathische zenuwstelsel wordt aangegeven. Hierna volgt een beschrijuing van het gebled tussen nomale bloeddruk en hypertensie, de borderline hypertensie. Het v56rkomen, de risiko's en de mogelijke ontwikkeling tot hypertensie herinnert de lezer eraan dit tussengebled borderline hypertenste niet te veronachtzamen. Een beschrijuing van afwijkende parameters zoalls deze bij borderline hypertensie gevonden werden, volgt. Het doel van de studle warin borderline hypertensieve personen longltudinaal gevolgd werden wordt uiteengezet. Het profijt van de behandeling van tnilde hypertensie en de niet altid eenvoudige beslissing om milde hypertensie wel of niet aktief te behandelen worden besproken. Een korte beschrijuing van de belangrijkste antihypertensiva die hierwoor ter beschikking staan sluit dit hoofdstuk af.

In hoofdstuk 2 worden de resultaten van de longltudinale studie met 24 borderline hypertensieve en 26 nomotenstve personen, jonge mannen van vergelijkbare leeftijd, beschreven. Het doel was de plasma katecholaminespiegels en de plasma renine akitivitelt (PRA) in rust en tijdens lichamelijke insparning gedurende meerdere jaren te volgen. Tevens kon met behulp van regelmatige bloeddruk kontroles de mogelijke ontwikkeling tot essentiële hypertensle vroegtijdig ontdekt worden. Nomotensie werd gedefinteerd als $\leqslant 125 / 85$ mmg (gemlddelde bloeddruk (MAP) $\leqslant 98 \mathrm{mmHg}$ ) en borderline hypertenste was $\$ 140 / 90-<160 / 100 \mathrm{mmHg}$ (MAP $\geqslant 107-<120 \mathrm{mmHg}$ ) na $2 \mathrm{~min}$ staan (Korotkoff IV). A1s hypertensle werd beschouwd $\geqslant 160 / 100 \mathrm{mmHg}$ (MAP $\geqslant 120 \mathrm{mmHg}$ ) na 2 min staan tijdeng twee opeenvolgende kontroles. De proefpersonen die hypertensfef waren 
verlieten de studie en een antihypertensieve behandeling werd ingesteld. Het begin van de studie 1 ag in 1977 en het einde was in 1984. Drie proefpersonen ontrokken zich gedurende deze tijd aan de studie. In 1984 werden belde groepen onderverdeeld. Vifftien personen wit de nomotengleve kontrolegroep (subgroep 1) waren normotensief en 10 personen (subgroup 3) ult de borderline hypertensieve groep waren borderline hypertensief. Gedurende de 7 jaar observatie werden 5 oorspronkelijk borderline hypertensieve mannen definitief hypertensief (subgroep 4) en werden uit de studle genomen om met antihypertensiva behandeld te worden. De plasma noradrenalinekoncentratie in rust en tijdens inspanning verschilde niet tussen de totale groep van normotensleven en borderline hypertensleven tijdens achtereenvolgende metingen in de Jaren 1977, 1979 en 1984. Indien men de subgroepen afzonderlijk analyseert heeft subgroep 4 een aanhoudend hoge plasma noradrenalinekoncentratie in rust. In tegensteling tot subgroep 1 en 3 , die alleen bif het begin wan de studie relatief hoge plasma noradrenalinespiegels in rust hadden. De achtereenvolgende metingen van plasma noradrenaline bij subgroep 1 en 3 waren aanzienlijk lager dan bij subgroep 4. Plasma adrenaline en PRA in rust zowel als plasma noradrenaline, plasma adrenaline en PRA tijdens inspanning waren niet verschillend tussen de groepen en de subgroepen. Er werd vastgesteld dat $20 \%$ van een groep met borderline hypertensieve personen gedurende 7 jaar definitief hypertenstef werden. Verder wordt gesuggereerd dat de blijvend hoge plasma noradrenaline spiegels in rust bij deze personen een verhoogde aktivitelt van het sympathische zenuwstelsel weersplegelen.

Hoofdstuk 3 behandelt een studie over speekselsekretie in bovengenoende groepen met normale bloeddruk en borderline hypertensie. De speekselproduktie in rust werd tijdens adrenerge stimulatie en blokkade en tijdens parasympathische stimulatie en blokkade gemeten. De speekselproduktie staat in rust hoofdzakelijk onder invloed van het parasympathische zenuwstelsel. De tegelijkertijd in rust gemeten plasma noradrenalinekoncentratie was niet verschillend tussen de twee groepen. Speekselsekretie in rust was signifikant hoger in de nomotensieve groep dan in de borderline hypertensieve groep. Intraveneus toegediend propranolol, phentolamine en noradrenaline hadden geen 
invloed op de speekselsekretie. De speekselproduktie werd door atropine in beide groepen verlaagd. De parasympathische stimulatie van de speekselsekretie met neostigmine was meer ultgesproken in de nomotensieve dan in de borderline hypertensieve groep. De resultaten van deze studie suggereren dat de parasympathische invloed op de speekselklieren in de groep met borderline hypertensie veminderd is.

Hoofdstuk 4 beschrijft een studie over effekten in rust en t1jdens inspanning van drie verschillende beta-blokkers (propranolol, metoprolo1 en pindolol) tijdens langdurige behandeling ( 6 maanden) bij 7 patienten met milde tot matige essentiële hypertensie. De bloeddruk en plasma noradrenaline spiegels werden in rust en tijdens submaximale fietsergometertesten gemeten. Verder werden mogelijke verschillen in volhoudtijd tussen de drie beta-blokkers onderzocht. Tijdens behandeling met de drie beta-blokkers daalde de systolische bloeddruk in rust en tijdens inspanning; de diastolische bloeddruk daalde alleen signifikant in 1iggende houding. De hartslag in rust daalde tijdens behandeling met metoprolol en propranolol, maar bleef onveranderd tijdens behandeling met pindolol. Tijdens submaximale inspanning werd een vergelijkbare daling van de hartfrekwentie tijdens alle drie beta-blokkers gevonden. Plasma noradrenaline in rust en tijdens inspanning vertoonde een tendens tot daling tijdens pindolol; tijdens metoprolol en propranolol werden geen veranderingen gevonden. De volhoudtijd was vergelljkbaar verlaagd tijdens behandeling met alle drie beta-blokkers. Het verschil tussen de beta-blokkers was niet statistisch signtflkant, hoewel de tendens tot sterker gedaalde volhoudtijd tijdens niet-selektieve beta-blokkade gevonden werd. De volloudtijd na 6 maanden was meer gedaald dan ma 1 week behandeling.

In hoofdstuk 5 worden de metabole parameters van de hierboven vermelde studie in rust en tijdens inspaning beschreven. Tijdens propranolol behandeling werd een toename van de totale en LDLFLDL. serum triglyceridekoncentratie gevonden. Plasma glycerol en miet-veresterde vrije vetzuren waren tijdens inspanning verlaagd, in sterkere mate tijdens niet-selektleve dan tijdens beta 1 -blokkade. De splegels van plasma glukose en laktaat waren weinig veranderd in rust en tijdens lichamelijke inspanning tijdens beta-blokkade. De zururstofopname was licht gedaald en het respiratoire kwotient verhoogd. Deze resul- 
taten 1 zen op een gedald gebruik van niet-veresterde vrije vetzuren en een verhoogde verbranding van koolhydraten tijdens behandeling met de drie beta-blokkers tijdens inspanning. Tijdens inspanning was de toename van plasma $\mathrm{K}^{+}$meer uitgesproken tijdens niet-selektieve dan t1jdens beta,-selektieve blokkade. De genoemde parameters verschilden tiljdens lnspanning bij vergelijkling van de le met de $20 / 24 \mathrm{e}$ week beta-blokker behandeling niet.

In hoofdstuk 6 wordt het verloop van de daling van de bloeddruk in de tijd en de dosis-werkingsrelatie van de nieuwe anglotensin converting enzyme remmer ramipril (HOE 498) onderzocht. Acht patienten met essentiële hypertensie kregen een enkele dosis van 2.5 tot $10 \mathrm{mg}$ ramipril oraal. Vergeleken met placebo verlaagde een dosis van $2.5 \mathrm{mg}$ ramipril de staande en liggende systollsche en diastolische bloeddruk. De effekten van hogere doses $(5,7.5$ en $10 \mathrm{mg})$ ramipril waren meer ultgesproken. Twaalf uur na toediening was nog een bloeddrukdaling aanwezig. Na toediening van het geneesmiddel trad geen reflex-tachykardie op. Alle bestudeerde doses ramipril onderdrukten de angiotensin converting enzyme aktiviteit. Er werden geen bifwerkingen gekonstateerd. De studie geeft aan dat de nieuwe anglotensin converting enzyne remmer ramipril na orale toedlening een effektief bloeddrukdalend midde 1 is en een lange werkingsduur heeft.

In hoofdstuk 7 wordt in de slotbeschouwing op de verschillende studies ingegaan. Er wordt onderstreept dat niet alle borderline hypertensieve personen ook essentleel hypertenslef worden. De relatie tussen een verminderde parasympathicus-tonus en een verhoogde aktivitelt van het sympathische zenuwstelsel en/of verhoogde gevoeligheid van de vaten voor noradrenaline wordt gelegd. Op grond van de verhoogde plasma noradrenalinesplegels in de borderline hypertensleve personen, die hypertenslef werden, wordt een verhoogde aktiviteit van het symathische zenuwstelsel verondersteld.

De reden voor verlaggde plasma noradrenalinesplegels in rust en tijdens inspanning tijdens behandeling met pindolol is niet duidelijk en vergt verder onderzoek. De verlaagde volhoudtijd tijdens submaximale inspanning met alle drte beta-blokkers en de mogelijke metabole oorzaken daarvan worden beschreven. Er wordt voorgesteld om in geval van afgenomen Inspannłngsvermogen van de pattënt tijdens beta-blokker 
behandeling calcium-antagonisten voor te schrijwen. De resultaten van de studie met de nieuwe angiotensin converting enzyme remmer ramipril worden kort met de andere vertegenwoordigers uit deze groep van antihypertensiva vergeleken. De noodzaak van nieuwe studies on de werking op lange termijn te onderzoeken wordt duldelijk gemaakt.

In hoofdstuk 8 van dit proefschrift is de referentlelijst opgenomen.

\subsection{LIST OF PUBLICATIONS}

\section{Articles}

Bogaard AEJM van den, Böhm ROB, Weldema WF. Antimikroblelle Prophylaxe in der Veterinärchirurgie. Der prakt Tierarzt 4: 287$294,1985$.

Rahn KH, Mooy J, Böhm R, Vet A van de. Reduction of bloavallability of verapamil by rifampla. New Engl J Med 312: 920-921, 1985.

Böhm R, Baak M van, Hooff $M$ van, Mooy J, Rahn KH. Sallvary fllow in borderline hypertension. Klin Wschr 63 (suppl 3): 154-156, 1985.

A rends BG, Böhr ROB, Kemenade JE van, Rahn KH, Baak MA van. "The influence of physical exerclse on the pharmacokinetics of propranolol. Eur J Clin Pharmaco1 (in press).

Boogaard AEJM van den, Böhm ROB. Silbersulfadiazin-creme als The rapie bel chronischen Pseudomonas Infektionen des ausserem Gehörganges des Hundes. Der prakt Therarzt (In press).

Böhm $R$, Baak MA van, Rahn KH. Studies of the antlhypertensive effects of the anglotensin converting enzyme findbitor ramipril (HOE 498) in man. Eur $J$ Clin Pharmacol (1n press).

Mooy $J$, A rends B, Kemenade $J$ van, Böhm R, Rahn KF, Baak M van. Influence of prolonged submaximal exerise on the pharmacokinetics of verapamil in mar. J Cardlovasc Pharmacol (in press)

\section{Abstracts}

Arends $B G$, Böhm $R$, Rahn KH, Baak MA van. Studies on the pharmacokinetics of propranolol durfing physical exerclse. Naunyn Schmledeberg's Arch Pharmacol, suppl 329: nr 392, 1985.

Arends $B G$, Böhm $R$, Hooff $M$ van, Rahn $K H$, Baak MA van. Comparison of three beta blockers during exercise. Naunyn Schmledeberg's 
Arch Phamacol suppl 330: R78, 1985.

Bark M van, Arends $B$, Böhm $R$, Rahn $k H$. The influence of prolonged exerclse on the phamacokinetics of the beta-adrenoceptor blocker propranolol after intravenous administration. Clin Physiol 5 (suppl 4): 26, 1985.

Baak MA van, Böhn R, Mooy J, Petri J, Rahn KA. Submaximal exerclse tolerance during antihypertensive therapy with proprano101 and verapami1. Med Sci Sports Exercise 18 (suppl): 39 , 1986.

Mooy J, Böhn R, Baak M van, Kemenade I van, Rahn KH. Treatment wth antituberculosis drugs strongly reduces the biavallability of oral verapami1. Naunyn Schmiedberg's Arch Pharmacol, supp1 330: R79, 1985.

Mooy $J$, Arends $B$, Böhm $R$, Kemenade J van, Rahn $\mathrm{KH}$. Studies on pharmacokinetic drug interactions with verapamil. Kidney Int $28: 707,1985$.

Böhm R, Bakk Man, Mooy $₫$, Rahn KH. Studies of the antihypertensive effect of the angiotensin converting enzyme inhibitor HOE 498 in man. Naunyn Schmiedeberg's Arch Pharmacol suppl $330: \mathrm{R} 47,1985$.

Böhm R, Baak M van, Hooff M van, Kemenade I van, Rahn KH. Longterm study of the sympathetic nervous system and the reninanglotensin system in borderline hypertension. Kidney Int 28 : 698. 1985 .

Böhm R, Hooff M van, Mooy J, Rahn KH. Langzeltstudie tiber das Verhalten des sympathischen Nervensystems und des Renin-Angiotensin Systems bel Grenzwerthypertonie. Klin Wschr 63 (suppl IV): $279: 667,1985$.

Böhm ROB, Arends BG, Hooff MEJ van, Rahn KG, Baak MA van. Longterm antihypertensive therapy with three different beta blockexs and submaximal exercise tolerance. Pharmaceut Wbl Sci Ed 8: $162,1986$.

Böhm ROB, Arends BG, Hooff MEJ van, Rahn KH, Baak MA van. Effects of long-tern antihypertensive treatment with three different beta blockers on submaxtmal exercise performance. Med Sc1 Sports Exerctse 18 (supp1): 39, 1986.

Mooy J, Böhn $R$, Petri $H$, Kemenade I van, Baak $M$ van, Rahn $K H$. Exerclse tolerance in hypertenslve patients during treatment with verapamil and propranolol. Naunyn Schmiedeberg"s Arch Pharmeol suppl 332: R98, 1986.

Rahn KH, Mooy J, Böhm R, Petri H, Baak M van. The influence of propranolol and verapamil on exercise tolerance in hypertensive patients. C1in Pharmacol Ther 39: 221, 1986. 


\subsection{DANKWOORD}

Mijn promotor, prof. dr. Rahn, wil $1 \mathrm{k}$ danken voor zijn leiding In het onderzaek. Uw opmerkingen hebben altijd op stimulerende wijze tot de voortgang van het werk bijgedragen. Zonder uw - goed bedoelde druk zow het maken dit proefschrift op deze ternijn niet halbaar zijn geweest. Mijn erkentelijkheid is groot.

Aan de referenten van dit proefschrift, prof. dr. Donker en prof. dr. Struyker Boudier, ben ik dank verschuldigd voor hun kritische en nauwgezette beoordeling van het manuskript. Eveneens dank $1 k$ prof. dr. Struyker Boudier voor zijn niet aflatende belangstelling en openheid die hij vanaf het begin voor het onderzoek toonde.

Bei Ihnen, Herr Prof. Dr. Steberth, möchte ich mich bedanken, dass Sie bereit waren als Referent aufzutreten und fü die kritischen Bemerkungen iber das Manuskript.

Het is mij een eer om jou, Marleen wan Baak, te bedanken. Jij hebt mij onschatbare diensten bewezen. Jouw steun in de totstandkoming van dit proefschrift. was onontbeerlijk. De tijd dat wij samenwerkten, zal $i k$ niet vergeten.

Natuurlijk ben $1 \mathrm{k}$ dank verschuldigd aan de mensen die v66r mij aan dit onderzoek werkten: Michel Schols, Marlies van Hooff, Beate Arends, Judith van Kemenade en Jaap Mooy.

Jet Bost, Riet Daamen en Monique Fuss wil ik hierblj danken voor het vele werk dat zij in het lab in het kader van dit onderzoek hebben verzet.

E1s Geurts en Mia Hogenboom dank ik voor het velle typewerk gedaan voor dit proefschrift. Mijn bemoelenis hiermee stelde jullie geduld wel erg op de proef.

Alle proefpersonen dank ik voor hun medewerking aan dit onderzoek. Wij allen hebber het soms zwar gehad.

Verder dank $i k$ al degenen die op de ene of andere wijze aan de totstandkoming van dit proefsichrift hebben bijgedragen. 


\subsection{CURRICULUM VITAE}

The author of this thesis bas born in Schwabisch-Hall, Federal Repub11c of Germany on July $4 \mathrm{th}, 1957$.

His first school years he spent in Hannover (FRG) and Vaalserquartier (FRG). He graduated fron the International Afcent-School, Brunssum (The Netherlands) in 1975. Afterwards he volunteered for miltary service in the FRG and graduated from officer school in 1976. He left miltary service in 1978 .

In september 1978, he started his medical studies at the Rijksuniversiteit Limburg in Maastricht. In his 4 th year of medical studies he worked for one year as a student assistent at the Department of Pharmacology. He graduated in July 1984.

Then, he started to work as a research fellow win the Hypertension and Clinical Pharmacology Program (head prof. dr. K.H. Rahn) at the University of Limburg in Mastricht. For one year, he was a member of the Department of Internal Medicine (head: prof. dr. J.A. Flendrig). Since October 1985, he is member of the Department of Pharmacology (head: prof. dr. H.A.J. Struyker Boudier). 